\title{
RECENT RESULTS IN SOLID STATE CHEMISTRY OF IONIC OZONIDES, HYPEROXIDES, AND PEROXIDES
}

\author{
Werner Hesse, Martin Jansen and Wolfgang Schnick \\ Institut für Anorganische Chemie der Universität Bonn, \\ Gerhard-Domagk-Straße 1, D-5300 Bonn 1, F.R.G.
}

\section{CONTENTS}

1. Introduction

2. Ozonides

2.1. Alkali metal ozonides

2.1.1. Syntheses of alkali metal ozonides 51

2.1.2. Crystal structures of alkali metal ozonides 53

2.1.2.1. Potassium ozonide 53

2.1.2.2. Rubidium ozonide 56

2.1.2.3. Cesium ozonide 57

2.1.3. Thermal properties and decomposition of $\mathrm{KO}_{3}, \mathrm{RbO}_{3}$, and $\mathrm{CsO}_{3}$

2.1.4. Magnetic properties of $\mathrm{KO}_{3}, \mathrm{RbO}_{3}$, and $\mathrm{CsO}_{3}$

2.1.5. Spectroscopic properties of ionic ozonides 58

2.2. Further ozonides 59

2.2.1. Syntheses of tetraalkylammonium ozonides $\quad 59$

2.2.2. Crystal structures $\quad 60$

$\begin{array}{lll}\text { 2.2.2.1. Crystal structure of } \mathrm{NMe}_{4} \mathrm{O}_{3} & 60\end{array}$ 
2.2.2.2. Crystal structure of $\mathrm{NEt}_{4} \mathrm{O}_{3} \quad 62$

2.2.3. Thermal properties and decomposition of $\mathrm{NMe}_{4} \mathrm{O}_{3}$ and $\mathrm{NEt}_{4} \mathrm{O}_{3} \quad 62$

$\begin{array}{ll}\text { 2.3. } & 63\end{array}$

$\begin{array}{ll}\text { 3. Hyperoxides } & 64\end{array}$

3.1. Alkali metal hyperoxides $\quad 64$

3.1.1. Syntheses of alkali metal hyperoxides 64

$\begin{array}{ll}\text { 3.1.1.1. Lithium hyperoxide } & 64\end{array}$

3.1.1.2. Sodium hyperoxide 65

3.1.1.3. Potassium, rubidium, and cesium hyperoxides 65

3.1.2. Crystal structures and magnetic properties of alkali metal hyperoxides $\quad 66$

3.1.2.1. Sodium hyperoxide $\quad 69$

$\begin{array}{lll}\text { 3.1.2.2. Potassium hyperoxide } & 71\end{array}$

3.1.2.3. Rubidium- and cesium hyperoxides 75

3.1.3. Spectroscopic investigations, lattice dynamics 78

3.1.3.1. Optical properties and electronic structure of alkali metal hyperoxides 82

3.1.3.2. Electronic spectra of alkali metal hyperoxides 82

3.1.4. Thermal properties and decomposition of alkali metal hyperoxides 83

$\begin{array}{ll}\text { 3.1.5. } & \text { Applications }\end{array}$

3.2. Alkaline earth metal hyperoxides 84

3.2.1. Syntheses of alkaline earth metal hyperoxides $\quad 84$

3.2.2. Crystal structures, decomposition, and thermal properties 86

$\begin{array}{lll}\text { 3.3. } & \text { Further hyperoxides } & 87\end{array}$

3.3.1. Syntheses and properties of tetraalkylammonium hyperoxides 87

3.3.2. Crystal structures, decomposition, and thermal properties 88

$\begin{array}{ll}\text { 3.3.3. Magnetic and spectroscopic properties } & 88\end{array}$

$\begin{array}{lr}\text { 4. Peroxides } & 89\end{array}$

4.1. Alkali and alkaline earth metal peroxides 89

4.1.1. Syntheses, chemical properties and structures of alkali and alkaline earth $\begin{array}{ll}\text { metal peroxides } & 89\end{array}$

4.1.2. Thermal and thermodynamic properties 91

4.2. Group-IIb peroxides 92

4.2.1. Syntheses and chemical properties of group-IIb peroxides 92

4.2.2. Crystal structures of group-IIb metal peroxides 94 
4.2.3. Thermal properties, phase transitions, and magnetic behavior 96

$\begin{array}{lll}\text { 4.3. } & \text { Further peroxides } & 97\end{array}$

4.4. Spectroscopic properties of ionic peroxides 99

4.5. Applications of alkali, alkaline earth, and group-IIb peroxides 99

$\begin{array}{ll}\text { Literature } & 101\end{array}$ 


\section{INTRODUCTION}

The exciting field of solid state chemistry of ionic compounds containing catenated oxygen species like ozonide $\left(\mathrm{O}_{3}{ }^{-}\right)$, hyperoxide $\left(\mathrm{O}_{2}\right)$ and peroxide $\left(\mathrm{O}_{2}{ }^{2-}\right)$ has been under continuing development. The first period, following their detection was mainly devoted to the investigation of the true chemical nature of these compounds, that had compositions thought to be rather unusual at the time. That period lasted until the 1960 s and the results have been reviewed thoroughly by N.G. Vannerberg [1] and I.I. Vol'nov [2]. Since these reviews appeared, considerable further progress has been achieved.

A special emphasis on preparative work can be recognized during this last period. Some of the compounds considered in this paper have become available in pure form and in large amounts, or as large single crystals, by recently developed synthetic methods. In other cases, recent research has focussed on crystal chemistry, phase transitions, and physical properties.

Some new peroxides have been found and their crystal structures have been investigated, whereas the technically important alkali and alkaline earth metal peroxides have been mostly ignored. No new hyperoxides have been found. It remains true that the only known compounds containing isolated $\mathrm{O}_{2}^{-}$anions are those formed by alkali metals. However, considerable progress has been achieved by investigating their physical properties using large single crystals. Very recently, pure ionic ozonides have become available, and their crystal structures and properties determined unequivocally. Preparative chemistry based on ionic ozonides seems to be starting. The results collected in this paper cover the literature between 1962 and 1988.

Only ionic ozonides, hyperoxides and peroxides in the solid state accessible as bulkmaterials are considered. Thus, thin films and reactive intermediates are not covered. 


\section{OZONIDES}

\subsection{Alkali Metal Ozonides}

The first indications of the existence of alkali metal ozonides were obtained by Wurtz in 1868 [3]. Baeyer and Villiger expected them to be salts of the hypothetical acid $\mathrm{H}_{2} \mathrm{O}_{4}$ [4]. The true composition $\mathrm{AO}_{3}$ ( $\mathrm{A}=$ alkali metal) was mentioned for the first time by Kazarnovskii in 1949 [5]. Because of their potential applicability for air revitalization, the ozonides were investigated intensively in the1960s and1970s [6-27]. These efforts, however, were only partly successful.

E.g., no synthetic route was developed that would allow syntheses of pure samples on a preparative scale. Furthermore, structural investigations finally remained incomplete and the existence of the $\mathrm{O}_{3}{ }^{-}$anion could not be unequivocally settled. The geometry of this $19 \mathrm{e}^{-}$radical anion was especially controversial; $\mathrm{Zhdanova}$ and $\mathrm{Zvonkova}$ even suggested a linear $\mathrm{O}_{3}{ }^{-}$group like $\mathrm{N}_{3}{ }^{-}$in $\mathrm{KN}_{3}$ [28]. More reasonable results were obtained by theoretical methods [29, 30, 31]. Not until 1985 was a general synthetic route for the preparation of pure, coarse crystalline samples of alkali metal ozonides in gram amounts developed [32]. It then became possible to carry out precise structure determinations and reliable investigations on some basic physical properties.

\subsubsection{Syntheses of Alkali Metal Ozonides}

In textbooks generally the following route for synthesizing ozonides is described

$$
3 \mathrm{AOH}+4 \mathrm{O}_{3}=2 \mathrm{AO}_{3}+\mathrm{AOH} \cdot \mathrm{H}_{2} \mathrm{O}+7 / 2 \mathrm{O}_{2} \quad(\mathrm{~A}=\text { alkali metal })
$$

The great disadvantage of this procedure is the formation of water, which causes decomposition of the ozonide formed. According to Vol'nov, it is more suitable to use alkali metal hyperoxides as starting materials [33]. However, all attempts applying this procedure led to unsatisfactory results. Alkali metal ozonides are metastable compounds. Obviously, the exothermal character of both formation

$$
\mathrm{AO}_{2}+\mathrm{O}_{3}=\mathrm{AO}_{3}+\mathrm{O}_{2}
$$

as well as decomposition of the ozonides

$$
\mathrm{AO}_{3}=\mathrm{AO}_{2}+1 / 2 \mathrm{O}_{2}
$$

was not considered properly. These special features require careful temperature control ensuring sufficient activation of formation and, at the same time, suppression of decomposition. 
Jansen and coworkers have developed and optimized a procedure which allows the preparation of pure ozonides in gram amounts by reaction of gaseous ozone/oxygen mixtures with alkali metal hyperoxides followed by extraction with liquid ammonia [32, 34].

In order to avoid decomposition, the reaction must be performed at low temperatures. On the other hand, the dissociation of ozone $\left(\mathrm{O}_{3}=\mathrm{O}_{2}+\mathrm{O}\right)$ producing monooxygen diradicals, as well as the heterogeneous reaction which enables oxygen diffusion within the solid $\left(\mathrm{O}+\mathrm{AO}_{2}=\mathrm{AO}_{3}\right)$, both require a minimum temperature. These two conflicting aspects require precise temperature control during reaction.

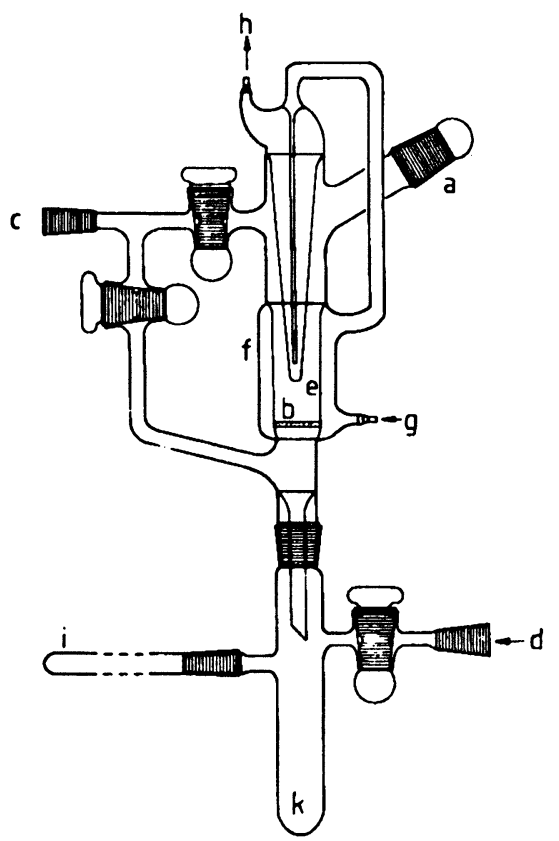

Fig. 1:

Apparatus for preparation of alkali metal ozonides [34].

a: filler neck; b: glas frit; c: argon, vacuum, ammonia feeding line; d: $\mathrm{O}_{3} \mathrm{O}_{2}$ supply;

e: cooling finger, $\mathrm{f}$ : cooling jacket; $\mathrm{g}, \mathrm{h}$ : cooling liquid; $\mathrm{i}$ : glas tube; $\mathrm{k}$ : recipient

The apparatus developed (see Fig. 1) allows the reaction to be carried out under controlled temperature conditions: The cylindrical reactor equipped with a cooling jacket allows temperature control in the range from -75 to $+30^{\circ} \mathrm{C}$. When starting the reaction at room temperature, the red color of alkali metal ozonide appears almost immediately. Because of the self heating reaction, however, the initially formed ozonide decomposes instantly. Upon cooling, a radial temperature gradient within the sample arises. The outer parts of the sample are the first to reach a temperature at which ozonides may form and exist. This reaction zone moves along the gradient on reducing 
the temperature slowly to $-50^{\circ} \mathrm{C}$ during one hour.

By subsequent extraction with liquid ammonia, separation of the soluble ozonide from the poorly soluble hyperoxide is achieved. Slow evaporation of ammonia leads to red, transparent crystals of $\mathrm{KO}_{3}, \mathrm{RbO}_{3}$, and $\mathrm{CsO}_{3}$, respectively. Purity may be improved by additional recrystallization from liquid ammonia.

Thermal stability of the alkali metal ozonides increases with increasing size of the cations. As a consequence, pure $\mathrm{NaO}_{3}$ has not been prepared via this preparation route as yet. Partial decomposition to the hyperoxide was observed during evaporation of liquid ammonia [35]. Earlier results, obtained on impure samples of $\mathrm{NaO}_{3}$, are contradictory with respect to thermal stability and solubility in $\mathrm{NH}_{3}$ [36-40]. Lithium ozonide is not known at all, while a tetraammoniate $\mathrm{LiO}_{3} \cdot 4 \mathrm{NH}_{3}$ has been reported [41].

\subsubsection{Crystal Structures}

The first structural investigations were undertaken using powder methods. Crystallographic data derived by these methods are generally unreliable. The tetragonal crystal systems assigned to $\mathrm{NaO}_{3}[42,43]$ and $\mathrm{CsO}_{3}[44]$ are unlikely because of considerable deviations between observed and calculated d-values. Powder $\mathrm{X}$-ray and neutron diffraction on $\mathrm{KO}_{3}$ led to several contradictory proposals, especially with respect to the geometry of the $\mathrm{O}_{3}{ }^{-}$ion and the space group [45, 46]. The crystal structure of $\mathrm{RbO}_{3}$ was investigated by film methods using twinned crystals [47]. The structure was determined by the heavy-atom method and refined to $R=0.200$. As a result, unreasonable dimensions for the ozonide ion were obtained $\left(142 \mathrm{pm}, 101^{\circ}\right)$, while theoretical predictions are in the range between 128 and $135 \mathrm{pm}$ for the bond lengths and 108 and $120^{\circ}$ for the bond angle $[29,30,31]$.

Recent progress in preparation and handling of single crystals of these compounds has made precise structure determinations possible using diffractometer data.

\subsubsection{Potassium Ozonide}

The crystal structure of $\mathrm{KO}_{3}$ was solved by single crystal X-ray techniques [48]. Lattice constants were refined from the $\mathrm{X}$-ray powder pattern of $\mathrm{KO}_{3}$ which was indexed in agreement with the single crystal results. The metastable $\mathrm{KO}_{3}$ crystals, which are extremely reactive upon contact with water and carbon dioxide, were wedged in capillary tubes under dry argon. Because of its thermal instability, all X-ray measurements were undertaken at $-20^{\circ} \mathrm{C}$. Table I shows the results of the structure determination of $\mathrm{KO}_{3}$. 


\begin{tabular}{|c|c|c|c|c|}
\hline Table I: & Crystallographic data of a & ali metal ozonides & & \\
\hline & $\mathrm{KO}_{3}[48]$ & $\mathrm{RbO}_{3}[34,51]$ & $\alpha-\mathrm{CsO}_{3}[52]$ & $\mathrm{B}-\mathrm{CsO}_{3}[52]$ \\
\hline Space group & $I 4 / \mathrm{m} \mathrm{cm}$ & $\mathrm{P} 2{ }_{1} / \mathrm{c}$ & $P 2_{1} / c$ & $\operatorname{Pm} \overline{3} m$ \\
\hline $\begin{array}{l}\text { Lattice parameters } \\
{[\mathrm{pm}, 0]}\end{array}$ & $\begin{array}{l}\mathrm{a}=863.58(10) \mathrm{pm} \\
\mathrm{c}=714.06(8) \mathrm{pm}\end{array}$ & $\begin{array}{l}\mathrm{a}=645.6(7) \mathrm{pm} \\
\mathrm{b}=602.2(6) \mathrm{pm} \\
\mathrm{c}=877.5(9) \mathrm{pm} \\
\beta=122.37(7)^{0}\end{array}$ & $\begin{array}{l}a=675.1(2) \mathrm{pm} \\
b=626.7(2) \mathrm{pm} \\
c=901.5(3) \mathrm{pm} \\
\beta=120.74(3)^{0}\end{array}$ & $\mathrm{a}=436.06(3) \mathrm{pm}$ \\
\hline $\mathbf{Z}$ & 8 & 4 & 4 & 1 \\
\hline Structural details & $\begin{array}{ll}\text { Geometry of the } \mathrm{O}_{3}{ }^{-} \text {ion: } \\
\mathrm{O} 1-\mathrm{O} 2 & 134.6(2) \mathrm{pm} \\
\mathrm{O} 2-\mathrm{O} 1-\mathrm{O} 2 & 113.5(1)^{\mathrm{O}}\end{array}$ & 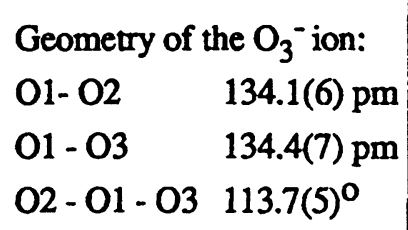 & $\begin{array}{l}\text { Isostructural } \\
\text { with } \mathrm{RbO}_{3}\end{array}$ & $\begin{array}{l}\text { Orientational disorder } \\
\text { of } \mathrm{O}_{3}^{-} \\
\text {(CsCl-type) }\end{array}$ \\
\hline
\end{tabular}


The crystal structure of potassium ozonide consists of $\mathrm{K}^{+}$and $\mathrm{O}_{3}{ }^{-}$ions. With respect to the jacking of cations and anions, there is a close relationship to the CsCl-type of structure Fig. 2).

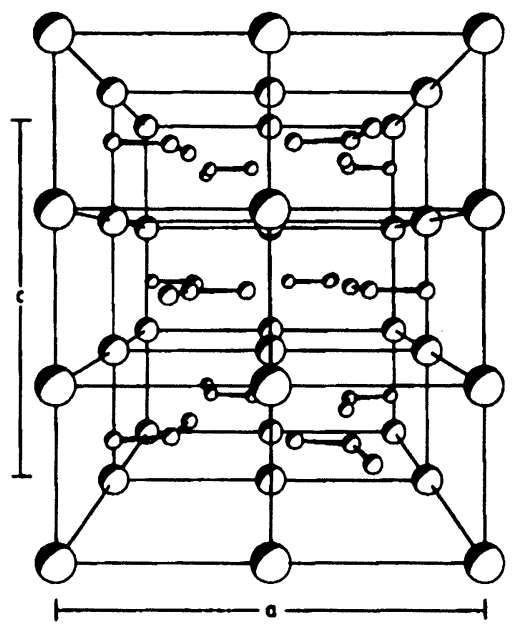

Fig. 2:

Perspective drawing of the crystal structure of $\mathrm{KO}_{3}$. View along [100]. [32]

The shortest contacts between oxygen and potassium are those at the terminal O-atoms of the ozonide group. The resulting distances correspond to the sum of the ionic radii of potassium and oxygen $(289 \mathrm{pm})$ [49]. Therefore, the terminal oxygen atoms seem to be polarized negatively, which agrees with SCF-MO-calculations [50]. The ozonide groups are arranged in a strictly ordered manner forming layers parallel to (001). This type of ordering causes a tetragonal flattening of the $\mathrm{CsCl}$ analogous units. Within these layers positively and negatively polarized oxygen atoms in adjacent $\mathrm{O}_{3}{ }^{-}$ions exhibit the shortest intermolecular contacts indicating Coulomb-type interactions (see Fig. 3).

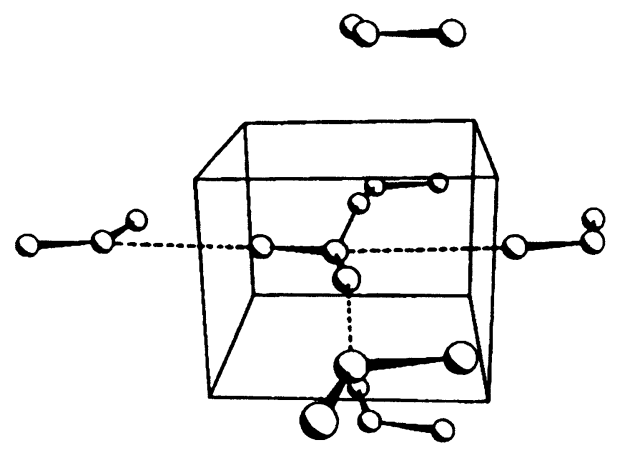

Fig. 3:

$\mathrm{CsCl}$-analogous section of the crystal structure of $\mathrm{KO}_{3}$ with neighboring $\mathrm{O}_{3}{ }^{-}$groups and shortest intermolecular O-O-distances. [51] 


\subsubsection{Rubidium Ozonide}

Table I shows the results of the structure determination of $\mathrm{RbO}_{3}[34,51]$.

As depicted in Fig. 4, the atomic arrangement of $\mathrm{RbO}_{3}$ is also derived from a CsCl-type of structure.
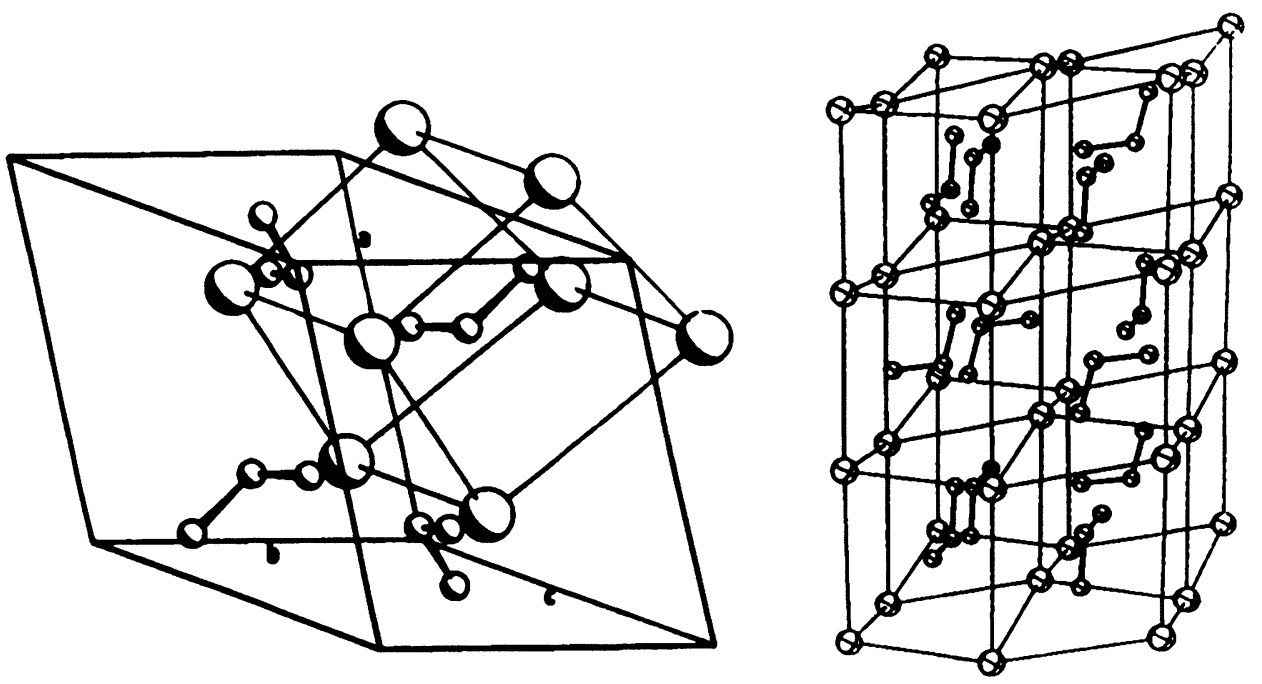

Fig.4:

a) Unit cell of $\mathrm{RbO}_{3}$ with $\mathrm{CsCl}$-analogous section [34].

b) Perspective drawing of the crystal structure of $\mathrm{RbO}_{3}$.

Within the experimental error, the geometry of the $\mathrm{O}_{3}{ }^{-}$ion is identical in $\mathrm{KO}_{3}$ and $\mathrm{RbO}_{3}$. This indicates that the influence of crystal fields on the geometry of the $\mathrm{O}_{3}{ }^{-}$group is negligible in both cases.

The distortion from tetragonal $\left(\mathrm{KO}_{3}\right)$ to monoclinic $\left(\mathrm{RbO}_{3}\right)$ results in an increase of the coordination number of the cations from $8\left(\mathrm{~K}^{+}\right)$to $9\left(\mathrm{Rb}^{+}\right)$. The shortest intermolecular O-O- distances around $300 \mathrm{pm}$ between terminal and bridging oxygen atoms prove the polarity of the $\mathrm{O}_{3}{ }^{-}$ion mentioned above (see Fig. 5).

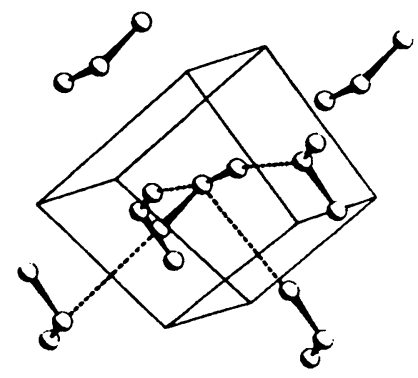

Fig. 5:

CsCl-analogous section of the crystal structure of $\mathrm{RbO}_{3}$ with neighboring $\mathrm{O}_{3}^{-}$groups and shortest intermolecular O-O-distances [34]. 


\subsubsection{Cesium Ozonide}

The structure determination of $\mathrm{CsO}_{3}$ has been hampered by a phase transition at $8^{\circ} \mathrm{Cproducing}$ transformational twins. Thus, both structures had to be solved by $\mathrm{X}$-ray powder methods [52]. The low temperature form $\left(\alpha-\mathrm{CsO}_{3}\right)$ is isostructural to $\mathrm{RbO}_{3}$; the crystal structure of $\beta-\mathrm{CsO}_{3}$, which shows orientational disorder with respect to the ozonide ion, corresponds to the $\mathrm{CsCl}$-type of structure. Further structural data are given in Table $\mathrm{I} . \mathrm{CsO}_{3}$ is the first ozonide known with rotationally disordered $\mathrm{O}_{3}{ }^{-}$ions. The related alkali metal nitrites also show rotational disorder: e.g., $\beta-\mathrm{CsO}_{3}$ and $\beta-\mathrm{CsNO}_{2}$ are isostructural.

\subsubsection{Thermal Properties and Decomposition of $\mathrm{KO}_{3}, \mathrm{RbO}_{3}$, and $\mathrm{CsO}_{3}$}

Ozonides are thermodynamically metastable with respect to decomposition into hyperoxides and oxygen. They decompose slowly at room temperature. However, at $-20^{\circ} \mathrm{C}$, samples show no visible decomposition over a period of months. The thermal behavior of alkali metal ozonides was studied applying DTA/TG-methods at various heating rates $[48,51,52]$. They decompose exothermally with an increasing decomposition enthalpy in the sequence $\mathrm{CsO}_{3}-\mathrm{RbO}_{3}-\mathrm{KO}_{3}$. The onset temperature of rapid decomposition decreases in the same sequence $\left(\mathrm{CsO}_{3}: 53^{\circ} \mathrm{C}\right.$, $\left.\mathrm{RbO}_{3}: 38^{\circ} \mathrm{C}, \mathrm{KO}_{3}: 35^{\circ} \mathrm{C}[51,52]\right)$.

\subsubsection{Magnetic Properties of $\mathrm{KO}_{3}, \mathrm{RbQ}_{3}$, and $\mathrm{CsO}_{3}$}

Ionic ozonides contain 19 electron radical anions $\mathrm{O}_{3}^{-}$. Like the alkali metal hyperoxides, which contain the 13 electron species $\mathrm{O}_{2}^{-}$(see Chapter 3), ozonides also exhibit the unique phenomenon of paramagnetism due to unpaired p-electrons.

Investigations of magnetic susceptibilities require very pure samples. So it is only very recently, that measurements by the Faraday technique in the temperature range between 3.6 and $250 \mathrm{~K}$ have been performed [53]. Paramagnetic behavior and antiferromagnetic ordering of these compounds, as already suggested on the basis of susceptibility andEPR data from impure samples of $\mathrm{KO}_{3}$ and $\mathrm{RbO}_{3}[8,17,19]$, was confirmed [53]. Above $50 \mathrm{~K}$ Curie-Weiss behavior was observed for all three compounds. Susceptibility maxima at 20 and $17 \mathrm{~K}_{\text {for }} \mathrm{KO}_{3}$ and $\mathrm{RbO}_{3}$, respectively, (see Table II) support the assumption of antiferromagnetic ordering of unpaired electrons. However, for the cesium compound only a very weak maximum of $\chi(T)$ was observed. A more accurate explanation of the magnetic structure at very low temperatures may be obtained by neutron diffraction experiments and EPR-measurements on single crystals. 
Table II: Characteristic magnetic data of polycrystalline $\mathrm{KO}_{3}, \mathrm{RbO}_{3}$, and $\mathrm{CsO}_{3}[53]$.

\begin{tabular}{|l|c|c|c|}
\hline & $\mathrm{KO}_{3}$ & $\mathrm{RbO}_{3}$ & $\mathrm{CsO}_{3}$ \\
\hline$\mu / \mathrm{H}_{\mathrm{B}}$ & $1,74(2)$ & $1,80(2)$ & $1,74(2)$ \\
$\theta / \mathrm{K}$ & $-34(1)$ & $-23(1)$ & $-10(1)$ \\
$\mathrm{T}\left(\chi_{\max }\right) / \mathrm{K}$ & $\sim 20$ & $\sim 17$ & \\
$\mathrm{~T}\left(\chi_{\min }\right) / \mathrm{K}$ & $\sim 6$ & $\sim 6$ & \\
\hline
\end{tabular}

\subsubsection{Spectroscopic Properties of Ionic Ozonides}

Molecular modes of the $\mathrm{O}_{3}{ }^{-}$anion have been investigated by IR and Raman techniques using both polycrystalline samples and liquid ammonia solutions of alkali metal ozonides. The data obtained prove the existence of isolated $\mathrm{O}_{3}{ }^{-}$anions, which seem only weakly affected by the crystal field in the solid state and solvation effects in solution.

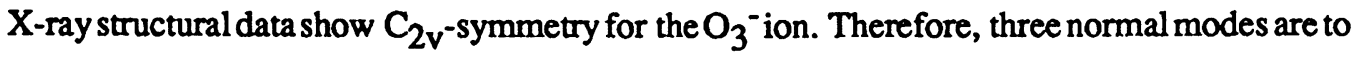
be expected: the symmetric stretching mode $v_{1}$, the symmetric deformation mode $v_{2}$, and the antisymmetric stretching mode $v_{3}$. Only the $v_{1}$-mode was detected in the Raman spectra, centered between 1008 and $1020 \mathrm{~cm}^{-1}[52,55,136]$. IR spectra of $\mathrm{KO}_{3}$ powder samples exhibit two modes: The $v_{2}$-vibration with medium intensity near $621 \mathrm{~cm}^{-1}$ and an intense asymmetrical band at $818 \mathrm{~cm}^{-1}\left(v_{3}\right)$ [55]. The positions of the three molecular modes of $\mathrm{O}_{3}^{-}$were also investigated using different ${ }^{18} \mathrm{O}$ isotopes in Ar-matrices [56 - 59].

On the basis of these spectroscopic data, as well as the geometry of the $\mathrm{O}_{3}{ }^{-}$anion from X-ray work, the force constants of $\mathrm{O}_{3}$ - have been redetermined [52]. The stretching force constant $f_{\mathrm{r}}$ is $4.27 \mathrm{mdyn} / \AA$ and fits well into force constant/bond length and force constant/bond strength correlations of different oxygen molecular anions [52].

Intramolecular electronic transitions in $\mathrm{O}_{3}^{-}$have been investigated using red colored liquid ammonia solutions of ionic ozonides. The UV-absorption spectra exhibit a typical fingerprint with a maximum centered around $450 \mathrm{~nm}[60,61]$. Accurate UV-investigations on solid ozonides at very low temperatures are desirable to understand the electronic structure of the slightly different colored ozonides. Such investigations should be supported by theoretical energy calculations of the $\mathrm{O}_{3}{ }^{-}$ion. 


\subsection{Further Ozonides}

Several attempts to obtain other than alkali metal ozonides have been reported in the literature. Preferentially, cations most similar to those of the alkali metals - e.g., alkaline earth, ammonium, and tetraalkylammonium - have been chosen $[6,23,27,62$ - 74].

Theoretically, the alkaline earth metal ozonides with formula type $\mathrm{M}\left(\mathrm{O}_{3} / 2\right.$ contain much more available oxygen than the alkali metal ozonides. For that reason, there was considerable interest in use of these compounds as auxiliary oxygen sources for astronauts. Vol' nov et al. have studied the ozonolysis of alkaline earth metal peroxides in concentrated solutions of ozone in Freon-12 at different temperatures $[23,27,62-64]$. The reactions at $-65^{\circ} \mathrm{C}$ yielded yellow colored products. In the case of strontium and barium peroxides, red colored substances were obtained at $-105^{\circ} \mathrm{C}$. EPR measurements showed the presence of $\mathrm{O}_{2}{ }^{-}$ions (in the case of the yellow products) and of $\mathrm{O}_{3}{ }^{-}$ions (in the case of the red samples). DTA and EPR measurements support a limit of stability for the ozonides having tentative formulas $\mathrm{Sr}\left(\mathrm{O}_{3}\right)_{2}$ and $\mathrm{Ba}\left(\mathrm{O}_{3}\right)_{2}$ at about $-70^{\circ} \mathrm{C}$. As no pure samples have been investigated, these values are rather uncertain. Accordingly, the existence of alkaline earth metal ozonides is not definitely established, and a prediction of thermal stability for pure compounds is impossible.

Because of the unavailability of solid ammonium hyperoxide or oxide, Solomon, Kacmarek et al. tried to synthesize ammonium ozonide $\left(\mathrm{NH}_{4} \mathrm{O}_{3}\right)$ by reacting gaseous $\mathrm{O}_{2} / \mathrm{O}_{3}$-mixtures with solid ammonia at $-100^{\circ} \mathrm{C}$ to $-105^{\circ} \mathrm{C}[6,65-67]$, but no preparation route was found. IR monitoring of the reaction between $\mathrm{NH}_{3}$ and $\mathrm{O}_{3}$ yielded unreliable results $[68,69]$. It has been postulated that ammonium ozonide is unstable above $-90^{\circ} \mathrm{C}[68,69]$.

Traube et al. [70,71] and Solomon et al. [72, 73] reported attempts to synthesize tetraalkylammonium ozonides via ozonolysis of the corresponding hydroxides. However, because of the oxidizability of the $\mathrm{N}(\mathrm{Alk})_{4}{ }^{+}$cations these experiments failed. Very recently, a new preparative route via an exchange reaction between alkali metal ozonides and tetramethylammonium hyperoxide has been reported to produce pure tetramethylammoniumozonide [74].

\subsubsection{Syntheses of Tetraalkylammonium Ozonides}

Syntheses of tetraalkylammonium ozonides start from alkali metal ozonides.

The $\mathrm{O}_{3}{ }^{-}$anions are introduced via an exchange reaction $\mathrm{AO}_{3}+\mathrm{NAlk}_{4} \mathrm{O}_{2}=\mathrm{NAlk}_{4} \mathrm{O}_{3}+\mathrm{AO}_{2}$ (Alk = methyl-, ethyl-; $\mathrm{A}=$ alkali metal) avoiding oxidation of the $\mathrm{NMe}_{4}{ }^{+}$cation by reaction with ozone. For example, $\mathrm{KO}_{3}$ may be reacted with $\mathrm{NMe}_{4} \mathrm{O}_{2}$ in liquid ammonia. All components with the exception of $\mathrm{KO}_{2}$ are quite soluble in $\mathrm{NH}_{3}$ and therefore precipitation of the less 
soluble $\mathrm{KO}_{2}$ forces the reaction towards the desired product. After separation of the $\mathrm{NMe}_{4} \mathrm{O}_{3}$ solution, slow evaporation of ammonia yields red, transparent crystals of $\mathrm{NMe}_{4} \mathrm{O}_{3}$ in nearly quantitative yield [74].

This new preparation route is generally practicable and has a number of advantages. Reaction conditions are very mild (low temperatures). Furthermore, the ozonide ion does not need to be formed by ozonolysis in the presence of oxidizable tetraalkylammonium cations. The reactant (a hyperoxide in the case mentioned above) may be an arbitrary salt of the respective cation, with the only restriction being that solubilities and redox stabilities must be adjusted.

\subsubsection{Crystal Structures}

\section{2 .2 .1 . Crystal Structure of $\mathrm{NMe}_{4} \mathrm{O}_{3}$}

The crystal structure of $\mathrm{NMe}_{4} \mathrm{O}_{3}$ was solved by single crystal X-ray techniques [74]. Lattice constants were refined from the X-ray powder pattern of $\mathrm{NMe}_{4} \mathrm{O}_{3}$, which was indexed in agreement with the single crystal results. The results of the $\mathrm{X}$-ray structure analysis are shown in Table III. The relation to the CsCl-type of structure is readily apparent (Fig. 6).

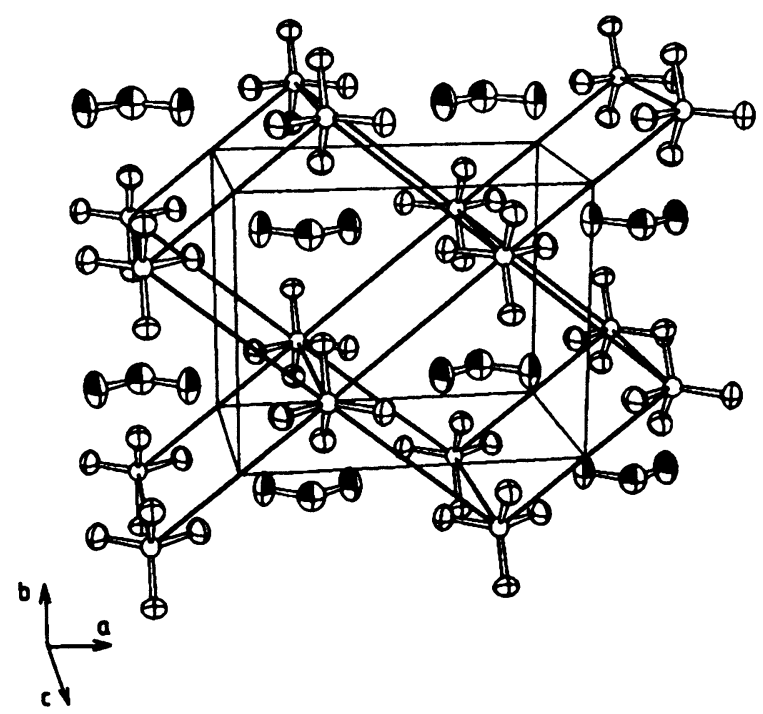

Fig. 6:

Perspective drawing of the crystal structure of $\mathrm{NMe}_{4} \mathrm{O}_{3}$ (H atoms omitted). [74] 
Table III:

Crystallographic data of tetraalkylammonium ozonides

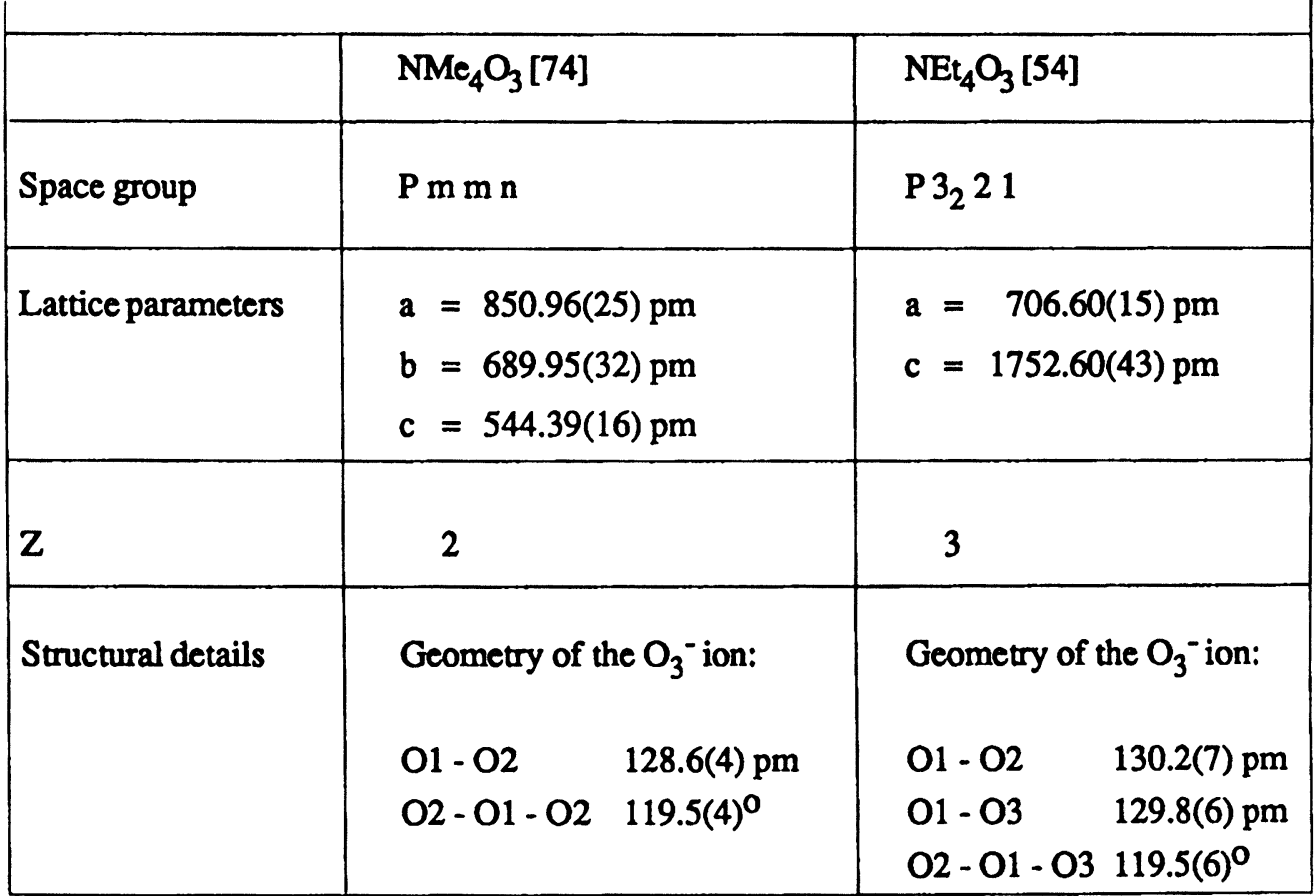

The crystal structures of the ionic ozonides determined so far can be related as shown in Fig. 7.

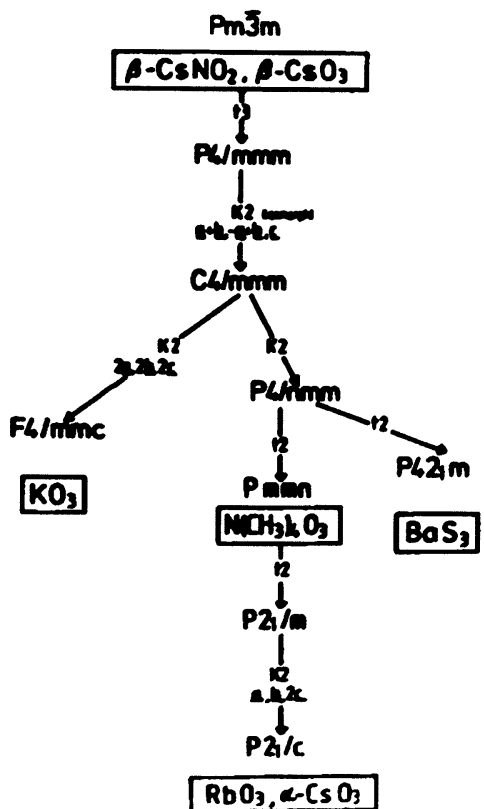

Fig. 7:

Group-subgroup relations between the crystal structures of ionic ozonides, $\mathrm{BaS}_{3}$, and $\beta-\mathrm{CsNO}_{2}$. [48] 
Despite these common features there is a marked difference between the alkali metal ozonides and $\mathrm{NMe}_{4} \mathrm{O}_{3}$ with respect to their structures. In the alkali metal ozonides, the $\mathrm{O}_{3}{ }^{-}$groups are arranged such that the terminal $\mathrm{O}$-atoms of each molecule are directed towards bridging oxygen atoms of neighboring ozonide groups, resulting in rather short intermolecular O-O distances $(\sim 300 \mathrm{pm})$. In the case of $\mathrm{NMe}_{4} \mathrm{O}_{3}$, the $\mathrm{O}_{3}^{-}$dipoles are arranged in an antiferroelectric sense with the shortest intermolecular O-O-distances $(438.8 \mathrm{pm})$ being those between terminal oxygen atoms.

\subsubsection{Crystal Structure of $\mathrm{NEt}_{4} \mathrm{O}_{3}$}

The crystal structure of $\mathrm{NEt}_{4} \mathrm{O}_{3}$ was solved by single crystal X-ray techniques [54]. The results are shown in Table III.

In contrast to the other ozonides described above, the atomic arrangement in solid $\mathrm{NEt}_{4} \mathrm{O}_{3}$ is related to the $\mathrm{NaCl}$-type of structure (see Fig. 8). This structural difference may be explained by the increasing size of the cation in the sequence $\mathrm{K}-\mathrm{Rb}-\mathrm{Cs}-\mathrm{NMe}_{4}-\mathrm{NEt}_{4}$.
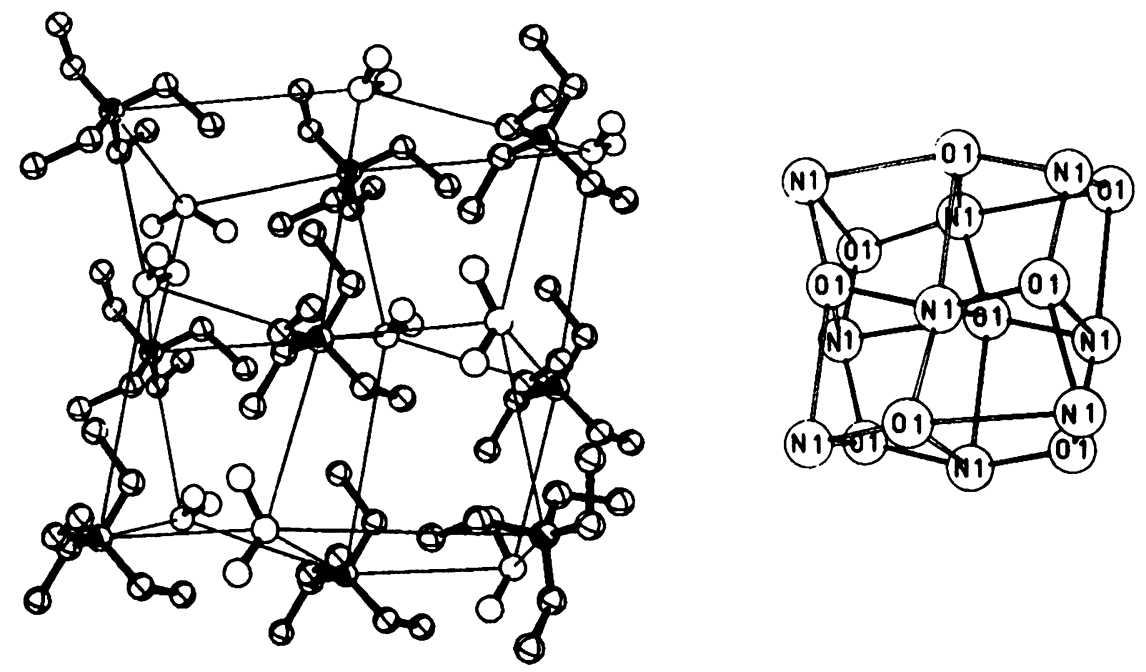

Fig. 8:

Perspective drawing of the crystal structure of $\mathrm{NEt}_{4} \mathrm{O}_{3}$ (H-atoms omitted) and the relation to the $\mathrm{NaCl}$-type of structure.

\subsubsection{Thermal Properties and Decomposition of $\mathrm{NMe}_{4} \mathrm{O}_{3}$ and $\mathrm{NE}_{4} \mathrm{O}_{3}$}

Surprisingly, the bright red $\mathrm{NMe}_{4} \mathrm{O}_{3}$ is thermally more stable than the alkali metal ozonides. DTA/TG and temperature dependent $\mathrm{X}$-ray powder investigations indicate the decomposition point to be $75^{\circ} \mathrm{C}$, which is more than $20^{\circ} \mathrm{C}$ above the value for $\mathrm{CsO}_{3}$, the most stable ozonide previously known. 
In the case of the alkali metal ozonides, the decomposition products are the respective hyperoxides. The most probable mechanism involves transfer of monooxygen from an $\mathrm{O}_{3}{ }^{-}$group to a neighboring hyperoxide group; the hyperoxide groups are primarily close to the surface. This type of reaction is suppressed in the case of $\mathrm{NMe}_{4} \mathrm{O}_{3}$ because of the long intermolecular O-Odistances. Instead, an oxidative attack on the cation is observed by MS and DTA/TG techniques. A white substance is formed by an exothermic reaction. Above ca. $100^{\circ} \mathrm{C}$, it decomposes into gaseous products, identified by mass spectrometry as $\mathrm{NMe}_{3}, \mathrm{CO}, \mathrm{O}_{2}, \mathrm{H}_{2} \mathrm{O}, \mathrm{Me}_{2} \mathrm{O}, \mathrm{MeOH}$, and $\mathrm{C}_{3} \mathrm{H}_{7} \mathrm{NO}$ (possibly DMF) [74].

In the case of $\mathrm{NEt}_{4} \mathrm{O}_{3}$, the decomposition mechanism of the alkali metal ozonides is also suppressed. $\mathrm{NEt}_{4} \mathrm{O}_{3}$ is less stable than $\mathrm{NMe}_{4} \mathrm{O}_{3}$ because of the presence of $\beta$-hydrogen atoms, which cause a decomposition reaction like a Hofmann-elimination. Above $30-40^{\circ} \mathrm{Celimination}$ products $\mathrm{NEt}_{3}$, ethylen and $\mathrm{O}_{2}$ were identified by $\mathrm{MS}$ spectroscopy. Small amounts of oxidation products (e.g., $\mathrm{NEt}_{3} \mathrm{O}$ ) are also observed [54].

\subsection{Applications and Perspectives}

The considerable interest in ionic ozonides was stimulated by possible applications in air revitalization (e.g., for use in emergency breathing apparatus for miners and as auxiliary oxygen sources for astronauts) and as rocket monopropellants. Ozonides are compounds with the highest amount of available oxygen known: e.g., $14.35 \mathrm{~L} \mathrm{O}_{2} / \mathrm{kg} \mathrm{KO}_{3}$ is nearly $50 \%$ better than the technically used $\mathrm{KO}_{2}\left(10.55 \mathrm{~L} \mathrm{O}_{2} / \mathrm{kg} \mathrm{KO}_{2}\right)$. Because of their extreme sensitivity to moisture and $\mathrm{CO}_{2}$ and other disadvantageous properties (metastability and lack of a proper synthetic route), practical application of these compounds has not been established.

Solids containing paramagnetic radical $\mathrm{O}_{3}{ }^{-}$anions ionic ozonides are of scientific interest. Now, as pure ozonides have become available in larger amounts, synthetic applications of this class of compounds arise. Potentially attractive uses are for exchange of cations (see Section 2.2.), as an oxidant [75 - 77], and for 1,3 - dipole addition to molecular species. 


\section{HYPEROXIDES}

\subsection{Alkali Metal Hyperoxides}

Ionic hyperoxides contain the diatomic molecular anion $\mathrm{O}_{2}-$ This unique species only seems to occur in the presence of low valent, non oxidizable, and rather electropositive metallic cations. Accordingly, only hyperoxides of sodium, potassium, rubidium, and cesium are known to exist in a pure state. As compared to the stability of the "normal" oxides $\mathrm{M}_{2} \mathrm{O}$, formation of the corresponding hyperoxides $\mathrm{MO}_{2}(\mathrm{M}=\mathrm{Na}, \mathrm{K}, \mathrm{Rb}, \mathrm{Cs})$ is increasingly favored with increasing atomic number of the alkali metal. While rubidium and cesium immediately react to form the corresponding hyperoxides on exposure to an oxygen atmosphere, sodium produces the corresponding peroxide. Under similar conditions, potassium forms a mixture of peroxide and hyperoxide. Both sodium and potassium hyperoxides are obtained at higher temperatures $\left(\sim 500^{\circ} \mathrm{C}\right)$ and increased oxygen partial pressure $(\sim 300 \mathrm{bar})$.

Basic properties and average crystal structures of alkali hyperoxides, at room temperature, have been described by Vol'nov and Vannerberg [1,2]. However, the alkali hyperoxides represent an unique group of compounds with some extraordinary properties, which in part have just been investigated recently. Because they contain the paramagnetic 13 -electron anion $\mathrm{O}_{2}^{-}$, ionic hyperoxides represent a class of rare compounds which are suitable for investigation of magnetic ordering phenomena associated with unpaired p-electrons.

On the other hand, the alkali metal hyperoxides exhibit a series of very interesting crystallographic phase transitions due to molecular ordering of the disordered $\mathrm{O}_{2}$-anions. Cooperative phenomena have been observed giving rise to the assumption that molecular and magnetic ordering processes should not be considered independently from each other. Detailed investigations of the physical and crystallographic properties of these compounds were not possible before single-crystals became available and modern solid state research methods (inelastic neutron scattering, EPR, FIR-, Raman-, Brillouin-scattering techniques, susceptibility-measurements, etc.) could be applied to determine the highly anisotropic properties of these compounds.

\subsubsection{Syntheses of Alkali Metal Hyperoxides}

\subsubsection{Lithium Hyperoxide}

Up to now preparation of pure solid lithium hyperoxide had never been achieved. Only impure samples were obtained from reaction of an ozone solution in Freon- 12 with suspended $\mathrm{Li}_{2} \mathrm{O}_{2}$ at 
$-65^{\circ} \mathrm{C}[64,78,79]$. Formation of hyperoxide was detected by EPR spectra, however, above $-35^{\circ} \mathrm{C}$, decomposition to $\mathrm{Li}_{2} \mathrm{O}_{2}$ was observed. Puxeddu et al. suggested electrocatalytic formation of " $\mathrm{LiO}_{2}$ " by controlled potential reduction of a cobalt chelate in pyridine in the presence of $\mathrm{LiClO}_{4}$ and oxygen [80]. The yellowish precipitate, which was obtained at the $\mathrm{Hg}$ cathode, was identified only by the "nitroblue tetrazolium" test [81]. Bruno et al. investigated a similar electroreduction in DMSO and got an insoluble film of " $\mathrm{LiO}_{2}$ " at the $\mathrm{Hg}$ cathode [82].

Vannerberg attributes the instability of lithium hyperoxide to the small radius of the lithium ion $(60 \mathrm{pm})$ and, therefore, no stable hyperoxide structure is produced [1].

\section{1,1,2, Sodium Hyperoxide}

It is rather difficult to synthesize sodium hyperoxide of high purity. Oxidation of the metal dissolved in liquid ammonia or the dissociation of $\mathrm{Na}_{2} \mathrm{O}_{2} \cdot 2 \mathrm{H}_{2} \mathrm{O}_{2}$ leads to mixtures of hyperoxide and peroxide. The most suitable method for synthesis of $\mathrm{NaO}_{2}$ is oxidation of $\mathrm{Na}_{2} \mathrm{O}_{2}$ with oxygen at elevated temperatures and pressures. Kleinberg et al. obtained a product containing approximately $96 \% \mathrm{NaO}_{2}$ by oxidizing sodium peroxide at $475^{\circ} \mathrm{C}$ and an oxygen partial pressure of 280 bar $[83,84]$. Information concerning the solubility of sodium hyperoxide in liquid ammonia is contradictory. In reference [85] it is stated that the solubility at -50 to $-33^{\circ} \mathrm{C}$ is $0.06 \mathrm{~g} / \mathrm{LNH}_{3}$, whereas in reference [86] the solubility is reported as 6.4 to $3.8 \mathrm{~g} / \mathrm{LNH} 3$ from -40 to $-70^{\circ} \mathrm{C}$. $\mathrm{Re}$ crystallisation from liquid ammonia has been used to produce $\mathrm{NaO}_{2}$ single crystals for $\mathrm{X}$-ray structural analysis and further investigations. Another method for producing sodium hyperoxide is via reactions involving the use of organic substances. In a method suggested by Le Berre, $\mathrm{NaO}_{2}$ is produced by self-oxidation of sodium benzophenone in tetrahydrofuran [87]. Sokolov and Matsulevich investigated the oxidation of alkali-metal $(\mathrm{Na}, \mathrm{K})$ in the presence of organic compounds (phenazine, xanthone, fluorenone, benzophenone, biphenyl, naphthalene, phenanthrene, anthracene). Samples with a purity of 95-99\% were obtained [88-91].

Reaction of $\mathrm{Na}_{2} \mathrm{O}_{2}$ with ozone at $-10^{\circ} \mathrm{C}$ to $-60^{\circ} \mathrm{C}$ leads to $\mathrm{NaO}_{3}$ which rapidly decomposes to sodium hyperoxide [35].

\subsubsection{Potassium-. Rubidium- and Cesium Hyperoxides}

Vol'nov has described [2] six methods to synthesize $\mathrm{KO}_{2}, \mathrm{RbO}_{2}$, and $\mathrm{CsO}_{2}$ : (1) oxidation of the metal dissolved in liquid ammonia; (2) direct oxidation of the metal; (3) oxidation of alkali amalgam; (4) oxidation of alkali metal oxide; (5) oxidation of alkali metal hydroxide; and (6) the disproportionation of alkali metal peroxide peroxyhydrate.

A laboratory method for the preparation of large quantities of these hyperoxides is given in reference [92] and is based on the second method. In the case of $\mathrm{RbO}_{2}$ and $\mathrm{CsO}$, the resulting 
purity is $\sim 97 \%$, while the potassium compound contains marked amounts of $\mathrm{K}_{2} \mathrm{O}_{2}$. A product of high purity is obtained if this peroxide/hyperoxide mixture reacts with further oxygen under increased temperature and pressure [51]. On an industrial scale, $\mathrm{KO}_{2}$ is produced by the oxidation of dispersed liquid potassium with oxygen enriched air [93]. $\mathrm{Like} \mathrm{NaO}_{2}, \mathrm{KO}_{2}$ can be synthesized by oxidation of the metal with catalyzing organic acceptors $[88,89]$. Two Japanese patents describe $\mathrm{KO}_{2}$ production by drying the product of the reaction between $\mathrm{KOH}$ and $\mathrm{H}_{2} \mathrm{O}_{2}$ using $\mathrm{Na}_{2} \mathrm{O}_{2}$ [94] or by spray-drying of $\mathrm{KOH} / \mathrm{H}_{2} \mathrm{O}_{2}$ solutions [95].

Formation of $\mathrm{KO}_{2}$ was also observed during disproportionation of $\mathrm{K}_{2} \mathrm{O}_{2}$ by a smooth reaction with water vapor [96]. In the presence of $\mathrm{K}^{+}$the electrochemical reduction of oxygen in liquid ammonia leads to precipitation of solid $\mathrm{KO}_{2}$ [97].

Higher oxides (peroxides and hyperoxides) of alkali and alkaline earth metals, especially highpurity $\mathrm{KO}_{2}$, have been prepared by subjecting the hydroxide of the respective metal to a radiofrequency discharge sustained in oxygen or a glow discharge [98-101]. The oxidation of alkoxides or hydroxylamines with oxygen yields hyperoxide anions, which in the presence of $\mathrm{K}^{+}$ precipitate as yellow $\mathrm{KO}_{2}[102,103]$.

\subsubsection{Crystal Structures and Magnetic Properties of Alkali Metal Hyperoxides}

The crystal structures of ionic alkali metal hyperoxides $\left(\mathrm{M}^{+} \mathrm{O}_{2} ; \mathrm{M}^{+}=\mathrm{Na}^{+}, \mathrm{K}^{+}, \mathrm{Rb}^{+}, \mathrm{Cs}^{+}\right)$at higher temperatures derive from the $\mathrm{NaCl}$-type of structure with disordered hyperoxide $\left(\mathrm{O}_{2}\right)$ anions. On cooling to the temperature of liquid helium, all four compounds pass through a series of polymorphic phase transitions caused by increasing orientational ordering of the anions. This crystallographic ordering process is connected with a magnetic ordering of unpaired p-electrons in the paramagnetic $\mathrm{O}_{2}^{-}$groups.

Earlier attempts to identify completely all modifications of these hyperoxides that occur, which had been undertaken using powder X-ray methods, yielded only average structural information. A deeper insight, which led to a more precise understanding of the observed phase transitions, was not possible before Känzig and coworkers succeeded in preparation of proper single crystals of these rather sensitive compounds [104, 105].

Two main problems occur during structure determination of these compounds: (1) Disorder due to the motion of the $\mathrm{O}_{2}{ }^{-}$anions results in a rapid decrease of scattered X-ray intensity with increasing Bragg-angle, leading to inaccurate or incorrect structural data. (2) Formation of twindomains results in superposition of $\mathrm{X}$-ray reflections, which can be resolved only by single crystal methods, while powder techniques yield only average structural data [106]. Furthermore, 
diffuse scattering occurs and has to be interpreted. By the use of single-crystal X-ray and neutron-diffraction methods, Känzig et al. were able to overcome most of these problems [106, 107]. The single crystals were synthesized by enrichment of the hyperoxides from liquid ammonia solutions around $-32.5^{\circ} \mathrm{C}$ using a particular crystal growth apparatus (see Fig. 9) [104]. Sodium hyperoxide is obtained only above $-35^{\circ} \mathrm{C}$, because, below this temperature, $\mathrm{NaO}_{2} \cdot 2 \mathrm{NH}_{3}$ is formed. Potassium, rubidium, and cesium hyperoxides exhibit a considerably lower solubility in liquid ammonia $(\sim 5 \mathrm{mg} / \mathrm{L})$ than $\mathrm{NaO}_{2}(\sim 60 \mathrm{mg} / \mathrm{L})$. Crystal growth of $\mathrm{KO}_{2}$ was enhanced by addition of tetramethylammoniumhyperoxide to the $\mathrm{KO}_{2} / \mathrm{NH}_{3}$ solution [104]. This procedure yields phase $\mathrm{I}\left(\mathrm{NaO}_{2}\right)$ and phase $\mathrm{II}\left(\mathrm{KO}_{2}, \mathrm{RbO}_{2}\right.$, and $\left.\mathrm{CsO} \mathrm{O}_{2}\right)$ single crystals, respectively.

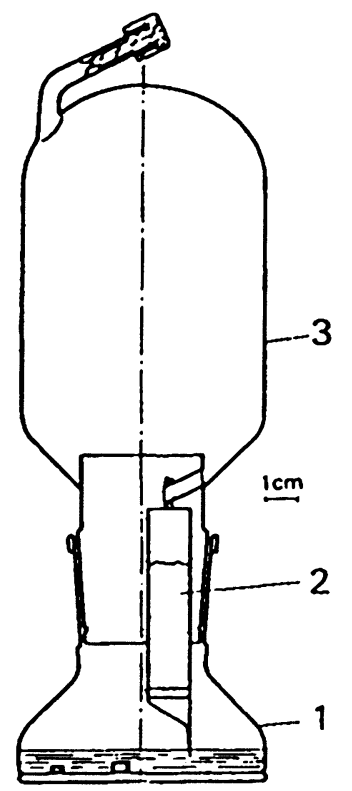

Fig. 9:

Apparatus for crystal growth of alkali metal hyperoxides [104]

1: Enrichment and crystallization vessel; 2: Ammonia condenser

3: Container for solid alkali metal hyperoxide

Transformation to lower symmetrical modifications upon cooling inevitably causes twinning of the single crystals [106]. Attempts to avoid this domain formation by application of mechanical stress failed because of the extreme softness of the crystals [108]. The number of domains formed through phase transformations has been detected by the use of single-crystal methods, but complete resolution of these domains was only partly successful. For this reason the exact orientation of the linear $\mathrm{O}_{2}{ }^{-}$groups in alkali metal hyperoxides could not be evaluated by diffraction techniques only, but it has been determined by EPR-methods at very low temperatures. 
Athigher temperatures (phases I, II, and III) there is a close relationship between the structures of the heavier alkali metal hyperoxides $\left(\mathrm{KO}_{2}, \mathrm{RbO}_{2}, \mathrm{CsO}\right)$, while $\mathrm{NaO}_{2}$ exhibits some marked differences. At very low temperatures all four compounds show different behavior.

In phase $\mathrm{I}$, rather freely rotating anions have been observed in $\mathrm{KO}_{2}, \mathrm{RbO}_{2}$, and $\mathrm{CsO}_{2}$ [107]. In the corresponding phase of $\mathrm{NaO}_{2}$, correlation of the disordered $\mathrm{O}_{2}^{-}$groups has been established [106]. At lower temperatures the heavier alkali-hyperoxides $\left(\mathrm{KO}_{2}, \mathrm{RbO}_{2}, \mathrm{CsO} \mathrm{O}_{2}\right)$ exhibit modulated structures as manifested by observation of diffuse scattering [107]. With $\mathrm{KO}_{2}$ a large distortion of the lattice accompanied by a reorientation of the $\mathrm{O}_{2}^{-}$groups has been found [107], while in $\mathrm{RbO}_{2}$ and $\mathrm{CsO}_{2}$ the modulated structures persist down to $5 \mathrm{~K}$ [107] . In contrast, sodium hyperoxide transforms from a disordered pyrite-type, via an ordered pyrite-type, to a marcasitetype phase [106].

Alkali metal hyperoxides exhibit very complex behavior in the solid state. Orbital degeneracy of the linear $\mathrm{O}_{2}{ }^{-}$anions causes structural phase-transitions due to a Jahn-Teller distortion and the spin degeneracy suggests that there will be magnetic phase transitions. Hence, the $\mathrm{O}_{2}^{-}$groups have different orientations and, simultaneously, the paramagnetic anions exhibit mutual interactions among neighboring $\mathrm{O}_{2}^{-}$groups. Each of these individual effects by themselves could give rise to cooperative phenomena, and all of them in combination seem to bring about the observed phase transitions. Obviously, there is an interdependence between all of these effects. Because of that, some of the observed phase transitions must not be interpreted to be purely crystallographic. For example, Zeeman-splitting of the ground state of $\mathrm{O}_{2}{ }^{-}\left({ }^{2} \Pi_{g}\right)$ depends on both the orientation of the anion' s molecular axis as well as the crystal field splitting.Thus, magnetization gives rise to a change in orientation of the anion's molecular axis [109]. In fact, such magnetoelastic interactions (magnetogyration) have been observed in the case of potassium hyperoxide $[110,111,112]$.

As complete knowledge of the anion's orientation in alkali metal hyperoxides at lower temperatures could not be obtained solely from diffraction data, numerous further investigations have been performed to understand magnetic ordering in this class of compounds and its relation to the structural phase transitions. For example, magnetic properties have been studied using magnetic susceptibility and differential magnetic susceptibility (as magnetic field) measurements, magnetization curves (in static and pulsed fields), electron paramagnetic resonance (EPR) and antiferromagnetic-resonance (AFMR). Spectroscopic investigations have been performed by Raman, IR, FIR, UV, VUV (vacuum-UV) and Brillouin scattering techniques, and thermal properties have been studied using DTA-TG methods and specific heat measurements. Furthermore, the refractive indices, birefringence, and compressibility of alkali metal hyperoxides have been determined. In the present overview, results of such investigations will be described with respect to 
the chemical, magnetic, and structural properties of the alkali metal hyper oxides, complementing the crystallographic results also mentioned.

\subsubsection{Sodium Hyperoxide}

As summarized in Table IV, the crystal structure of $\mathrm{NaO}_{2}$ derives from the $\mathrm{NaCl}$-type of structure there being increasing ordering of the $\mathrm{O}_{2}^{-}$groups upon cooling. In the room-temperature phase (I- $\mathrm{NaO}_{2}, \mathrm{NaCl}$-type with disordered $\mathrm{O}_{2}{ }^{-}$anions) both statistical disorder and hindered rotation of the $\mathrm{O}_{2}^{-}$anions have been discussed, but choise of one of these models was not possible on the basis of powder-diffraction data. X-ray-data obtained from single crystals revealed a local short-range order of the $\mathrm{O}_{2}^{-}$groups in this phase.

\begin{tabular}{|c|c|c|c|c|c|}
\hline phase & $\begin{array}{c}\text { temperature } \\
\text { [K] }\end{array}$ & $\begin{array}{l}\text { lattice constants } \\
\text { [pm] }\end{array}$ & $\begin{array}{l}\text { space } \\
\text { group }\end{array}$ & structure & remarks* \\
\hline $\mathrm{I}-\mathrm{NaO}_{2}$ & $223<T$ & $\begin{array}{l}a=551.2 \\
{[106,114]}\end{array}$ & Fm3m & $\begin{array}{l}\mathrm{NaCl} \text {; } \\
\text { (disordered } \\
\text { pyrite-type) }\end{array}$ & $\begin{array}{l}\text { diffuse scattering on } \\
\text { single-crystal X-ray- } \\
\text { photographs [106]. } \\
\text { X-P; X-SC; N-P }\end{array}$ \\
\hline II-NaO & $196<\mathrm{T}<223$ & $\begin{array}{l}a=546 \\
{[114,115]}\end{array}$ & $\mathrm{Pa} \overline{3}$ & $\begin{array}{l}\text { ordered } \\
\text { pyrite-type }\end{array}$ & $\begin{array}{l}\text { forbidden } \\
\text { reflections due to } \\
\text { formation of twin } \\
\text { domains [3]. } \\
\text { X-P; X-SC. }\end{array}$ \\
\hline III- $\mathrm{NaO}_{2}$ & $43<T<196$ & $\begin{array}{l}a=433.2 \\
b=554.0 \\
c=336.4 \\
{[106]}\end{array}$ & Pnnm & $\begin{array}{l}\text { marcasite- } \\
\text { type } \\
{[106,116]}\end{array}$ & $\begin{array}{l}\text { twinning-law established } \\
\text { distinct domains } \\
\text { resolved [106], antiferromagnetic } \\
\text { short range order [106] } \\
\text { X-P; X-SC } \\
\text { N-P;N-SC. }\end{array}$ \\
\hline $\mathrm{IV}-\mathrm{NaO}_{2}$ & $T<43$ & $\begin{array}{l}a=433.5 \\
b=553.7 \\
c=335.3 \\
{[106]}\end{array}$ & Pnnm & $\begin{array}{l}\text { marcasite- } \\
\text { type }\end{array}$ & $\begin{array}{l}\text { supposed antiferromagnetic } \\
\text { long range order [109] could } \\
\text { not be proved [106]. } \\
\text { N-P. }\end{array}$ \\
\hline
\end{tabular}

The equilibrium orientations of the anions were found to be presumably parallel to [111], suggesting hindered rotation. Distribution over the four [111] - axes does not seem to be entirely random. Diffuse scattering occurs in reciprocal space at those sites, where new Bragg-Reflections are ob- 
served from the lower symmetrical phase II- $\mathrm{NaO}_{2}$. Thus, in $\mathrm{I}-\mathrm{NaO}_{2}$, the data were correlated by an assumption equivalent to pyrite-type local order [106]. In II- $\mathrm{NaO}_{2}$, this local order extends to long range order [113]. Neutron diffraction experiments on $\mathrm{NaO}_{2}$ single-crystals also confirm these results [106] (see Section 3.1.3).
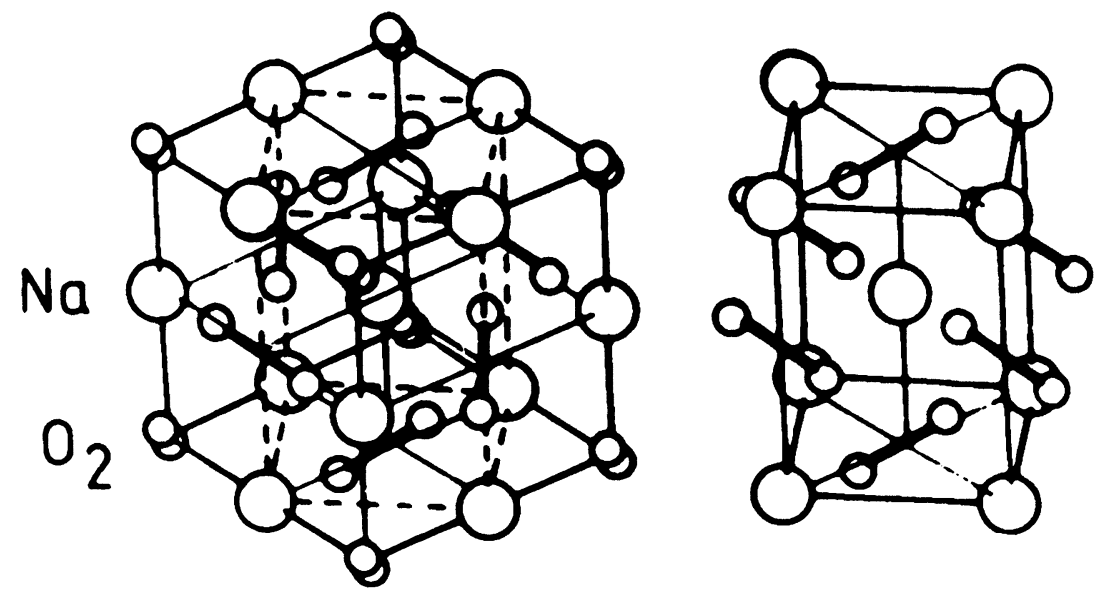

Fig. 10:

Relation between the ordered pyrite structure (left side) and the marcasite structure [113].

In phase II of $\mathrm{NaO}_{2}$, forbidden reflections incompatible with the spacegroup $(\mathrm{Pa} \overline{3})$ that had been determined were observed by single crystal X-ray methods [106]. However, accurate analysis showed that these reflections probably are due to formation of twin domains, and the twinninglaw was formulated by Känzig et al. [106]. Transformation from cubic II-NaO $\mathrm{N}_{2}$ to orthorhombic $\mathrm{II}-\mathrm{NaO}_{2}$ (see Fig.10) results in formation of 12 different domains. The twinning law has been reported and all reflections of the obtained Buerger-precession photographs have been indexed, but no analysis of the intensity data has been performed so far. Structural data have been obtained by $\mathrm{X}$-ray and neutron diffraction experiments [106]. In contrast to $\mathrm{I}-\mathrm{NaO}_{2}$, temperature dependencies for III- $\mathrm{NaO}_{2}$ were found to be markedly smaller, indicating long-range ordering of the $\mathrm{O}_{2}^{-}$anions within the single domains [106]. Magnetic susceptibility measurements proved phases $\mathrm{I}$ and II of $\mathrm{NaO}_{2}$ to be paramagnetic. At the phase transition from the ordered pyrite-type (II$\mathrm{NaO}_{2}$ ) to the marcasite-type (III-NaO 2 ), the susceptibility drops, indicating a first order phase transition [109,113]. In phase III, the susceptibility decreases with decreasing temperature, suggesting magnetic ordering. Based on diffraction experiments with polarized neutrons, long- 
rage order has been ruled out, but the paramagnetic diffraction intensity goes to zero below $100 \mathrm{~K}$. This indicates a reduction of the magnetic moment of the $\mathrm{O}_{2}^{-}$anions caused by local antiferromagnetic order [106].

Specific heat measurements on $\mathrm{NaO}_{2}$ reveal a typical $\mathrm{T}^{3}$-dependence of $\mathrm{C}_{\mathrm{p}}$ between 1.8 and $8 \mathrm{~K}$. However, above $8 \mathrm{~K}$ the specific heat of sodium peroxide increases rapidly [109]. Formation of the low-temperature phase, $\mathrm{IV}-\mathrm{NaO}_{2}$, below $43 \mathrm{~K}$ could not be proven by calorimetric measurements or X-ray diffraction, but is shown by a small discontinuous decrease in the magnetic susceptibility [113]. Fitting neutron powder-diffraction data on phase IV by Rietveld-refinement assuming the marcasite structure was impossible without contradictions [106]. Below $20 \mathrm{~K}$, the magnetic susceptibility of $\mathrm{NaO}_{2}$ increases with decreasing temperature. This has been explained by assumption of a dilute paramagnet with a concentration of about one mole per cent. However, the exact cause of the observation remains unclear [113].

\subsubsection{Potassium Hyperoxide}

The cubic high-temperature phase $\mathrm{I}-\mathrm{KO}_{2}$ (c.f. Table $\mathrm{V}$ ), existing above $383 \mathrm{~K}$, is only poorly characterized, because in the temperature range quoted, this unstable compound slowly decomposes by evolution of oxygen [106, 117]. X-ray powder investigations support a NaCl-type of structure (disordered pyrite-type) with fairly freely rotating hyperoxide anions for $\mathrm{I}-\mathrm{KO}_{2}[115,118]$. The $\mathrm{CaC}_{2}$-type of structure postulated for II- $\mathrm{KO}_{2}$ by earlier investigations [ $\left.119-121\right]$ turns out to be only an average structural model, as shown by observation of unexpected large temperature factors [121], as well as theoretical considerations [122]. Halverson pointed out that the $\mathrm{O}_{2}{ }^{-}$group

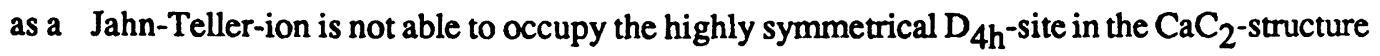
with the anion's molecular axis coinciding with the c-axis of the tetragonal unit-cell [122]. Accordingly, Halverson derived a structural model for potassium hyperoxide with the $\mathrm{O}_{2}$-groups executing circular motions about the c-axis in the tetragonal lattice [122]. In a more recent investigation, utilizing X-ray single crystal data including the interpretation of the observed diffuse scattering, Känzig et al. [106] gave a more precise description of the disorder in phases II and III of $\mathrm{KO}_{2}$ (see Fig. 11). They assume both inclination of the anion's axis within the planes $(100)$ and $(010)$ and shifting of the anions perpendicular to the c-axis within these planes.

Transformation to orthorhombic III- $\mathrm{KO}_{2}$ is accompanied by twinning of the crystal, as (100) and (010) are equivalent in the tetragonal cell. Nevertheless, tetragonal symmetry is observed because the orthorhombic distortion is rather small. Complete resolution of separate domains was not achieved, but formation of orthorhombic domains was established by the fact that the volume ratio of the two possible domains varies from crystal to crystal [106]. The observed diffuse scattering has been interpreted by the assumption of stacking faults of the planes mentioned above. The ob- 
served distribution of diffuse intensity in reciprocal space probably indicates correlation in the arrangement of these planes.

Diffuse intensity observed in II- $\mathrm{KO}_{2}$ condenses to new sattelite reflections in III- $\mathrm{KO}_{2}$, dividing the reciprocal lattice of this phase into a non rational ratio (incommensurate superstructure) with a modulation period of $(3.4 \pm 0.02)$ a $[106,113,123]$. A study of the ferroelastic domains by polarization microscopy of $\mathrm{III}-\mathrm{KO}_{2}$ has been reported [107].

Below $196 \mathrm{~K}$, half of the $\mathrm{O}_{2}^{-}$groups reorient, such that the former tetragonal unit cell $\left(\mathrm{CaC}_{2}^{-}\right.$ analogue) is sheared and doubled to become monoclinic. In this $\mathrm{IV}-\mathrm{KO}_{2}$ phase, all $\mathrm{O}_{2}^{-}$groups are arranged parallel to each other (see Fig. 12). The transformation of III- $\mathrm{KO}_{2} \rightarrow \mathrm{IV}-\mathrm{KO} 2 \mathrm{re-}$ sults in a twinning of the crystal $[106,107,124]$ (two orthorhombic domains $\rightarrow$ four monoclinic domains). While carlier investigations supported the assumption that $\mathrm{V}-\mathrm{KO}_{2}$ is a triclinic distorted variant of $\mathrm{IV}-\mathrm{KO}_{2}$ [125], Känzig et al. revealed the true nature of this phase by singlecrystal X-ray techniques [107]. Analyses of rotating crystal and Weissenberg- equiinclinationphotographs indicated coexistence of $\mathrm{IV}-\mathrm{KO}_{2}$ and $\mathrm{VI}-\mathrm{KO}_{2}$ in the stability region of $\mathrm{V}-\mathrm{KO}_{2}$ between 7 and $12 \mathrm{~K}$. The authors emphasized this was not an artifact due to experimental shortcomings [3a]. Below 7.1 $\mathrm{K}$ triclinic $\mathrm{VI}-\mathrm{KO}_{2}$ is stable with a distorted $\mathrm{NaCl}$-type of structure [107].
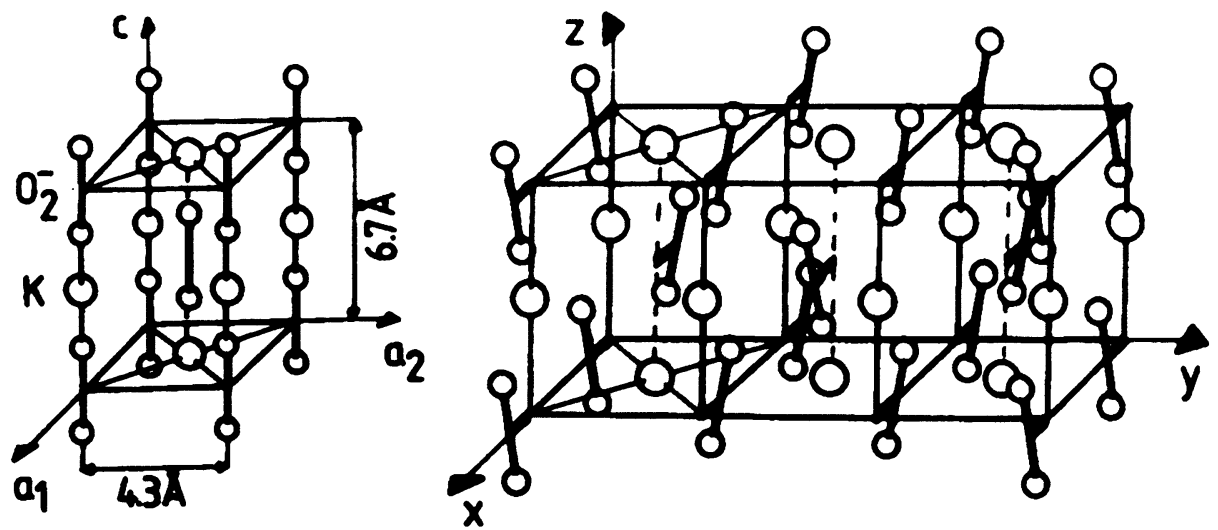

Fig. 11:

Relation between the symmetrized (average) structure (left side) and the structure of an orthorhombic domain in the phases II and III of $\mathrm{KO}_{2}$ schematic) [113].

Magnetic susceptibility measurements showed phases I, II, III, and IV of potassium hyperoxide to be paramagnetic $[109,113,126,127]$. No peculiar change of the magnetic behavior at the phase transitions II $\rightarrow$ III has been observed, which is quite reasonable because molecular order is rather similar in both phases. However, the transformation III $\rightarrow$ IValso only manifests itself 
y a comparatively small drop in the susceptibility curve. As IV- $\mathrm{KO}_{2}$ exhibits parallel ordering If the $\mathrm{O}_{2}$-anions, this small effect is quite surprising when compared to the ordered pyrite to marsasite transformation of sodium hyperoxide (II- $\mathrm{NaO}_{2} \rightarrow \mathrm{II}-\mathrm{NaO}_{2}$ ).

The very complex magnetic behavior of $\mathrm{KO}_{2}$ at low temperatures could not be explained before sxtensive electron paramagnetic and antiferromagnetic-resonance experiments (EPR, AFMR) were performed [109, 110,113, 127-129]. Initially $\mathrm{KO}_{2}$ was characterized as exhibiting metamagnetism at low temperatures $[109,126]$. However, more recently AFMR, EPR and two magnon spectroscopy (FIR) experiments using single crystals of $\mathrm{KO}_{2}$ have been reported, which support a spin-flop (SF) behavior rather than metamagnetism [110, 129]. Finally, the complete magnetic phase-diagram of $\mathrm{KO}_{2}$ at low temperatures has been reported (see Fig. 13) [110]. Single crystal EPR and AFMR studies produced a detailed knowledge of the geometrical orientation of the molecular axes of the $\mathrm{O}_{2}$-anions in IV- $\mathrm{KO}_{2}$ [129]. Moreover, in V- $\mathrm{KO}_{2}$, the molecular orientation has been determined from EPR data, which also yielded information on the domain structure [129]. Because of this complicated crystallographic domain formation, the exact structure could not be determined by diffraction methods [107]. However, the combination of EPR and AFMR data also yields information about the magnetic structure of $\mathrm{KO}_{2}$ [129]. Antiferromagnetic order in VI- $\mathrm{KO}_{2}$ below $7.1 \mathrm{~K}$ at sufficiently low magnetic fields originally was shown by neutron-diffraction measurements [125]. More recently it has been confirmed by EPR and AFMR techniques $[110,126]$, as well as specific-heat measurements $[109,130]$. Careful investigation of the magnetic behavior of potassium hyperoxide revealed a very uncommon phenomenon called magnetogyration [110].

Fig. 12:

Crystal structure of IV- $\mathrm{KO}_{2}[106]$.

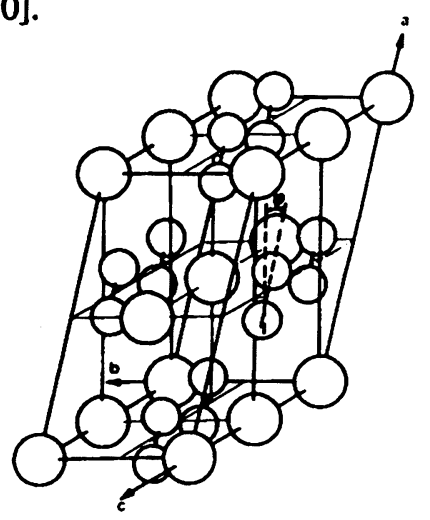

This effect concerns the magnetoelastic coupling between localized magnetic moments and the rotation of the $\mathrm{O}_{2}^{-}$molecules in solid state. For example, in the case of 3d- or 4s-electron systems, magnetic-field-induced magnetoelastic interactions causes magnetostriction. In contrast, the (2p) $\pi$-electron system $\mathrm{O}_{2}{ }^{-}$in potassium hyperoxide exhibits a peculiar crystallograhic phase transition (spin-flop phase (VI) $\rightarrow$ paramagnetic phase (IV)), when placed in an applied magnetic field, that involves a considerable change in the molecular orientation of the $\mathrm{O}_{2}{ }^{-}$ groups [110]. Upon lowering the temperature, magnetic ordering occurs in the magnetogyric phase, but this can be destroyed discontinuously by application of an external magnetic field 
[111]. A quantitative description of the discontinuous rotation of the $\mathrm{O}_{2}-$ groups in $\mathrm{KO}_{2}$ driven by magnetic forces and involving a modulation of exchange paths by the rotation has been given by Lines [112].

Fig. 13.

Magnetic phase diagram of $\mathrm{KO}_{2}$ : $P$, paramagnetic phase; $\mathrm{AF}$, antiferromagnetic phase; SF, spin-flop phase. The numbers in parantheses designate the crystallographic structures [110].

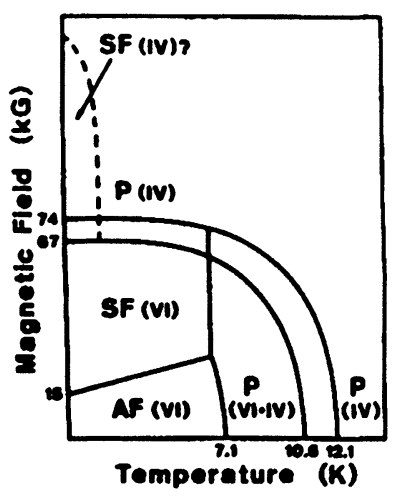

\begin{tabular}{|c|c|c|c|c|c|}
\hline phase & $\begin{array}{l}\text { temperature } \\
\text { [K] }\end{array}$ & $\begin{array}{l}\text { lattice constants } \\
{[\mathrm{pm}, \overline{0}]}\end{array}$ & $\begin{array}{l}\text { space } \\
\text { group }\end{array}$ & structure & remarks* \\
\hline${\mathrm{I}-\mathrm{KO}_{2}}_{2}$ & $383<T$ & $a=609$ & $\mathrm{Fm} \overline{3} \mathrm{~m}$ & $\begin{array}{l}\text { NaCl-type } \\
{[115,118]}\end{array}$ & $\begin{array}{l}\text { phase decomposes } \\
\text { by oxygen evolution; }[106,117] \\
\text { X-P. }\end{array}$ \\
\hline $\mathrm{II}-\mathrm{KO}_{2}$ & $231<T<383$ & $\begin{array}{l}a=403.3(2) \\
c=669.9(2)\end{array}$ & $14 / \mathrm{mmm}$ & $\begin{array}{l}\mathrm{CaC}_{2} \text {-type } \\
\text { (average structure) } \\
\text { [119-122] }\end{array}$ & $\begin{array}{l}\text { two orthorhombic } \\
\text { domains simulating tetra- } \\
\text { gonal symmetry [106]; diffuse } \\
\text { scattering [106, 123]. X-P; X-SC. }\end{array}$ \\
\hline $\mathrm{III}-\mathrm{KO}_{2}$ & $196<\mathrm{T}<231$ & $\begin{array}{l}a=400.4(3) \\
c=670.4(2)\end{array}$ & $14 / \mathrm{mmm}$ & $\begin{array}{l}\mathrm{CaC}_{2} \text {-type } \\
\text { (average structure) }\end{array}$ & $\begin{array}{l}\text { incommensurate } \\
\text { superstructure modulation } \\
\text { period: }(3.4 \pm 0.02) \mathrm{a} \\
{[106,107,123] \mathrm{X} \cdot \mathrm{P} ; \mathrm{X}-\mathrm{SC} .}\end{array}$ \\
\hline $\mathrm{IV}-\mathrm{KO}_{2}$ & $12.1<\mathrm{T}<196$ & $\begin{array}{l}a=788.0(5) \\
b=403.6(5) \\
C=796.8(5) \\
B=122.85(5)\end{array}$ & $C 2 / c$ & $\begin{array}{l}\mathrm{CaC}_{2} \text {-similar } \\
\text { with } \mathrm{O}_{2}^{-} \text {groups } \\
\text { reoriented } \\
{[106,107,124]}\end{array}$ & $\begin{array}{l}\text { four monoclinic domains } \\
{[106,107,124]} \\
\text { X-SC. }\end{array}$ \\
\hline $\mathrm{V}-\mathrm{KO}_{2}$ & $7.1<\mathrm{T}<10.6$ & \multicolumn{3}{|c|}{ coexistence of IV- $\mathrm{KO}_{2}$ and VI- $\mathrm{KO}_{2}$} & EPR [128]; X-SC [107] \\
\hline $\mathrm{VI}-\mathrm{KO}_{2}$ & $T<7.1$ & \multicolumn{3}{|c|}{$\begin{array}{l}a=596(1) \alpha=94.0(1) \\
b=543(1) \beta=87.5(1) \\
c=659(1) \gamma=90.0\end{array}$} & $\begin{array}{l}\text { X-SC [107] } \\
\text { N-P [125] } \\
\text { antiferromagnetic } \\
\text { ordering [107, 125] }\end{array}$ \\
\hline $\begin{array}{l}* \text { : X-P, } \\
\text { N-P: }\end{array}$ & $\begin{array}{l}X \text {-SC: } X \text {-ray } \\
\text { neutron powd }\end{array}$ & $\begin{array}{l}\text { owder, single cry } \\
\text { ex diffraction data }\end{array}$ & stal (resp.) & Fraction data. & \\
\hline
\end{tabular}




\subsubsection{Rubidium and Cesium Hyperoxides}

As depicted in Tables V, VI, and VII, the high temperature phases (I, II, III) of potassium, rubidium, and cesium exhibit rather similar structural properties. In the case of $\mathrm{RbO}_{2}$ and $\mathrm{CsO}_{2}$ modulated structures not only occur in phase III, as found for the potassium compound, but also extend down to $5 \mathrm{~K}$ [107]. In contrast to $\mathrm{RbO}_{2}$, no monoclinic distortion of the orthorhombic phase III of $\mathrm{CsO}_{2}$ at very low temperatures has been observed so far $[106,107]$. But neutron diffraction experiments performed on powdersamples of $\mathrm{CsO}_{2}$ indicate a further lowering of the symmetry below $1.3 \mathrm{~K}$ [106]. While long range structural ordering of the $\mathrm{O}_{2}^{-}$groups parallel to each other makes long range antiferromagnetic order possible in $\mathrm{KO}_{2}$. In the rubidium and cesium compounds, at most, short range order seems to occur [108].

Kemeny et al. tried to explain the occurrence of the modulated structures of $\mathrm{KO}_{2}, \mathrm{RbO}_{2}$, and $\mathrm{CsO}_{2}$. As summarized in Tables V-VII all three crystals exhibit an incommensurate transversal charge-density wave in the tetragonal basal plane. The $k$-vector of this wave lies in the tetragonal basal plane along the $y$-axis, and connects charges of the same sign with periodicity lengths that vary between $3.1 \mathrm{a}$ and $3.45 \mathrm{a}$ for the three compounds ( $\mathrm{a}=$ lattice constant). Kemeny et al. calculated the energy lowering of the observed commensurate and incommensurate charge density wave structures. They concluded that a displacive cooperative Jahn-Teller effect might be the source of the observed modulated structures [131].

Measurements of the magnetic susceptibility [109], along with electron-paramagnetic-resonance (EPR) and antiferromagnetic-resonance (AFMR) data, proved that both rubidium and cesium hyperoxide order antiferromagnetically with Néel-temperatures of 15 and $9.6 \mathrm{~K}$ respectively [129]. The observed anomalies in the adiabatic differential susceptibility, at fields of about 25 , 26 , and $28 \mathrm{kG}$ in $\mathrm{KO}_{2}, \mathrm{RbO}_{2}$, and $\mathrm{CsO}_{2}$, respectively [109], which disappear above the Nél temperatures, have been assigned to a spin-flop transition [129].

The magnetic axes have been determined for $\mathrm{KO}_{2}, \mathrm{RbO}_{2}$, and $\mathrm{CsO}_{2}$ from the relation of the g-tensor (which has been determined by EPR spectroscopy) to the orientation of the $\mathrm{O}_{2}{ }^{-}$groups, combined with the field dependence of the AFMR. The easy axis of magnetization is perpendicular to the interatomic axis of the $\mathrm{O}_{2}^{-}$groups, and the hard axis is parallel to it, for all three compounds [129]. The critical behavior of the EPR line width and of the EPR resonance field support the assumption of an antiferromagnetic short-range order below the Neel-temperature [129]. The magnetic interactions in $\mathrm{KO}_{2}, \mathrm{RbO}_{2}$, and $\mathrm{CsO}_{2}$ have been evaluated using the Nél temperatures, the Curie-Weiss temperatures, the spin-flop-field, the temperature dependence of the EPR resonance field, and the AFMR frequencies on the basis of a mean-field approximation [129]. 


\begin{tabular}{|c|c|c|c|c|}
\hline phase & $\begin{array}{l}\text { temperature } \\
\text { [K] }\end{array}$ & $\begin{array}{l}\text { lattice parameters } \\
{[\mathrm{pm}, 9]}\end{array}$ & \begin{tabular}{|l} 
space group/ \\
symmetry
\end{tabular} & remarks* \\
\hline $\mathrm{I}-\mathrm{RbO}_{2}$ & $420<T$ & $\begin{array}{l}a=633(1) \\
(430 \mathrm{~K})\end{array}$ & $F \bar{m} \bar{m}$ & $\begin{array}{l}\mathrm{NaCl} \text {-type; similar to } \mathrm{I}-\mathrm{KO}_{2}[106,107,132] \\
\mathrm{X}-\mathrm{P} \text {. }\end{array}$ \\
\hline II-RbO & \multirow{4}{*}{$\begin{array}{l}194<T<420 \\
\text { transformation: } 194 \\
\text { transformation: } \\
135-175\end{array}$} & $\begin{array}{l}a=421.5(5) \\
c=700.4(2) \\
(293 \mathrm{~K})\end{array}$ & $14 / \mathrm{mmm}$ & $\begin{array}{l}\mathrm{CaC}_{2} \text {-type (average structure); similar to II - } \mathrm{KO}_{2} \text {; stacking faults of } \\
\text { planes (001); ordering of } \mathrm{O}_{2}^{-} \text {-groups within planes }[106,132,133] \text {. X-P. }\end{array}$ \\
\hline IIIa-RbO 2 & & $\begin{array}{l}a=416.4(5) \\
c=700.4(2) \\
(180 \mathrm{~K})\end{array}$ & $\begin{array}{l}\text { pseudo } \\
\text { tetragonal }\end{array}$ & $\begin{array}{l}\mathrm{CaC} \text {-type (average structure); similar to III- } \mathrm{KO}_{2} \text {. orthorhombic } \\
\text { domains; sharp incommensurate superstructure reflections } \\
{[106,107,1323] . \mathrm{X}-\mathrm{SC} \text {. }}\end{array}$ \\
\hline $\mathrm{II} \beta-\mathrm{RbO} 2$ & & $\begin{array}{l}a=411.7(5) \\
b=415.8(5) \\
c=700.4(2) \\
(100 \mathrm{~K})\end{array}$ & orthorhombic & $\begin{array}{l}\mathrm{CaC}_{2} \text {-type; similar to III- } \mathrm{KO}_{2}[107] \text {. } \\
\mathrm{X}-\mathrm{SC} \text {. } \\
\text { sharp incommensurate superstructure reflections (satellites); con- } \\
\text { stant modulation period: }(3.12 \pm 0.02) \mathrm{a}\end{array}$ \\
\hline $\mathrm{II} \gamma \boldsymbol{\mathrm { RbO }} 2$ & & $\begin{array}{l}a=410.5(2) \\
b=414.6(2) \\
c=700.4(2) \\
\gamma=90.69(1) \\
(45 \mathrm{~K})\end{array}$ & $\begin{array}{l}\text { monoclinic } \\
\text { (1st setting) }\end{array}$ & $\begin{array}{l}\text { as refemed to tetragonal unit cell of II-RbO } \\
\text { Strongly correlated stacking [107]. } \\
\text { XSC. }\end{array}$ \\
\hline IV-RbO 2 & $14.7<T<15.1$ & [109] & \multicolumn{2}{|c|}{ no further details investigated due to experimental problems [107] } \\
\hline $\mathrm{V}-\mathrm{RbO}_{2}$ & $T<14.7$ & $\begin{array}{l}a=409.9(2) \\
b=414.8(2) \\
c=700.3(2) \\
\gamma=90.71(1) \\
(10 \mathrm{~K})\end{array}$ & $\begin{array}{l}\text { monoclinic } \\
\text { (1 st setting) }\end{array}$ & $\begin{array}{l}\text { see III-RbO丶; } \\
\text { antiferromagnetic order similar to VI-KO } 2 \text { [109]. X-SC. }\end{array}$ \\
\hline
\end{tabular}




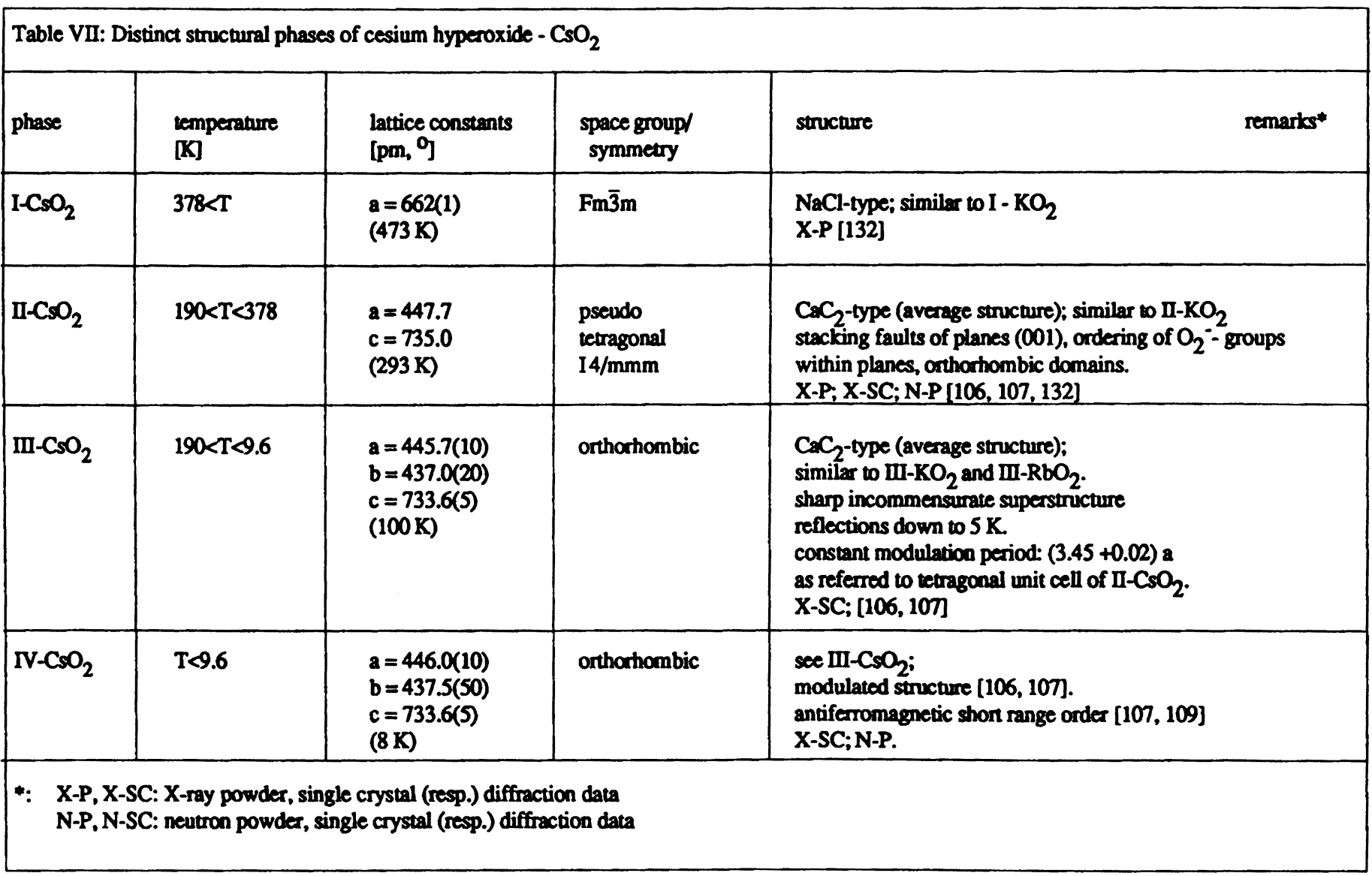




\subsubsection{Spectroscopic Investigations, Lattice Dynamics}

The first investigations of the Raman-spectra of $\mathrm{NaO}_{2}, \mathrm{KO}_{2}$, and $\mathrm{RbO}_{2}$ performed on powder samples of these compounds only yielded one observed line around $1140 \mathrm{~cm}^{-1}[134,135]$. Tentatively, this frequency was assigned to the molecular O-O-stretching vibration of the diatomic $\mathrm{O}_{2}$-anion. A more detailed study of the spectra of all alkali metal hyperoxides in the temperature range between 75 and $300 \mathrm{~K}$ confirmed this assignment and, in addition, several lattice modes were determined [136]. However, a group-theoretical analysis of the experimental data has not been performed because the complex crystal chemistry of these compounds at low temperatures has not been investigated. Complete study and assignment of the lattice and molecular modes of alkali metal hyperoxides was not possible before Känziget al. succeeded in the preparation and handling of single crystals of these compounds [104]. On the basis of detailed structural data evaluated by $\mathrm{X}$-ray and neutron-diffraction methods (see above), several of the observed modes have been assigned (Table VIII, IX) [104].

The Raman-active mode at about $1150 \mathrm{~cm}^{-1}$, which occurs in all hyperoxide phases, has been assigned to the molecular O-O-stretching vibration. Känzig et al. reported a slight correlation of the temperature dependence of this mode to the observed crystallographic phase transitions of sodium hyperoxide. These authors assumed an increase in frequency of this mode on lowering the point symmetry of the anion's site $[137,138]$. The Raman shift decreases with increasing size of the cation in the series of the alkali metal hyperoxides $\mathrm{NaO}_{2}, \mathrm{KO}_{2}, \mathrm{RbO}_{2}$, and $\mathrm{CsO}_{2}$. This may be understood in terms of a decreasing cationic field in the sequence of hyperoxides given above (see Table VIII). As expected, the frequencies of the observed O-Ostretching modes increase with increasing $\mathrm{O}-\mathrm{O}-$-bond order in the series $\mathrm{O}_{2}{ }^{2-}\left(\sim 800 \mathrm{~cm}^{-1}\right.$; see Chapter 4.4), $\mathrm{O}_{2}^{-}\left(\sim 1150 \mathrm{~cm}^{-1}\right), \mathrm{O}_{2}\left(1550 \mathrm{~cm}^{-1}\right.$ [29]), and $\mathrm{O}_{2}^{+}\left(1843 \mathrm{~cm}^{-1}[139]\right)$.

The observed stretching mode of the $\mathrm{O}_{2}{ }^{-}$anion in sodium hyperoxide is quite close to the value obtained for this anion in a $\mathrm{NaCl}$-host lattice $\left(1144 \mathrm{~cm}^{-1}\right.$ [140]). This result supports the assumption, that sodium hyperoxide is an ionic solid similar to sodium chloride. Accordingly, the compressibility of sodium hyperoxide determined experimentally has a value between those for sodium fluoride and chloride [104].

The lattice vibrations of alkali hyperoxide single crystals have been investigated using farinfrared reflection and Raman-spectroscopy, as well as inelastic neutron scattering techniques $[104,108,138]$. As summarized in Table IX, all phases that have been investigated exhibit a group of bands around a higher frequency of about $240 \mathrm{~cm}^{-1}$ and a low-frequency group centered at about $100 \mathrm{~cm}^{-1}$. 
Table VIII: Molecular O-O stretching modes of alkali metal hyperoxides determined by Raman-spectroscopy on single crystals $[104,137,138]$.

compound mode $\left[\mathrm{cm}^{-1}\right]$ (point-symmetry : irreducible representation)

$\begin{array}{lllllll}\text { I }- & \mathrm{NaO}_{2} & 1156 & \left(\mathrm{O}_{\mathrm{h}}\right. & : & \mathrm{A}_{1 \mathrm{~g}}, & \left.\mathrm{~F}_{2 \mathrm{~g}}\right) \\ \text { II }- & \mathrm{NaO}_{2} & 1155 & \left(\mathrm{~T}_{\mathrm{h}}\right. & : & \mathrm{A}_{\mathrm{g}} & \left.\mathrm{F}_{\mathrm{g}}\right) \\ \text { III }- & \mathrm{NaO}_{2} & 1161 & \left(\mathrm{D}_{2 \mathrm{~h}}\right. & : & \mathrm{A}_{\mathrm{g}} & , \\ \mathrm{IV}- & \mathrm{NaO}_{2} & 1164 & \text { unassigned } & & & \end{array}$

\begin{tabular}{|llllllll|}
\hline II - & $\mathrm{KO}_{2}$ & 1146 & $\left(\mathrm{D}_{4 \mathrm{~h}}\right.$ & $:$ & $\mathrm{A}_{1 \mathrm{~g}}$, & $\left.\mathrm{E}_{\mathrm{g}}\right)$ \\
\hline II - & $\mathrm{RbO}_{2}$ & 1141 & $\left(\mathrm{D}_{4 \mathrm{~h}}\right.$ & $:$ & $\mathrm{A}_{1 \mathrm{~g}}$, & $\left.\mathrm{E}_{\mathrm{g}}\right)$ \\
\hline $\mathrm{II}-$ & $\mathrm{CsO}_{2}$ & 1135.5 & $\left(\mathrm{D}_{4 \mathrm{~h}}\right.$ & $:$ & $\mathrm{A}_{1 \mathrm{~g}}$, & $\left.\mathrm{E}_{\mathrm{g}}\right)$ \\
\hline
\end{tabular}

Table IX: Lattice modes of alkali metal hyperoxides determined by Raman- and IRspectroscopy and inelastic neutron scattering on single crystals $[104,108,137,138]$

$\begin{array}{ccccc}\text { compound: } & \mathrm{I}-\mathrm{NaO}_{2} & \mathrm{II}-\mathrm{NaO}_{2} & \mathrm{II}-\mathrm{NaO}_{2} & \mathrm{II}-\mathrm{KO}_{2} \\ \text { (point-symmetry) } & \left(\mathrm{O}_{\mathrm{h}}\right) & \left(\mathrm{T}_{\mathrm{h}}\right) & \left(\mathrm{D}_{2 \mathrm{~h}}\right) & \left(\mathrm{D}_{4 h}\right)\end{array}$

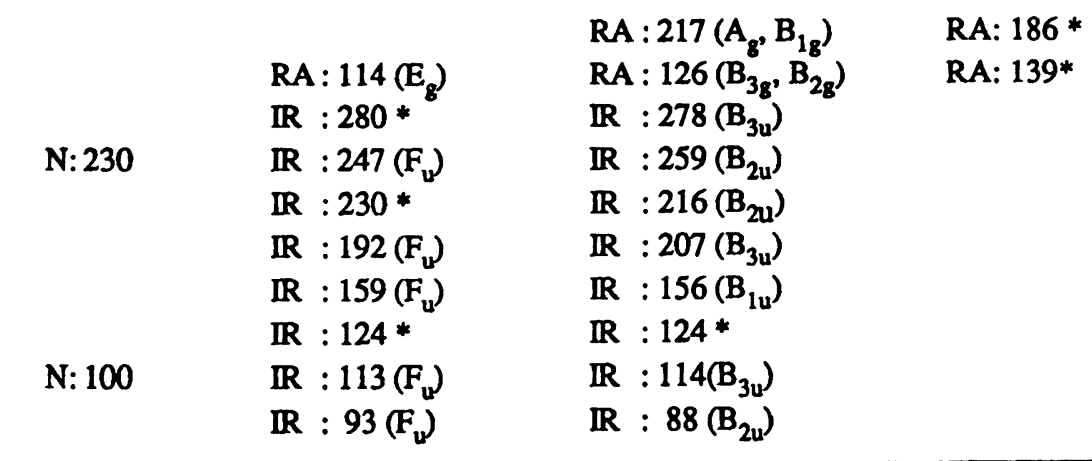

IR, RA, N: Far infrared-, Raman-spectroscopy, inelastic neutron scattering.

*: unassigned 
The crystallographic phase transitions of $\mathrm{NaO}_{2}$ mainly represent a change in the orientations of the $\mathrm{O}_{2}$ anions, resulting in relations between certain zone center and zone boundary phonons in the corresponding Brillouin zones [108]. Thus, the high-frequency vibrations essentially seem to be equivalent to the $\mathrm{NaCl}$ reststrahlen bands, while the low-frequency vibrations originate from the orientational ordering of the $\mathrm{O}_{2}{ }^{-}$anions, resulting in an enlargement of the $\mathrm{NaO}_{2}$ unit cell [108]. As determined by inelastic neutron scattering techniques, even in the disordered pyrite-type phase $\mathrm{I}-\mathrm{NaO}_{2}$ two broad bands $\left(\sim 230 \mathrm{~cm}^{-1}\right.$ and $\left.\sim 100 \mathrm{~cm}^{-1}\right)$ occur. Accordingly, disordering of the $\mathrm{O}_{2}^{-}$group seems not to be totally random in $\mathrm{I}-\mathrm{NaO}_{2}$; rather a short-range orientational correlation between the hyperoxide anions is assumed [108]. Observation of diffuse X-ray scattering in $\mathrm{I}-\mathrm{NaO}_{2}$, which condenses to new Bragg-reflections in $\mathrm{II}^{-\mathrm{NaO}_{2}}$ independently, supports this conclusion (see above).

Fig. 14:

Phonon dispersion curves for III- $\mathrm{NaO}_{2}[104]$.

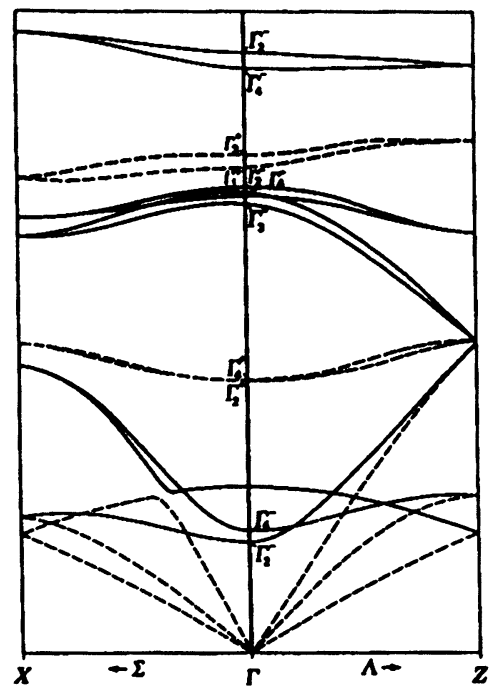

Acoustic phonons in cubic sodium hyperoxide above and below the order-disorder transition (I- $\mathrm{NaO}_{2} / \mathrm{II}-\mathrm{NaO}_{2}$ ) have been investigated by inelastic neutron scattering techniques [141]. In the disordered pyrite-type phase $\left(\mathrm{I}-\mathrm{NaO}_{2}\right)$, the $\mathrm{O}_{2}$ - ions perform rapid reorientation about the body diagonals of the cubic unit cell, while the equilibrium orientation of the linear anions is confined within these body-diagonal directions. This reorientation couples with, and affects, certain acoustic modes in the crystal. The experimental results have been described in terms of a phonon-pseudospin coupling theory [141]. Känzig et al. determined the phonon dispersion of the acoustic and lowest optic branch in the ordered pyrite phase of $\mathrm{NaO}_{2}$ by the use of inelastic neutron scattering, and they evaluated the elastic constants of this compound from the slope of the dispersion curves [108]. As compared to the results obtained by Brillouin scattering from $\mathrm{NaO}_{2}$, rather large differences occur that could not be explained by the authors $[108,104]$. On the basis of a simple rigid ion model, phonon-dispersion curves (see Fig. 14) for $\mathrm{III}-\mathrm{NaO}_{2}$ (marcasite-type phase) have been evaluated by Känzig et al. [104], yielding a fairly good 
agreement with the experimental data. However, calculations on the same basis for the pyritetype phase of $\mathrm{NaO}_{2}$ resulted in less satisfactory results [104].

Mahanti et al. have studied the nature of interionic forces in $\mathrm{NaO}_{2}$ and the factors which influence the relative stability of the ordered pyrite and marcasite phases of $\mathrm{NaO}_{2}$ at different temperatures [142 - 145]. These authors point out that electrostatic interactions including the direct quadrupole-quadrupole interaction between $\mathrm{O}_{2}^{-}$molecular anions support stability of the ordered pyrite-type phase of $\mathrm{NaO}_{2}$. In contrast, the marcasite-type phase is favored by effects due to the crystal field and orbital degeneracy [142]. However, indirect orientation-dependent interactions between the $\mathrm{O}_{2}$ - anions, brought about by orientation-translational coupling, were assumed not to affect the relative stability of the different phases of $\mathrm{NaO}_{2}$ [143]. In contrast to the sodium compound, $\mathrm{KO}_{2}, \mathrm{RbO}_{2}$, and $\mathrm{CsO}_{2}$ show ferroelastic rather than disordered pyrite/ordered pyrite type phase transitions. For the latter compounds, the ordered pyrite-type structure has never been observed. On lowering the temperature, these compounds undergo a ferroelastic phase transition from disordered pyrite to a tetragonal structure with the molecular axes of the $\mathrm{O}_{2}$ - anions oriented along the tetragonal c-axis. Because of this difference, Kemeny and Mahanti supposed that both direct and indirect interactions, as mentioned above, might be essential for understanding the orientational phase transitions of these compounds [143].

With regard to these considerations Fracassi, Klein et al. developed quasi-harmonic lattice dynamics for the ionic molecular crystal $\mathrm{Na}^{+} \mathrm{O}_{2}^{-}$within the framework of the rigid ion approximation. The calculations were performed for the phases I, II, and III of $\mathrm{NaO}_{2}$ and phonondispersion curves for the ordered pyrite phase were obtained (see Fig.15) [146, 147]. Deviations from experimental results [141] have been attributed to the fact that polarization effects were neglected and that refined atom-atom potentials for the $\mathrm{Na}$-O-interaction, as well as a realistic model for the charge distribution of the $\mathrm{O}_{2}{ }^{-}$ions, were not available [146].

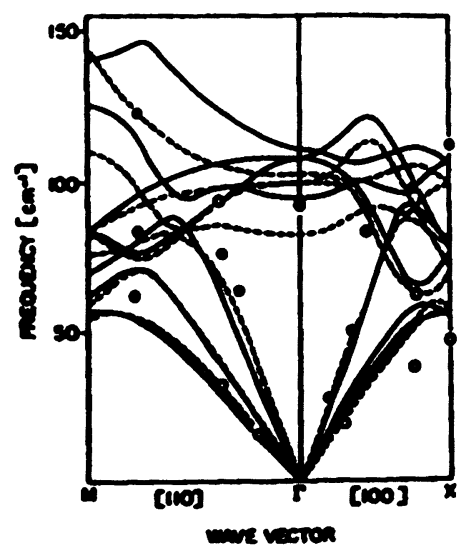

Fig. 15:

Phonon dispersion curves for II- $\mathrm{NaO}_{2}$ [147]. The circles refer to experimental data from [141]. 
Being ionic molecular crystals, the alkali metal hyperoxides (similar to the corresponding alkali metal cyanides) undergo ferroelastic phase transitions accompanied by orientational melting. In the disordered pyrite-type phases (I) the crystals exhibit unusual thermoelastic behavior. On lowering the temperature the elastic constants $\mathrm{C}_{11}$ and $\mathrm{C}_{44}$ show anomalous softening and undergo a ferroelastic phase transition to a structure of lower symmetry. Mahanti and Sahu discussed the strong influence of the competition between quadrupole moment and fluctuating field gradient on the observed elastic softening and ferroelastic instabilities [144].

\subsubsection{Optical Properties and Electronic Structure of Alkali Metal Hyperoxides}

The alkali metal hyperoxides discussed in this chapter represent a group of optically highly anisotropic compounds. Bossch and Hoffmann tried to extend the concept of electronic polarizability of individual ions [148] in alkali metal halides to the corresponding hyperoxides by introducing anisotropic polarizabilities [149]. These authors have measured refractive indices and birefringence of $\mathrm{NaO}_{2}, \mathrm{KO}_{2}, \mathrm{RbO}_{2}$, and $\mathrm{CsO}_{2}$ in the visible region and at room temperature using a double beam interference method. The $\mathrm{O}_{2}^{-}$polarizability tensor determined by experiment shows that the polarizability of the $\mathrm{O}_{2}^{-}$anion along its molecular axis is twice the polarizability perpendicular to it. Furthermore, comparison of the data obtained for the different alkali metal hyperoxides with different crystal structures at room temperature supports the assumption that, within this group of compounds, the electronic structure of the hyperoxide anion shows no significant dependence upon its crystallographic surroundings in the solid state [149].

\subsubsection{Electronic Spectra of Alkali Metal Hyperoxides}

Localized intramolecular transitions from the ground state of the hyperoxide anion $\left({ }^{2} \Pi_{g}\right)$ to the excited states ${ }^{2} \Delta_{u}$ and ${ }^{2} \Pi_{u}$ for $\Pi$ - and $\Sigma$ - polarization respectively have been observed [104, 149]. The absorption spectra of $\mathrm{NaO}_{2}$ down to $5 \mathrm{~K}$ for the intramolecular electronic transitions have been studied and discussed extensively by Bösch and Känzig [104]. Thus, the yellow color of the hyperoxides has been assigned to the $\Sigma_{\text {-polarized intermolecular }}{ }^{2} \Pi_{g}-{ }^{2} \Delta_{u}$ transition in the hyperoxide anion [104]. A rather qualitative band structure for $\mathrm{NaO}_{2}$ has been constructed by analogy with $\mathrm{NaCl}$ (see Fig.16) [104]. 


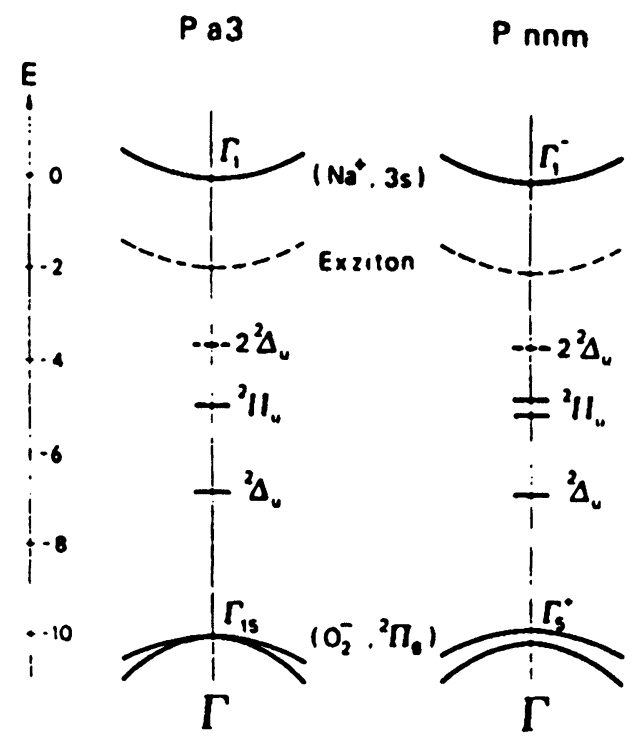

Fig. 16:

Simple energy band scheme for II- and III-NaO ${ }_{2}$ [104].

\subsubsection{Thermal Properties and Decomposition of Alkali Metal Hyperoxides}

The melting temperature of $\mathrm{KO}_{2}$ was found to be $778 \mathrm{~K}$ [150]. Thermal decomposition of rubidium and cesium hyperoxides at various oxygen equilibrium pressures has been determined, and melting points of $813 \mathrm{~K}$ and $723 \mathrm{~K}$ (equilibrium oxygen pressure $=10^{5} \mathrm{~Pa}$ ) for $\mathrm{RbO}_{2}$ and $\mathrm{CsO}_{2}$, respectively, have been reported $[133,151]$. The first value, differing markedly from values previously reported by Vol'nov [2], obviously has been determined using samples which are contaminated by a few weight $-\%$ of rubidium hydroxide. Thermal decomposition of alkali metal hyperoxides results in formation of the respective peroxides $[133,151$ - 154].

\subsubsection{Applications}

On an industrial scale only $\mathrm{KO}_{2}$ is produced. It is used mainly in air revitalization systems and in self-contained isolating-type breathing apparatus. Potassium hyperoxide represents a powerful oxygen source. On exposure of this compound to expired respiratory air, carbon dioxide is absorbed while stored oxygen is evolved:

$$
\begin{gathered}
4 \mathrm{KO}_{2}+2 \mathrm{CO}_{2}=2 \mathrm{~K}_{2} \mathrm{CO}_{3}+3 \mathrm{O}_{2} \\
4 \mathrm{KO}_{2}+4 \mathrm{CO}_{2}+2 \mathrm{H}_{2} \mathrm{O}=4 \mathrm{KHCO}_{3}+3 \mathrm{O}_{2}
\end{gathered}
$$


Alkali metal hyperoxides are used in several different chemical reactions as starting materials: For example, Range etal. prepared the new peroxide $\mathrm{Nd}_{2} \mathrm{O}_{2}\left(\mathrm{O}_{2}\right)$ by reaction of $\mathrm{KO}_{2}$ and $\mathrm{Nd}_{2} \mathrm{O}_{3}$ under very high pressure (see Section 4.3). Attempts to synthesize neodymium peroxide by an exchange reaction between $\mathrm{Nd}\left(\mathrm{ClO}_{4}\right)_{3}$ and $\mathrm{NaO}_{2}$ in THF have also been reported [155]. Bruner et al. have investigated mixtures and melts of potassium hyperoxide with different alkali metal and alkaline earth metal nitrates and perchlorates. X-ray powder diffraction studies at different temperatures support formation of new phases; however, reliable identification of these compounds has failed [156-162].

$\mathrm{KO}_{2}$ reduces fluorine to fluoride with formation of $\mathrm{O}_{2}$ [24]. The reaction of $\mathrm{KO}_{2}$ with $\mathrm{LiCl}$, $\mathrm{NaCl}, \mathrm{CaCl}_{2}, \mathrm{Li}_{2} \mathrm{CO}_{3}$ and $\mathrm{CaCO}_{3}$ at $200-250^{\circ} \mathrm{C}$ leads to the formation of the respective peroxides and $\mathrm{O}_{2}$ [24]. Also, $\mathrm{KO}_{2}$ has been used for preparation of high temperature superconductors [163].

Last, but not least, alkali metal hyperoxides are used as starting materials for syntheses of alkali metal ozonides (see Section 2.1.)

\subsection{Alkaline Earth Metal Hyperoxides}

Pure alkaline earth metal hyperoxides have not been isolated so far. Though several attempts have been undertaken to synthesize high purity products, only mixtures or solid solutions with peroxides were obtained. Preparation routes leading to alkali metal hyperoxides cannot be employed for syntheses of alkaline earth metal hyperoxides. Combustion of metallic calcium, strontium, and barium with molecular oxygen results in the formation of oxides with formula type MO (M = Ca, Sr, Ba). Reaction of alkaline earth metal peroxides with oxygen at increased pressures and temperatures, analogous to the synthesis of sodium hyperoxide, leads to products containing only $10 \%$ hyperoxide at most [164].

Recently, three promising routes for production of better products have been reported: The first method is based on the decomposition of calcium peroxide diperoxyhydrate, $\mathrm{CaO}_{2} \cdot 2 \mathrm{H}_{2} \mathrm{O}_{2}$, the second one on the oxidation of metals or peroxides with oxygen ozone mixtures in a solvent (Freon, $\mathrm{NH}_{3}$ ), and the last one on an exchange reaction between alkaline earth metal salts (e.g., nitrates) and hyperoxides of other elements (alkali, $\mathrm{NMe}_{4}$ ) in a solvent (see below).

\subsubsection{Syntheses of Alkaline Earth Metal Hyperoxides}

Theoretically, pure calcium hyperoxide, $\mathrm{Ca}\left(\mathrm{O}_{2}\right)$, contains more active oxygen than potassium hyperoxide. For this reason, there is considerable interest in this compound for use in emergency breathing apparatus for miners and as auxiliary oxygen sources for astronauts. The first attempts to prepare calcium hyperoxide by the reaction of calcium peroxide octahydrate, 
$\mathrm{ZaO}_{2} \cdot 8 \mathrm{H}_{2} \mathrm{O}$, and hydrogen peroxide, $\mathrm{H}_{2} \mathrm{O}_{2}$, were reported by Vol'nov in 1956 [164]. Higher rields (up to $16 \mathrm{wt} . \%$ ) were obtained by direct drying of the intermediate product $\mathrm{CaO}_{2} \cdot 2 \mathrm{H}_{2} \mathrm{O}_{2}$. n subsequent work, the latter compound was spread over a large surface and after optimizing the eaction parameters $\left(323 \mathrm{~K}, 1.3 \mathrm{kPa}, 1800 \mathrm{~cm}^{2} / \mathrm{g}\right)$ the reported yield was increased to $55.4 \mathrm{wt} . \%$ $\mathrm{Ja}\left(\mathrm{O}_{2}\right)_{2}$ [165]. The authors pointed out that $55.4 \%$ was close to the maximum value (58.4\%) sredicted for the postulated equimolar disproportionation reaction:

$$
2\left(\mathrm{CaO}_{2} \cdot 2 \mathrm{H}_{2} \mathrm{O}\right)=\mathrm{Ca}\left(\mathrm{O}_{2}\right)+\mathrm{Ca}(\mathrm{OH})_{2}+3 \mathrm{H}_{2} \mathrm{O}+1.5 \mathrm{O}_{2}
$$

However, the purity of $55.4 \%$ has never been reproduced and instead yields between $20-40 \%$ for the above reaction have been obtained. Kinetic studies led to unreliable results, and characterization of the products failed [166-168]. More recently, further investigations on decomposition of $\mathrm{CaO}_{2} \cdot 2 \mathrm{H}_{2} \mathrm{O}_{2}$ have been reported [169-172]. A free radical mechanism analogous to the disproportionation of $\mathrm{K}_{2} \mathrm{O}_{2} \cdot 2 \mathrm{H}_{2} \mathrm{O}_{2}$ [173] was assumed, which theoretically yields quantitative conversion to calcium hyperoxide:

$$
2 \mathrm{CaO}_{2} \cdot 2 \mathrm{H}_{2} \mathrm{O}_{2}=2 \mathrm{Ca}\left(\mathrm{O}_{2}\right)_{2}+4 \mathrm{H}_{2} \mathrm{O}
$$

Yields between $65-70 \%$ of the desired product suggest that decomposition occurs by a reaction according to equation (7) rather than to equation (6). Probably, the improved yields were caused by better control and monitoring of the reaction chamber conditions, and, particularly,by provisions to remove $\mathrm{H}_{2} \mathrm{O}$ from the reaction site at a rapid rate. All the investigations seem to be rather unreliable as far as determining the reaction that is occuring.

Neither direct ozonisation of solid alkaline earth metal hydroxides or peroxides nor reactions of ozone or oxygen with solutions of alkaline earth metals in ammonia has ever yielded solid hyperoxides. The ozonolysis of alkaline earth metal peroxides was studied in concentrated solutions of ozone in Freon-12 at low temperatures $[23,27,62,63,64,174,175]$. The formation of $\mathrm{Mg}\left(\mathrm{O}_{2}\right)_{2}, \mathrm{Sr}\left(\mathrm{O}_{2}\right)_{2}$, and $\mathrm{Ba}\left(\mathrm{O}_{2}\right)_{2}$ was cited to be demonstated by EPR and X-ray diffraction results. The peroxide suspensions were stirred for 5-20 minutes at temperatures around $-75^{\circ} \mathrm{C}$ leading to precipitates containing $54 \%\left(\mathrm{Mg}\left(\mathrm{O}_{2}\right), 11 \%\left(\mathrm{Sr}\left(\mathrm{O}_{2}\right)\right), 30 \%\left(\mathrm{Ba}\left(\mathrm{O}_{2}\right)\right)\right.$ hyperoxides $[23,27,62,63,64,174,175]$.

Exchange reactions between some alkaline earth metal nitrates and hyperoxides of other elements have been only partly successful. Barium nitrate dissolved in liquid ammonia reacts with potassium hyperoxide to give a chocolate brown substance, which, upon removal of the liquid ammonia, changes in color to a light $\tan$ [176]. The authors suppose the net reaction to be 
(8)

$$
\mathrm{Ba}\left(\mathrm{NO}_{3}\right)+4 \mathrm{KO}_{2}=\mathrm{K}_{2} \mathrm{Ba}\left(\mathrm{O}_{2}\right)_{2} \mathrm{O}_{2}+2 \mathrm{KNO}_{3}+\mathrm{O}_{2}
$$

with the mixed hyperoxide-peroxide compound being analogous to the "sesquioxides" $\left(\mathrm{A}_{4} \mathrm{O}_{6}, \mathrm{~A}=\mathrm{Rb}, \mathrm{Cs}\right.$ ) of the alkali metals (see Section 4.3). Analogous $\mathrm{Na} / \mathrm{Sr}-, \mathrm{Na} / \mathrm{Ba}-$, or $\mathrm{K} / \mathrm{Sr}$ compounds have notbeen obtained to date. Formation of the $\mathrm{K} / \mathrm{Ba}$-compound mentioned above may be favored by similarity of the ionic radii of $\mathrm{K}^{+}$and $\mathrm{Ba}^{2+}(133 \mathrm{pm}$ and $135 \mathrm{pm}$, respectively). However, this compound has not been well characterized so far. The exchange reaction between $\mathrm{NMe}_{4} \mathrm{O}_{2}$ and $\mathrm{Ca}\left(\mathrm{NO}_{3}\right)$ dissolved in liquid ammonia has been reported. The solid reaction products contained $\mathrm{Ca}\left(\mathrm{O}_{2}\right)_{2}, \mathrm{CaO}_{2}$, and the less soluble $\mathrm{NMe}_{4} \mathrm{NO}_{3}[177,178]$.

\subsubsection{Crystal Stmuctures. Decomposition and Thermal Properties}

$\mathrm{X}$-ray diffraction studies of impure polycrystalline samples of magnesium and barium hyperoxides have been reported. The powder diagram could be indexed by assuming a rhombohedral ( $a=788 \mathrm{pm}, \alpha=93^{\circ}[179]$ ) or a tetragonal lattice ( $a=538 \mathrm{pm}, c=687 \mathrm{pm}$ [180]) for the magnesium or the barium compound, respectively. Both compounds were obtained by reaction of peroxides with an ozone solution in Freon. As the lattice constants of the barium compound are rather similar to those of $\mathrm{BaO}_{2}(\mathrm{a}=538 \mathrm{pm}, \mathrm{c}=684 \mathrm{pm}$ [181]) formation of solid solutions between barium peroxide and hyperoxide was assumed [180]. Analytical examination of the product (containing $\mathrm{Ba}\left(\mathrm{O}_{2}\right) \sim 64.5 \%, \mathrm{BaO}_{2} \sim 17.2 \%$, and $\mathrm{Ba}(\mathrm{OH})_{2} \sim 12.1 \%$ ) proves that no single phase solid solution was obtained.

Thermal decomposition of alkaline earth metal hyperoxides leads to the respective alkaline earth metal peroxides, as proved by DTA/TG and EPR- measurements $[23,62,63,64,182]$. Orange products obtained by ozonolysis of magnesium, strontium, and barium peroxide in Freon-12 at temperatures around $-75^{\circ} \mathrm{C}$ exhibit an anisotropic line in the EPR-spectra, which is characteristic for centers with axial symmetry of the $\mathrm{g}$ factor $\left(\mathrm{O}_{2}\right)$. At temperatures above $-50^{\circ} \mathrm{C}$ this signal disappears indicating dissociation of the hyperoxide. Accordingly, heating curves of ozonized $\mathrm{SrO}_{2}$ and $\mathrm{BaO}_{2}$ show an endothermic effect with a maximum at $\sim-55^{\circ} \mathrm{C}$, accompanied by vigorous evolution of oxygen. The authors could not distinguish whether the composition originates from the hyperoxides or the similarly formed ozonides.

Thermal decomposition of $\mathrm{Ca}\left(\mathrm{O}_{2}\right)$ upon heating of $\mathrm{CaO}_{2} \cdot 2 \mathrm{H}_{2} \mathrm{O}_{2}$ was assumed to produce the respective oxide $(\mathrm{CaO})$ above $+250^{\circ} \mathrm{C}$ [167]. However, it seems more reasonable that these authors observed decomposition to the peroxide.

Theoretical estimations of thermodynamic data for $\mathrm{Ca}\left(\mathrm{O}_{2}\right)_{2}$ (standard heat, entropy, and free energy of formation) have been reported. Accordingly, the free energy of formation is strongly 
legative in the temperature range between 100 and $550 \mathrm{~K}$. But the compound was assumed to be hermodynamically unstable with respect to decomposition to $\mathrm{CaO}$ and $\mathrm{CaO}_{2}$ [183].

\subsection{Further Hyperoxides}

Up to 1960 hyperoxides reported in the literature were almost without exception derivatives of the alkali and alkaline earth metals. Only the hyperoxides of sodium and the heavier alkali metals are both available in high purity and stable at ambient or higher temperatures.

Ammonium behaves chemically as an alkali metal. Alkyl derivatives such as tetramethyl ammonium are alkali metal-like too, and these cations are generally more resistant to degradation than the ammonium ion. Therefore it was predicted that tetraalkylammonium hyperoxides would be stable, and the results described below verify this prediction. In the 1960s Hashman et al. succeeded in carrying out the synthesis of $\mathrm{NMe}_{4} \mathrm{O}_{2}$ by three routes [184186].

In the following years, the corresponding ethyl-, propyl-, and butyl-compounds were synthesized too. Most investigations have been performed on the methyl-compound, but no detailed characterization has been achieved so far. In contrast to the alkali metal hyperoxides, tetraalkylammonium hyperoxides are well soluble in liquid ammonia and some aprotic organic solvents. Therefore, this class of compounds is more suitable than alkali metal hyperoxides for exchange reactions requiring participation of the hyperoxide anion.

\subsubsection{Syntheses and Properties of Tetraalkylammonium Hyperoxides}

The first attempts to prepare tetramethylammonium hyperoxide involved electrolysis of liquid ammonia solutions of $\mathrm{NMe}_{4} \mathrm{Cl}$ using a magnesium anode and an oxygen-platinum cathode. In this reaction, further cathodic reduction, possibly to peroxide, limits the yield of hyperoxide $[184,185]$. The exchange reaction between tetramethylammonium fluoride and potassium hyperoxide in ammonia, producing insoluble potassium fluoride and soluble tetramethylammonium hyperoxide, is a suitable method for synthesis of $\mathrm{NMe}_{4} \mathrm{O}_{2}$ in gram amounts [184, 186].

The most effective method of synthesizing $\mathrm{NMe}_{4} \mathrm{O}_{2}$ is the route based on the exchange reaction (equation 9) in solid state between tetramethylammonium hydroxide and potassium hyperoxide with subsequentextraction with liquid ammonia. All participants in this reaction, except $\mathrm{NMe}_{4} \mathrm{O}_{2}$, are insoluble in liquid ammonia. For this reason, the desired product can be isolated upon evaporation of the solvent [184].

$$
\mathrm{NMe}_{4} \mathrm{OH} \cdot 5 \mathrm{H}_{2} \mathrm{O}+11 \mathrm{KO}_{2}=\mathrm{NMe}_{4} \mathrm{O}_{2}+11 \mathrm{KOH}+7.5 \mathrm{O}_{2} \text {. }
$$


Because tetramethylammonium hydroxide is employed as a pentahydrate, potassium hyperoxide has to be supplied in excess. It is rather difficult to get high purity products, and results based on failed reactions even gave rise to speculations about diamagnetic dimers of $\mathrm{NMe}_{4} \mathrm{O}_{2}$ $[187,188]$.

Use of these hyperoxides in exchange reactions (e.g., liquid ammonia) requires that they be soluble in the appropriate solvent. Quantitative data on solubility in liquid ammonia have been reported: $7 \mathrm{~g} / 100 \mathrm{~g}$ at $-35^{\circ} \mathrm{C}$ and $0.4 \mathrm{~g} / 100 \mathrm{~g}$ at $-79^{\circ} \mathrm{C}$ for $\mathrm{NMe}_{4} \mathrm{O}_{2}[188]$ and $43.7 \mathrm{~g} / 100 \mathrm{ml}$ at $-50^{\circ} \mathrm{C}$ for $\mathrm{NEt}_{4} \mathrm{O}_{2}$ [190].

\subsubsection{Crystal Structures, Decomposition, and Thermal Properties}

The crystal structures of the tetraalkylammonium hyperoxides are unknown. On the basis of powder data lattice parameters have been evaluated. Tetragonal symmetry was assumed for $\mathrm{NMe}_{4} \mathrm{O}_{2}(\mathrm{a}=870 \mathrm{pm}, \mathrm{c}=1052 \mathrm{pm})[191]$ and $\mathrm{NEt}_{4} \mathrm{O}_{2}(\mathrm{a}=886 \mathrm{pm}, \mathrm{C}=1108 \mathrm{pm})$ [192]. The poor agreement between observed and calculated d-values indicates that these data need to be reexamined. Contradictory results have been reported for thermal decomposition of $\mathrm{NMe}_{4} \mathrm{O}_{2}$ : Melting at $97^{\circ} \mathrm{C}$ and decomposition at about $100^{\circ} \mathrm{C}$ were reported by $\mathrm{Mc}$ Elroy and Hashman [184], while other authors observed explosive decomposition at $127^{\circ} \mathrm{C}$ and no phase transition down to $-120^{\circ} \mathrm{C}$ by DTATG-methods [190, 193]. The products of decomposition are gaseous $\left(\mathrm{O}_{2}, \mathrm{H}_{2} \mathrm{O}, \mathrm{NMe}_{3}\right)$, as well as an unidentified solid residue. $\mathrm{NEt}_{4} \mathrm{O}_{2}$ is likely to melt at $50^{\circ} \mathrm{C}$ and decomposes at $55-69^{\circ} \mathrm{C}$, liberating oxygen [178, 190].

\subsection{Magnetic and Spectroscopic Properties}

Studies of $\mathrm{NAlk}_{4} \mathrm{O}_{2}$ by magneto-chemistry, EPR-and UV-spectroscopy confirm the assumption that the compounds mentioned in this chapter contain the paramagnetic molecular anion $\mathrm{O}_{2}^{-}$. The UV-VIS spectrum of $\mathrm{NMe}_{4} \mathrm{O}_{2}$ in acetonitrile exhibits the typical $\mathrm{O}_{2}^{-}$absorption maximum in the region of $250 \mathrm{~nm}[187,188,190]$.

EPR $[187,188]$ and susceptibility measurements $[187,188,194]$ prove the presence of the $\mathrm{O}_{2}^{-}$ anion, but there are considerable discrepancies at more detailed levels. 


\section{PEROXIDES}

\subsection{Alkali and Alkaline Earth Metal Peroxides}

In general, peroxides containing isolated $\mathrm{O}_{2}^{2-}$ anions only exist in combination with cations of electropositive metals, forming ionic compounds. As the peroxide group has both oxidizing and reducing properties, the corresponding cations usually occur in a quite stable low valency state. Accordingly, ionic peroxides are only known to exist in combination with alkali, alkaline earth, and group-IIb metals $(\mathrm{Zn}, \mathrm{Cd}, \mathrm{Hg}$ ). (For a recently discovered exception see Section 4.3). This section deals only with anhydrous peroxides and simple peroxide hydrates, all of which contain isolated $\mathrm{O}_{2}{ }^{2-}$ peroxide anions. Other peroxide compounds (e.g., hydroperoxides, addition compounds between peroxides and hydrogen peroxides, mixed hydrates and peroxohydrates of peroxides), as discussed in detail by Vannerberg [1], will not be covered.

Most of the preparation routes leading to peroxides use water as a solvent, and hydrogen peroxide as one of the educts. Several peroxide compounds described in the literature have not been prepared in a pure state or well characterized. In these cases the products turned out to be mixtures of peroxides, their hydrates, water, or hydrogen peroxide. Because of the lack of suitable single crystals, most structural proposals are based on $\mathrm{X}$-ray powder diffraction results. Accordingly, the question whether $\mathrm{H}_{2} \mathrm{O}$ and/ or $\mathrm{H}_{2} \mathrm{O}_{2}$ is included as part of the structure of a certain compound or only physically adsorbed - coexisting as a different phase in a mixture with the peroxide - is not easy to decide. Attempts have been made to solve this problem by chemical analyses and vibrational spectroscopy, as well as by NMR methods, resulting in partly contradictory and unreliable data.

Though the basic properties of and preparation routes leading to, ionic peroxides have been well known since the early 1960s [1], and the industrial application and production of these compounds are rather important, only a few detailed properties of these compounds have been reported in the recent literature.

\subsubsection{Synthesis. Chemical Properties and Structures}

of Alkali and Alkaline Earth Metal Peroxides

The following general routes to obtain ionic peroxides have been summarized by Vannerberg [1] and Vol'nov [2]: (1) oxidation of the corresponding metal, metal oxide, or hydroxide with molecular oxygen or nitric oxide; (2) thermal decomposition of the corresponding metal hyperoxide; (3) oxidation of a metal ammonia solution at low temperatures by oxygen or hyperoxide; (4) decomposition of hydrated peroxides; and ( 5) reactions involving hydrogen peroxide. 
Except for the use of molecular oxygen in reactions with both alkali and alkaline earth metal hydroxides for preparation of peroxides, Vol'nov et al. [101] have shown that peroxides of sodium, magnesium, calcium, and strontium are formed by application of a low pressure glow discharge sustained in oxygen on the corresponding hydroxides. However, application of a radio frequency glow discharge on potassium, rubidium, and cesium hydroxides resulted in formation of the corresponding hyperoxides $[98,100]$. The advantages of this preparation route, which is based on the production of "singlet" oxygen $\left(\mathrm{O}_{2}\left({ }^{1} \Delta_{\mathrm{g}}\right)\right)$, are that the reaction is carried out at ambient temperatures and that no solvent is required.

According to the results reported by Vannerberg [1] and Vol'nov [2], only the peroxides and hydrates tabulated in table $\mathrm{X}$ are likely to exist. Most of these compounds are well characterized, and their crystal structures have been determined, as summarized in detail by Vannerberg [1].

Though several further hydrates of group-I and group-II metal peroxides have been postulated in the literature during the last three decades, none of them has been proved convincingly to exist in a pure state. Vol'nov et al. [173] reported the formation of beryllium peroxide $\left(\mathrm{BeO}_{2}\right)$ by reaction of ozone with a $\mathrm{Be}(\mathrm{OH})_{2}$ suspension in Freon- 12 at $-65^{\circ} \mathrm{C}$ without giving furthercharacterization of this compound. Wriedt quoted $\mathrm{BeO}_{2}$ to be unstable even at moderately high $\mathrm{O}_{2}$-pressure [206]. Accordingly, the existence of beryllium peroxide remains uncertain.

Table X: Peroxides and peroxide hydrates of alkali and alkaline metals.

$\mathrm{Li}_{2} \mathrm{O}_{2}[195]^{+}$

$\mathrm{Na}_{2} \mathrm{O}_{2}[196]^{+}$

$\mathrm{K}_{2} \mathrm{O}_{2}[196]^{+}$

$\mathrm{Rb}_{2} \mathrm{O}_{2}[196]^{+}$

$\mathrm{Cs}_{2} \mathrm{O}_{2}[196]^{+}$

$\mathrm{MgO}_{2}[200]^{+}$

$\mathrm{CaO}_{2}[201]^{+}$

$\mathrm{SrO}_{2}[203]^{+}$

$\mathrm{BaO}_{2}[17]^{+}$

$$
\mathrm{Na}_{2} \mathrm{O}_{2} \cdot 2 \mathrm{H}_{2} \mathrm{O} \text { [197]* }
$$$$
\mathrm{K}_{2} \mathrm{O}_{2} \cdot 2 \mathrm{H}_{2} \mathrm{O} \text { [199] }^{-}
$$

$\mathrm{Na}_{2} \mathrm{O}_{2} \cdot 8 \mathrm{H}_{2} \mathrm{O}[198]^{*}$

$\mathrm{CaO}_{2} \cdot 8 \mathrm{H}_{2} \mathrm{O}[202]^{+}$

$\mathrm{SrO}_{2} \cdot 8 \mathrm{H}_{2} \mathrm{O}[204]^{+}$

$\mathrm{BaO}_{2} \cdot 8 \mathrm{H}_{2} \mathrm{O}[205]^{+}$

$+:$ crystal structure solved

* : unit cell determined; no detailed crystal data

- : no X-ray investigation reported 


\subsubsection{Thermal and Thermodynamic Properties of Alkaline and Alkaline Earth MetalPeroxides} Tanifuji et al. [207] reported a detailed investigation on heat capacity and thermal decomposition of lithium peroxide by adiabatic scanning calorimetry. This compound is of marked interest for economical preparation of $\mathrm{Li}_{2} \mathrm{O}$. Thermal decomposition of lithium peroxide according to the first order reaction

$$
\mathrm{Li}_{2} \mathrm{O}_{2}=\mathrm{Li}_{2} \mathrm{O}+1 / 2 \mathrm{O}_{2} \quad \Delta_{\mathrm{R}} \mathrm{H}=25.8 \mathrm{KJ} / \mathrm{mol}
$$

occurs at about $350^{\circ} \mathrm{C}$. Detailed thermodynamic and kinetic data have been given [207]. Sodium peroxide octahydrate has been the subject of several investigations [208, 209, 210]; however, formation of the intermediate dihydrate and monohydrate [208] during thermal decomposition of $\mathrm{Na}_{2} \mathrm{O}_{2} \cdot 8 \mathrm{H}_{2} \mathrm{O}$, starting at temperatures above $30-60^{\circ} \mathrm{C}$, could not be proved unequivocally. Anhydrous $\mathrm{Na}_{2} \mathrm{O}_{2}$ melts at $675^{\circ} \mathrm{C}$ as reported by Bunzel et al. [211]. The existence of two additional high-temperature modifications of this compounds, as quoted by Tallman et al. [212], explaining the thermal anomalies described by Foppel [196], has never been proved. The melting temperature of $\mathrm{K}_{2} \mathrm{O}_{2}$ has been determined by DTA-methods to be $545^{\circ} \mathrm{C}$ [150], which is markedly higher than the value previously reported by Blumenthal $\left(490^{\circ} \mathrm{C}\right)$ [213]. The thermodynamic properties of $\mathrm{K}_{2} \mathrm{O}_{2}$ and other potassium oxides have been reexamined and compared to literature data and the phase diagram for the $\mathrm{KO}_{0,5}-\mathrm{O}$ system has been reported (see Fig. 17) [214].

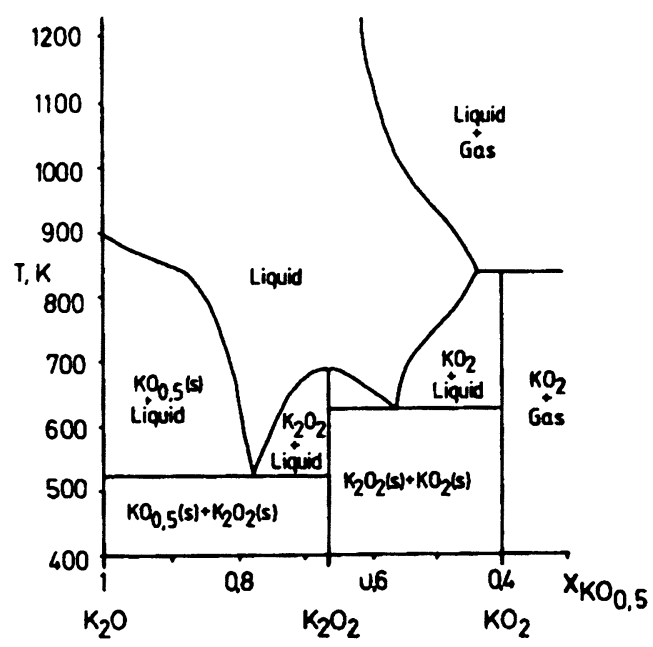

Fig. 17:

Phase diagramm for the $\mathrm{KO}_{0.5}-\mathrm{O}$ system calculated from thermodynamic data [214]. 
As determined by Kraus et al. [151], cesium peroxide decomposes directly to the monoxide:

$$
\mathrm{Cs}_{2} \mathrm{O}_{2}=\mathrm{Cs}_{2} \mathrm{O}+1 / 2 \mathrm{O}_{2}
$$

Thermodynamic data for the above reaction as well as $\mathrm{O}_{2}$ equilibrium pressure as a function of temperature have been reported [151].

A critically reviewed detailed collection of thermodynamic data for binary alkali metal oxides including the peroxides, covering the literature until the end of 1982, is in a paper by Lamoreaux and Hildenbrand [216].

Kjekshus and Rakke [200] found the decomposition temperature of $\mathrm{MgO}_{2}$ to be $360^{\circ} \mathrm{C}$. By DTAVTmethods Vol'nov [217] and Azuma et al. [218] determined the decomposition of $\mathrm{MgO}_{2}$ to occur in two steps, but in both investigations water-containing samples were used, which produced rather confusing thermograms.

Thermal investigations by DTA/TG and X-ray methods of the heavier alkaline earth metal peroxides and their octahydrates yielded decomposition temperatures of about 380,400 , and $780^{\circ} \mathrm{C}$ for $\mathrm{CaO}_{2}$, $\mathrm{SrO}_{2}$, and $\mathrm{BaO}_{2}$, respectively, with each peroxide reacting to the monoxide $\mathrm{MO}(\mathrm{M}=\mathrm{Ca}, \mathrm{Sr}, \mathrm{Ba})$ $[218,219]$, confirming the data quoted by Vol'nov [2]. Dehydration of the octahydrates produces the binary peroxides. The tendency to hydrolysis decreases from $\mathrm{CaO}_{2}$ to $\mathrm{BaO}_{2}$, the latter being hardly decomposed by water at all. The effect of varying oxygen pressures on dissociation and the heat of dissociation of $\mathrm{BaO}_{2}$ has been determined $[221,222]$.

\subsection{Group-IIb Peroxides}

Forming divalent cations, the elements of group-IIb are known to behave quite similarly in crystal chemistry to magnesium and the alkaline earth metals. Indeed, the group- Irb metals are the only elements beside alkali and alkaline earth metals which form stable ionic peroxide compounds with isolated $\mathrm{O}_{2}^{2-}$ anions.

\subsubsection{Syntheses and Chemical Properties of Group-IIb-Peroxides}

The existence of binary peroxides of group-IIb-elements was established by the investigations of Vannerberg [1, 223-225] and Hoffman et al. [226]. Zinc peroxide could be obtain either by precipitation from a solution of zinc nitrate in hydrogen peroxide with sodium peroxide or by reaction of $\mathrm{ZnO}$ with hydrogen peroxide [223]. The latter method yielded the higher peroxide content, but it was not possible to obtain anhydrous samples.

Kjekshus and Rakke investigated the preparation and properties of several binary dichalcogenides, 
ncluding zinc and cadmium peroxides. They tried the same preparation routes as mentioned above but obtained only poor samples of $\mathrm{ZnO}_{2}$ and $\mathrm{CdO}_{2}$, which did not justify an attempt to carry out a structure determination [200]. In more recent work, Puselj et al. describe two new methods for the syntheses of group-IIb-peroxides using elementary metals as starting materials. The first method is based on reaction between zinc or cadmium and an excess of $\mathrm{H}_{2} \mathrm{O}_{2}(30 \%)$ at $-20^{\circ} \mathrm{C}$. The second route applies anodic oxidation using a zinc or cadmium rod as anode, with iron as cathode.To avoid thermal decomposition of the reaction products, the current was not allowed to exceed $10 \mathrm{~mA}$ for zinc and $70 \mathrm{~mA}$ for cadmium and the electrolysis cell was cooled with ice to keep the temperature below $5^{\circ} \mathrm{C}$ [227].

Unlike the other group-IIb-peroxides, the mercuric compound has been found to exist in two polymorphic forms : $\alpha$ - and $\mathrm{B}-\mathrm{HgO}_{2}$ [225]. The latter compound is obtained in an analogous preparation route to the zinc and cadmium compounds, either starting from mercuric salt [225] or from elementary mercury via reaction with $\mathrm{H}_{2} \mathrm{O}_{2}(30 \%)$ at $-20^{\circ} \mathrm{C}$, or by electrochemical preparation (anodic oxidation of a mixture of mercury and $\mathrm{H}_{2} \mathrm{O}_{2}$; maximum current $1 \mathrm{~mA}$ ) [228]. According to Vannerberg [225] and Puselj et al. [228], conversion to $\alpha-\mathrm{HgO}_{2}$ is achieved by treatment of $\mathrm{B}-\mathrm{HgO}_{2}$ with $\mathrm{H}_{2} \mathrm{O}_{2}$ (15 weight-\%) below $-20^{\circ} \mathrm{C}$. X-ray powder analyses showed that conversion was complete after 48 hours [228]. Though several different preparation routes have been developed, none of them lead to completely anhydrous samples. Hoffman et al. [226] reported a water content of 2-3\%, Puselj et al. [227] of 4-5\% for cadmium peroxide. For zinc peroxide the water content was found to be 8-10\% [227]. These results correspond approximately to the formulas $\mathrm{ZnO}_{2} \cdot 0,5 \mathrm{H}_{2} \mathrm{O}$ and $\mathrm{CdO}_{2} \cdot 0,5 \mathrm{H}_{2} \mathrm{O}$, as suggested by Vannerberg $[223,224]$ and also confirmed by Lunenko- Burmakina et al. [229].

Apparently, no pure homogeneous and anhydrous peroxides $\mathrm{MO}_{2}(\mathrm{M}=\mathrm{Zn}, \mathrm{Cd}, \mathrm{Hg})$ have been obtained, as all preparation procedures reported in the literature have used aqueous solutions. Microscopic examination of the samples showed morphologically different particles [227], indicating inhomogenous samples. In consequence, analytical determinations of the average compositions has been less than satisfactory [227].

Peroxides of group-Irb elements are white or yellowish-white compounds, which decompose slowly at room temperature, i.e., they have to be stored at low temperatures [223-225, 227]. The most sensitive group-IIb-peroxide is $\alpha-\mathrm{HgO}_{2}$. According to Puselj et al. [228] it explodes for some rather unpredictable causes. Small mechanical activation of the substance can produce rather violent detonations.

Group-Ilb peroxides show slight solubility in $\mathrm{H}_{2} \mathrm{O}$. However, water may be adsorbed on their surfaces, which cannot be removed completely by a simple drying technique [227]. Dissolution in 
diluted acids yields the corresponding metal salt and a hydrogen peroxide solution [223-225, 227].

An improved preparation route leading to pure and coarse crystalline samples would be desirable for exact and reproduceable determination of the properties of group-IIb-peroxides. Because of the sensitivity of these compounds to contact with water, a preparation route excluding aqueous solutions, for example, high pressure/high temperature oxidation of the simple oxides ( $\mathrm{ZnO}, \mathrm{CdO}$, $\mathrm{HgO}$ ) in an autoclave, might open an appropriate access to pure binary peroxides.

\subsubsection{Crystal Structures of Group-Ilb Metal Peroxides}

Because of the unavailability of respective single crystals, all structural investigations on group$\mathrm{IIb}$ peroxides are based on $\mathrm{X}$-ray powder diffraction data. The refinements of the crystal structures of $\mathrm{ZnO}_{2}$ and $\mathrm{CdO}_{2}$ reported by Puselj et al. [227] are based on data already published by Vannerberg $[223,224]$. For $\alpha-\mathrm{HgO}_{2}$ Puselj et al. [228, 229] performed a structure refinement assuming monoclinic symmetry. The model corresponded to a tentative structural proposal given by Vannerberg [225] who, in contrast, had suggested a rhombohedral unit cell.

Isotypic to magnesium peroxide $[200,230], \mathrm{ZnO}_{2}$ and $\mathrm{CdO}_{2}$ crystallize with the cubic pyrite structure $[1,227]$ whereas $\mathrm{B}-\mathrm{HgO}_{2}$ (Fig. 18) forms a slightly distorted variant of this structure type $[1,225]$ resulting in formation of infinite zig-zag chains of mercury atoms and peroxide groups (Hg-O: $204 \mathrm{pm}$ ) extended along the c-axis of the orthorhombic unit cell.

$\alpha-\mathrm{HgO}_{2}$ crystallizes in a monoclinically distorted $\mathrm{CsCl}$-type of structure with the peroxide groups lying parallel to each other and parallel to the $c$-axis of the unit cell $[228,231]$. As depicted in Fig. 19, infinite zig-zag chains of mercury atoms and peroxide groups ( $\mathrm{Hg}-\mathrm{O}: 203 \mathrm{pm}$ ) extending along the [101]-direction are formed.

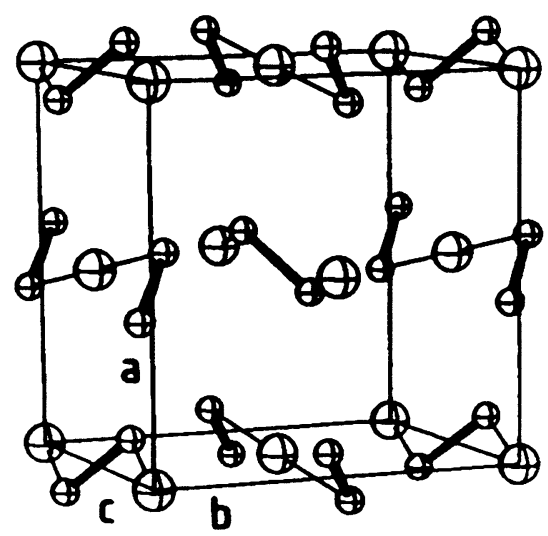

Fig. 18:

Crystal structure of orthorhombic $\beta-\mathrm{HgO}_{2}$. 


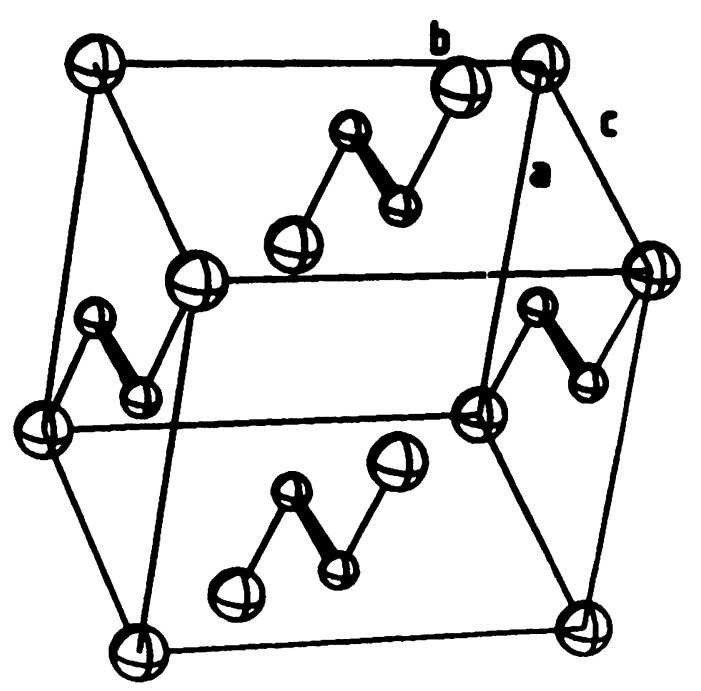

Fig. 19:

Crystal structure of monoclinic $\alpha-\mathrm{HgO}_{2}$

As the atomic arrangements of $\mathrm{ZnO}_{2}, \mathrm{CdO}_{2}$, and $\mathrm{MgO}_{2}$ derive from the $\mathrm{NaCl}$-type of structure, the metal cations are surrounded octahedrally by six equidistant oxygen atoms $\left(\mathrm{ZnO}_{2}: \mathrm{Zn}-\mathrm{O}=\right.$ $210 \mathrm{pm} ; \mathrm{CdO}_{2}: \mathrm{Cd}-\mathrm{O}=231 \mathrm{pm}$ ). In the distorted $\mathrm{B}-\mathrm{HgO}_{2}$ structure, two reduced (203 pm) and four larger (265 - $271 \mathrm{pm}$ ) $\mathrm{Hg}-\mathrm{O}$ distances occur. In the $\alpha-\mathrm{HgO}_{2}$ structure, which represents a distorted variant of the CsCl-type, Hg-O-contacts lie between 204 pm and 286 pm.

The intramolecular O-O-distances of the peroxide-anions found in the group-IIb peroxides are $146.5 \mathrm{pm}\left(\mathrm{ZnO}_{2}\right.$ [227] $)$ and $149 \mathrm{pm}\left(\mathrm{CdO}_{2}, \alpha-\mathrm{HgO}_{2}, \beta-\mathrm{HgO}_{2}[225,227,231]\right)$. Both values are well within the range accepted for this type of bond. Further crystallographic details for $\mathrm{ZnO}_{2}$, $\mathrm{CdO}_{2}, \alpha-$ and $\mathrm{B}-\mathrm{HgO}_{2}$ are given in Table XI. 
Table XI: Crystallographic data for $\mathrm{ZnO}_{2}, \mathrm{CdO}_{2}, \alpha$ - and $\mathrm{B}-\mathrm{HgO}_{2}$

\begin{tabular}{|c|c|c|c|c|}
\hline & $\mathrm{ZnO}_{2}[227]$ & $\mathrm{CdO}_{2}[227]$ & $\alpha-\mathrm{H}_{8} \mathrm{O}_{2}[228,231]$ & $\mathrm{B}-\mathrm{HgO}_{2}[1]$ \\
\hline Lattice parameters & $a=487.1 \mathrm{pm}$ & $a=531.3 \mathrm{pm}$ & $\begin{array}{l}a=447.0(2) \mathrm{pm} \\
b=545.9(2) \mathrm{pm} \\
\mathrm{C}=351.9(2) \mathrm{pm} \\
B=108.75^{\circ}\end{array}$ & $\begin{array}{l}a=608 \mathrm{pm} \\
b=601 \mathrm{pm} \\
c=480 \mathrm{pm}\end{array}$ \\
\hline Spacegroup & $\begin{array}{l}\mathrm{Pa}_{\overline{3}} \\
\text { (No. 205) }\end{array}$ & $\begin{array}{l}\mathrm{Pa} \overline{3} \\
(\mathrm{No} 0.205)\end{array}$ & $\begin{array}{l}\mathrm{C} / \mathrm{m} \\
(\mathrm{No} .12)\end{array}$ & $\begin{array}{l}\text { Poca } \\
\text { (No.61) }\end{array}$ \\
\hline $\mathbf{z}$ & 4 & 4 & 2 & 4 \\
\hline Atomic positions & $\begin{array}{l}\mathrm{Zn}: 0,0,0 \\
0: 0.413,0.413,0.413\end{array}$ & $\begin{array}{l}\text { Cd: } 0,0,0 \\
0: 0.419,0.419,0.419\end{array}$ & $\begin{array}{l}\mathrm{Hg}: 0,0,0 \\
\mathrm{O}: 0.476,0,0.28\end{array}$ & $\begin{array}{l}\mathrm{Hg}: 0,0,0 \\
\mathrm{O}: 0.075,0.062,0.405\end{array}$ \\
\hline Temperature-factors & $\begin{array}{l}\mathrm{Zn}: 1.0 \cdot 10^{4} \mathrm{pm}^{2} \\
0: 1.6 \cdot 10^{4} \mathrm{pm}^{2}\end{array}$ & $\begin{array}{l}C d: 0.66 \cdot 10^{4} \mathrm{pm}^{2} \\
0: 1.0 \cdot 10^{4} \mathrm{pm}^{2}\end{array}$ & $\begin{array}{l}\mathrm{Hg}: 0.27 \cdot 10^{4} \mathrm{pm}^{2} \\
O: 1.2 \cdot 10^{4} \mathrm{pm}^{2}\end{array}$ & $\begin{array}{l}\mathrm{Hg}: 2.6 \cdot 10^{4} \mathrm{pm}^{2} \\
O: 2.6 \cdot 10^{4} \mathrm{pm}^{2}\end{array}$ \\
\hline $\begin{array}{l}\text { Method for structure } \\
\text { determination }\end{array}$ & $\begin{array}{l}\text { Powder diffiraction } \\
\text { pattern }\end{array}$ & $\begin{array}{l}\text { Powder diffraction } \\
\text { pattern }\end{array}$ & $\begin{array}{l}\text { Powder diffraction } \\
\text { pattem }\end{array}$ & $\begin{array}{l}\text { Powder diffraction } \\
\text { pattern }\end{array}$ \\
\hline Reliability factor (R) & 0.029 & 0.05 & 0.049 & - \\
\hline
\end{tabular}

\subsubsection{Thermal Properties, Phase Transitions, and Magnetic Behavior of Group-Illb-Peroxides}

As pointed out in the previous chapter, none of the investigations reported so far has been undertaken using pure and anhydrous peroxide compounds. Accordingly, the published data concerning thermal dissociation of zinc-, cadmium-, and mercuric peroxides are quite unreliable and contradictory.

The thermal properties of these compounds are of considerable interest, particularly in order to determine optimal drying conditions for the initially hydrous samples.

Puselj et al. [227] observed by thermogravimetric analysis that water was lost in the temperature range between room temperature and $130^{\circ} \mathrm{C}$ and $150^{\circ} \mathrm{C}$ for zinc and cadmium peroxide, respectively. A sharp weight loss corresponding to the reaction

$$
\mathrm{MO}_{2}=\mathrm{MO}+1 / 2 \mathrm{O}_{2}(\mathrm{M}=\mathrm{Zn}, \mathrm{Cd})
$$

was observed up to $240^{\circ} \mathrm{C}$ and $290^{\circ} \mathrm{C}$, respectively [227]. Other authors report dissociation temperatures of about $200^{\circ} \mathrm{C}$ for zinc oxide $[232,233]$. 
Due to formation of paramagnetic species like $\mathrm{O}_{2}$ or $\mathrm{HO}_{2}$, drying of hydrous group- Ib peroxides in an oxygen atmosphere yielded EPR - active materials, while desiccator dried products are diamagnetic $[200,233]$.

Though several reaction mechanisms for the thermal decomposition of hydrous zinc-and cadmium peroxides have been suggested, it has not been possible to determine the true nature of the occuring paramagnetic species $[200,229,233]$.

\subsection{Further Peroxides}

To date, ionic peroxides with isolated $\mathrm{O}_{2}{ }^{2-}$ anions are known to exist only in combination with mono- or divalent cations of the most electropositive metals (e.g., alkali and alkaline earth metals and group-IIb metals).

Very recently, Range et al. [234] found an exception to this empirical rule. Trying to synthesize neodymium (IV) - oxide by reaction between $\mathrm{Nd}_{2} \mathrm{O}_{3}$ and $\mathrm{KO}_{2}$ at a pressure of $40 \mathrm{kbar}$ and a temperature of $1500^{\circ} \mathrm{C}$ in a modified BELT- apparatus, $\mathrm{Nd}_{2} \mathrm{O}_{2}\left(\mathrm{O}_{2}\right)$ neodymium (III) - oxide peroxide was obtained. This light-blue neodymium (III)- compound exhibits remarkable thermal stability (up to $420^{\circ} \mathrm{C}$ ) before it decomposes to $\mathrm{Nd}_{2} \mathrm{O}_{3}$ and $\mathrm{O}_{2}$. Single crystal $\mathrm{X}$-ray structure determination proved the compound to contain both $\mathrm{O}_{2}{ }^{2-}$ - and $\mathrm{O}^{2-}$ anions according to the formula $\mathrm{Nd}_{2} \mathrm{O}_{2}\left(\mathrm{O}_{2}\right.$ ) (see Fig.20). Every neodymium-cation is surrounded by eight oxygen-atoms, half of them belonging to peroxide anions, which are coordinated in a nearly side-on position to the metal cations (Nd-Odistances: $248.3 \mathrm{pm}$ and $264.9 \mathrm{pm}$ ) and, furthermore, as bridging ligands to other $\mathrm{Nd}^{3+}$-cations $(\mathrm{Nd}-$ O-distances: $2 \times 258.6 \mathrm{pm}$ ). The $\mathrm{Nd}^{3+}-\mathrm{O}^{2-}$ contacts are markedly smaller, varying between $234.3 \mathrm{pm}$ and $238.0 \mathrm{pm}$. For further details see Table XII.

\begin{tabular}{|l|l|}
\hline Table XII: Crystallographic data for $\mathrm{Nd}_{2} \mathrm{O}_{2}\left(\mathrm{O}_{2}\right)[234]$ \\
\hline Lattice parameters & $\mathrm{a}=664.95(7) \mathrm{pm}$ \\
& $\mathrm{b}=401.73(3) \mathrm{pm}$ \\
& $\mathrm{c}=651.74(9) \mathrm{pm}$ \\
Space group & $\beta=98.11(1)^{\mathrm{O}}$ \\
Z & $\mathrm{C} 2 / \mathrm{m}$ \\
Atomic positions & 2 \\
& $\mathrm{Nd:} 0.2009,0,0.2307$ \\
& $\mathrm{O}: 0.0771,0.5,0.4291$ \\
& $02: 0.6544,0.5,0.8619$ \\
Method for structure determination & Single crystal X-ray technique \\
Reliability factor (R) & 0.033 \\
\hline
\end{tabular}



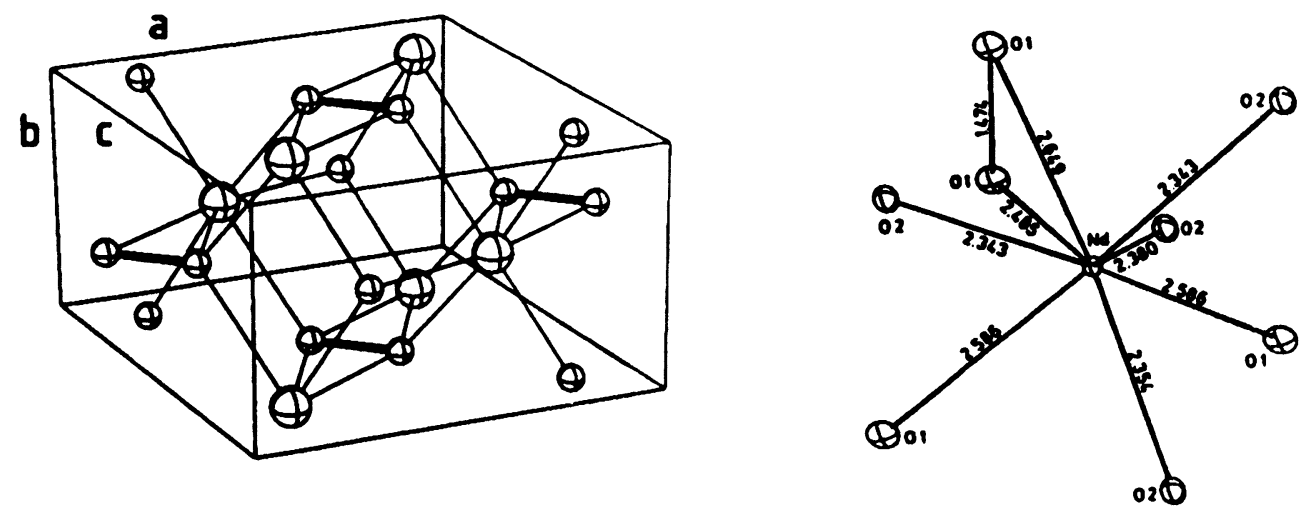

Fig. 20:

Crystal structure of $\mathrm{Nd}_{2} \mathrm{O}_{2}\left(\mathrm{O}_{2}\right)$ (left side) and atomic arrangement around $\mathrm{Nd}^{3+}$ [234]

The existence of other peroxide compounds of rare earth metals, e.g., $\mathrm{Y}_{4} \mathrm{O}_{9} \times \mathrm{xH}_{2} \mathrm{O}$ or $\mathrm{La}_{2} \mathrm{O}_{5} \cdot \mathrm{xH}_{2} \mathrm{O}$, as postulated by Vannerberg [1], has not been confirmed as yet.

Furthermore, the so-called "sesquioxides" $\mathrm{M}_{2} \mathrm{O}_{3}$ of the heavier alkali metals rubidium and cesium, which were described by Klemm et al. [120], were assumed to contain both $\mathrm{O}_{2}^{-}$and $\mathrm{O}_{2}{ }^{2-}$ anions. The structural model proposed (anti $\mathrm{Th}_{3} \mathrm{P}_{4}$-type, with $\mathrm{O}_{2}^{-}$and $\mathrm{O}_{2}{ }^{2-}$ groups at crystallographically identical positions) based on powder data still requires reexamination by single crystal methods for evaluation of more precise structural details.

More recently, even $\mathrm{K}_{2} \mathrm{O}_{3}[158,235,236]$ has been mentioned in the literature and, furthermore, the formation of solid solutions between $\mathrm{Na}_{2} \mathrm{O}_{2}$ and $\mathrm{NaO}_{2}$ at about $260^{\circ} \mathrm{C}$ has been reported [237] without giving details conceming the preparation, structure or properties of these compounds. The material reported to be $\mathrm{K}_{2} \mathrm{O}_{3}$ has been suggested to be an eutectic mixture of $\mathrm{K}_{2} \mathrm{O}_{2}$ and $\mathrm{KO}_{2}$ [214].

Up to now the existence of group-Ib peroxides has not been proved. Powder neutron diffraction [238] and more recently single-crystal $\mathrm{X}$-ray methods [239] show that $\mathrm{AgO}=\mathrm{Ag}_{2} \mathrm{O}_{2}$ contains no peroxide groups, but should be formulated as $\mathrm{Ag}^{1+} \mathrm{Ag}^{3+} \mathrm{O}_{2}$. Furthermore, $\mathrm{AgO}_{2}$, which was obtained as thin films and not as a bulk material, was reported to form a cubic-phase ( $\mathrm{a}=555 \mathrm{pm})$, fromelectron diffraction, but no structure has been proposed [240,241].Similarly, peroxide-ion formation in high- $\mathrm{T}_{c}$ superconducting cuprate phases $\left(\mathrm{YBa}_{2} \mathrm{Cu}_{3} \mathrm{O}_{-8}\right)$ as postulated by Goodenough [242] and other authors could not be verified. 


\subsection{Spectroscopic Properties of Ionic Peroxides}

Only a few spectroscopic investigations of solid ionic peroxides have been reported [135, 243, 244]. The change of dipole moment during the vibration is zero in the free $\mathrm{O}_{2}{ }^{2-}$ anion and it remains very small even in those crystal lattices where one of the internal modes becomes allowed for infrared absorption. Therefore, only Raman active modes have been observed [244]. The purity of peroxide compounds can be checked by spectroscopic investigation, as impurities like water, carbonate, and hyperoxide can easily be determined. Furthermore, spectroscopic studies reveal the dependence of the O-O-bond strength of the peroxide anions (as it can be correlated to the observed O-O-stretching vibrations) upon crystal field effects and, upon the degree of the ionicity of the different peroxide compounds.

Hendra etal. [135] did not realize that their peroxide samples were contaminated by carbonate, which led to misassignment of the Raman data [243]. Eysel et al. [244] performed a detailed Raman study of several alkali, alkaline earth, and group-IIb peroxides using powder samples. Though nearly all of their samples contained impurities $\left(\mathrm{O}^{2-}, \mathrm{CO}_{3}{ }^{2-}, \mathrm{H}_{2} \mathrm{O}\right)$, the $\mathrm{O}_{2}{ }^{2-}$ internal vibration was reported to occur between 730 and $950 \mathrm{~cm}^{-1}$. As expected, the observed O-O-frequencies of alkali peroxides are centered below $800 \mathrm{~cm}^{-1}$, while those of the peroxides of divalent metals, which cause a stronger cationic field, are centered above $800 \mathrm{~cm}^{-1}$. However, the observed variation of $\mathrm{O}-\mathrm{O}$-frequencies in the isostructural pyrite type series $\mathrm{MgO}_{2}, \mathrm{ZnO}_{2}$, $\left.\mathrm{CdO}_{2}\right)$ and the isostructural calcium carbide type series $\left(\mathrm{CaO}_{2}, \mathrm{SrO}_{2}, \mathrm{BaO}_{2}\right)$ could not be explained quantitatively without contradictions. Accordingly, a more precise investigation using oriented single crystals, which are still unavailable for these compounds, would be desirable.

\subsection{Applications of Alkali. Alkaline Earth, and Group-Ilb Peroxides}

Common applications of peroxides, like $\mathrm{Na}_{2} \mathrm{O}_{2}, \mathrm{CaO}_{2}, \mathrm{SrO}_{2}$, and $\mathrm{BaO}_{2}$, which are produced in industrial scale, will not be discussed in detail in this paper. Such applications are, for example, use of sodium peroxide as a bleaching component or as a starting material in syntheses of other peroxidic compounds, as a component in mixtures for air regeneration in enclosed spaces, and for treatment of metallic surfaces. Calcium peroxide is used to increase the plastic properties of dough or to initiate yeast growth, as well as being an intermediate in the production of hydrogen peroxide. Another application is the stabilization of vulcanized copolymers. Barium peroxide is also used as starting material for preparation of hydrogen peroxide, or in pyrotechnology as a strong oxidizing agent.

Some particular applications reported in more recent papers will be quoted in the following: $\mathrm{Si}$ milarly to their application for air revitalization, peroxides can be used for quantitative ab- 
sorption of special gases, which play an important role in air pollution: A technique has been developed to determine the average concentration of $\left(\mathrm{NO}_{\mathbf{x}}\right)$ in the atmosphere, using solid alkaline earth peroxides as absorbents. In the presence of humidity, these compounds (e.g., $\mathrm{MgO}_{2}, \mathrm{CaO}_{2}$, $\mathrm{SrO}_{2}$ ) oxidize both nitrogen oxide and dioxide from the air, producing nitrate, which can be determined quantitatively and can be correlated to the average concentration of $\left(\mathrm{NO}_{\mathbf{x}}\right)$ in the polluted air [245].

Removal of formaldehyde vapor as an atmospheric pollutant can be achieved by alkaline earth peroxides, oxidizing $\mathrm{CH}_{2} \mathrm{O}$ to produce formic acid, which can be absorbed by the alkaline earth hydroxide, which forms upon reaction of the peroxide with water vapor from the air [246]. A new synthetic application of alkali metal peroxides in solid state chemistry for syntheses of ternary metal oxides has recently been presented by Hoppe $[247-258]$ and other authors $[259,260]$. 
iterature

1] N.G. Vannerberg; Prog. Inorg. Chem. 4 (1962) 125.

2] I.I. Vol'nov, "Peroxides, Superoxides, and Ozonides of Alkali and Alkaline Earth Metals" (edited by A.W. Petrocelli), Plenum Press, New York, (1966).

3] C.A. Wurtz; Dictionnaire de Chimie pure et applique, Vol. II (1868) 721.

[4] A. Baeyer, V. Villiger, Chem. Ber. 35 (1902) 3038.

[5] I. A. Kazarnovskii, G.P. Nikol'skii; Dokl. Akad. Nauk SSSR 64 (1949) 69.

[6] A.J. Kacmarek; U.S. Dept. Com., Office Tech. Serv., AD 427, 772, 23 pp. (1962)

From: U.S. Govt. Res. Rept. 39 (7) (1964) 6.

[7] V.I. Sokol., V.V. Matveev, I.I. Vol'nov; Izv. Akad. Nauk SSSR, Ser. Khim. 1966 (12) 2235.

[8] I.A. Kazarnovskii, N.P. Lipikhin. N.N. Bubnov; Izv. Akad. Nauk SSSR, Ser. Khim. 1966 (12) 2247.

[9] I.I. Vol'nov, M.S. Dobrolyubova, A.B. Tsentsiper; Izv. Akad. Nauk SSSR, Ser. Khim. $1966(9) 1665$.

[10] V.I. Sokol, M.S. Dobrolyubova; Izv. Akad. Nauk SSSR, Ser. Khim. 1967 (11) 2561.

[11] A.B. Tsentsiper, M.S. Dobrolyubova; Izv. Akad. Nauk SSSR, Ser. Khim. 1967 (12) 2740.

[12] I.I. Vol'nov, V.N. Chamova, E.I. Latycheva; Izv. Akad. Nauk SSSR, Ser. Khim. $1967(6) 1183$.

[13] I.I. Vol'nov, V.V. Matveev; Redk. Shchelochnye Elem., Sb. Dokl. Vses. Soveshch., 2nd, Novosibirsk, Meeting Date 1964, 31-42. Edited by: Plyushchev, V.E., Izd. "Nauka". Sib. Otd.: Novosibirsk, USSR (1967).

[14] M.S. Dobrolyubova, A.B. Tsentsiper, V.I. Sokol, I.I. Vol'nov, V.M. Bakulina; Redk. Shchelochnye Elem. 7-13. From: Ref. Zh., Khim. 1970, Abstr. No. 13 V6.

[15] A.B. Tsentsiper, M.S. Dobrolyubova; Izv. Akad. Nauk SSSR, Ser. Khim. 1970 (3) 690.

[16] A.B. Tsentsiper, M.S. Dobrolyubova; Izv. Akad. Nauk SSSR, Ser. Khim. 1970 (3) 692.

[17] A.S. Borovik-Romanov, M.S. Dobrolyubova, A.B. Tsentsiper, V.P. Chemyshev; Magn. Resonance Relat. Phenomena, Proc. Congr. AMPERE, 16th, Meeting Date 1970, 515- 18. Edited by: Ursu, Ioan. Publ. House Acad. Soc. Repub. Rom.: Bucharest, Rom (1971).

[18] W. Petrocelli, A. Capotosto; Inorg. Chim. Acta 5 (3) (1971) 453. 
[19] A.D. Evdokimova, M.S. Dobrolyubova, A.B. Tsentsiper; Izv. Akad. Nauk SSSR, Ser. Khim. 1971 (2) 446.

[20] A.B. Tsentsiper, M.S. Dobrolyubova; Izv. Akad. Nauk SSSR, Ser. Khim. 1972 (2) 476.

[21] A.B. Tsentsiper, M.S. Dobrolyubova, L.V. Pirozhenko; Izv. Akad. Nauk SSSR, Ser. Khim. 1972 (7) 1467.

[22] A.B. Tsentsiper, M.S. Dobrolyubova; Izv. Akad. Nauk SSSR, Ser. Khim. $1972(7) 1471$.

[23] S.A. Tokareva, G.P. Pilipenko, V.I. Klimanov, I.I. Vol'nov; Tezisy Dokl. Vses. Soveshch. Khim. Neorg. Perekisnykh Soedin. 1973, 14. Edited by Vol'nov, I.I.; Blum, A.Ya. Rizh. Politekh.Inst.: Riga, USSR.

[24] A.B. Tsentsiper, M.S. Dobrolyubova, Z.I. Kuznetsova; Tezisy Dokl. Vses. Soveshch. Khim. Neorg. Perekisnykh Soedin. 1973, 17. Edited by Vol'nov, I.I. ;

Blum, A.Ya. Rizh. Politekh.Inst.: Riga, USSR.

[25] M.S. Dobrolyubova, V.Ya. Dudarev, V.A. Sarin, A.B. Tsentsiper; Izv. Akad. Nauk SSSR, Ser. Khim. 1973 (1) 146.

[26] A.B. Tsentsiper, M.S. Dobrolyubova; Neorg. Perekisnye Soedin., Dokl. Vses. Soveshch. 1973 (Pub. 1975), 186-91. Edited by Vol'nov, I.I. "Nauka": Moscow, USSR.

[27] I.I. Vol'nov, S.A. Tokareva; Mater.-Vses. Mezhvuz. Konf. Ozonu, 2nd. 1977, 3-4. Edited by Mal'tsev, Yu.A. Moskovskii Gos. Univ.: Moscow, USSR.

[28] G.S. Zhdanova, Z.V. Zvonkova; Zhur. Fiz. Khim. 25 (1951) 100.

[29] P. Smith; J. Phys. Chem. 60 (1956) 1471.

[30] L. Pauling; "The Nature of the Chemical Bond", $3^{\text {rd }}$ Ed., Cornell University Press, New York, 1960.

[31] S. Schlick; J. Chem. Phys. 56 (1) (1972) 654.

[32] W. Schnick, M. Jansen; Angew. Chem. Int. Ed. Engl. 24 (1985) 56.

[33] I.I. Vol'nov, E.I. Sokevnin, V.V. Matveev; Izv. Akad. Nauk SSSR, Ser. Khim. 19621127.

[34] W. Schnick, M. Jansen; Z. Anorg. Allg. Chem. 532 (1986) 37.

[35] W. Hesse, M. Jansen; unpublished work

[36] T.P. Whaley, J. Kleinberg; J. Am. Chem. Soc 73 (1951) 79.

[37] I.J. Solomon, A.J. Kacmarek; J. Phys. Chem. 64 (1960) 168.

[38] S.A. Tokareva, M.S. Dobrolyubova, S.Z. Makarov; Khim. Perekisnykh Soedin., Akad. Nauk SSSR, Inst. Obshch.i Neorgan. Khim. 1963188. 
[39] S.A. Tokareva, M.S. Dobrolyubova; Izv. Akad. Nauk SSSR, Ser. Khim. 1964 (4) 739.

[40] S.A. Tokareva, G.P. Pilipenko; Zh. Analit. Khim. 21 (3) (1966) 380.

[41] A.J. Kacmarek, J.M. McDonough, I.J. Solomon; Inorg. Chem. 1 (1962) 659.

[42] V.G. Kuznetsov, S.A. Tokareva, M.S. Dobrolyubova;

Zh. Neorgan. Khim. 7 (1962) 967.

[43] V.G. Kuznetsov, V.M. Bakulina, S.A. Tokareva, A.N. Zimina;

Zh. Struktur. Khim. 5 (1) (1964) 142.

[44] V.M. Bakulina, I.I. Vol'nov, V.V. Matveev, A.M. Zimina;

Zh. Struktur. Khim. 7 (6) (1966) 851.

[45] ～L.V. Azaroff, I. Corvin; Izv. Akad. Nauk SSSR, Ser. Khim. 19631136.

[46] R.A. Alikhanov, V.I. Bazin, L.S. Smimov, S.A. Tokareva; Neorg. Perekisnye Soedin., Dokl. Vses. Soveshch., Meeting Date 1973, (1975) 178.

[47] V.A. Sarin, V.Ya. Dudarev, M.S. Dobrolyubova;

Kristallografiya 19 (1) (1974) 74.

[48] W. Schnick, M. Jansen; Rev. Chim. Minér. 24 (1987), 446.

[49] R.D. Shannon, C.T. Prewitt; Acta Cryst. B25 (1969) 925.

[50] M.M. Cosgrove, M.A. Collins; J. Chem. Phys. 52 (1970) 989.

[51] W. Schnick, M. Jansen; Diss. Schnick, Hannover (1986)

[52] M. Jansen, W. Hesse; Z. Anorg. Allg. Chem. 560 (1988) 47.

[53] H. Lueken, M. Deussen, M. Jansen, W. Hesse, W. Schnick; Z. Anorg. Allg. Chem. 553 (1987) 179.

[54] W. Hesse, M. Jansen, to be published.

[55] A. I. Karelin, V. Ya. Rosolovskii, S.A. Tokareva, I. I. Vol'nov; Dokl. Akad. Nauk SSSR 206 (3) (1972) 641.

[56] M.E. Jacox, D.E. Milligan; Chem. Phys. Lett. 14 (4) (1972) 518.

[57] R.C. Spiker jr., L. Andrews; J. Chem. Phys. 59 (4) (1973) 1851.

[58] L. Andrews, R.C. Spiker jr.; J. Chem. Phys. 59 (4) (1973) 1863.

[59] L. Andrews; J. Am. Chem. Soc. 95 (14) (1973) 4487.

[60] P.A. Giguère, K. Herman; Can. J. Chem. 52 (23) (1974) 3941.

[61] L. Andrews; J. Chem. Phys. 63 (10) (1975) 4465.

[62] I.I. Vol' nov, S.A. Tokareva, V.N. Belevskii, V.I. Klimanov, G.P. Pilipenko; Izv. Akad. Nauk SSSR, Ser. Khim. 1972 (6) 1235.

[63] I.I. Vol' nov, S.A. Tokareva, G.P. Pilipenko, V. I. Klimanov, V.N. Belevskii; Izv. Akad. Nauk SSSR, Ser. Khim. 1973 (9) 2138. 
[64] I.I. Vol'nov, S.A. Tokareva, V.N. Belevskii, E.I. Latysheva, V.I. Klimanov, G.P. Pilipenko; Neorg. Perekisnye Soedin., Dokl. Vses Soveshch., Meeting Date 1973, (Pub. 1975), 110.

[65] I.J. Solomon, K. Hattori, A.J. Kacmarek, G.M. Platz, M.J. Klein; J. Am. Chem. Soc. 84 (1962) 34.

[66] K. Hattori; M.J. Klein, I.J. Solomon; T.A. Erikson, G.M. Platz; U.S. 3, 180, 771 (Cl. 149-45), Apr. 27, 1965, Appl. Jan. 16, 1958, 5 pp.

[67] B.R. Adelman; U.S. 3, 197, 957 (Cl. 60-35.4), Aug. 3, 1965, Appl. Oct. 8, 1958, 2 pp.

[68] K. Herman, P.A. Giguère; Can. J. Chem. 43 (6) (1965) 1746.

[69] T. Huston, I.C. Hisatsune, J. Heicklen; Can. J. Chem. 61 (9) (1983) 2070.

[70] W. Traube, E. Burmeister, B. Blaser, Ber. 60 (1927) 370.

[71] W. Traube, F. Kuhbier; Ber. 62B (1929) 809.

[72] I.J. Solomon, A.J. Kacmarek, K. Hattori; U.S. 2, 951, 869, Sept. 6, 1960.

[73] I.J. Solomon, A.J. Kacmarek, J.M. McDonough, K. Hattori; J. Am. Chem. Soc. 82 (1960) 5640.

[74] W. Hesse, M. Jansen; Angew. Chem. Int. Ed. Engl. 27 (10) (1988) 1341.

[75] I.A. Kazarnovskii, N.P. Lipikhin; Dokl. Akad. Nauk SSSR 231 (5) (1976) 1155.

[7] A.R. Forrester, V. Purushotham; J. Chem. Soc., Faraday Trans. 183 (1) (1987) 211.

[77] A.R. Forrester, V. Purushotham; Tetrahedron Letters 28 (28) (1987) 3279.

[78] V.M. Bakulina, S.A. Tokareva, I.I. Vol'nov; Zh. Strukt. Khim. 8 (6) (1967) 1104.

[79] I.I. Vol'nov, S.A. Tokareva, V.N. Belevskii, V.I. Klimanov; Izv. Akad. Nauk SSSR, Ser. Khim. 1967 (7) 1411.

[80] A. Puxeddu, N. Marsich, G. Costa; J. Chem. Soc., Chem. Commun. 1978 (8) 339.

[81] J.S. Valentine, A.B. Curtis; J. Amer. Chem. Soc., 97 (1975) 224.

[82] P. Bruno, M. Cadelli, A. Traini; Ann. Chim. 76 (11-12) (1986) 427.

[83] S.E. Stephanou, W.H. Schechter, W.J. Argersinger jr., J. Kleinberg; J. Amer. Chem. Soc. 71 (1949) 1819.

[84] J. Kleinberg; "Unfamiliar Oxidation States and their Stabilization", University of Kansas Press, Lawrence (1950), p. 25.

[85] S.H. Cohen, I.L. Margrave, V. Shelar, E.M. Montaban; Inorg. Nucl. Chem. 14 (1960) 301.

[86] O. Satybaldiev, A.E. Kharakoz; Zh. Neorg. Khim. 17(9) (1972) 2583.

[87] A. Le Berre, P. Goasguen; Compt. Rend. 254 (1962) 1306.

[88] N.A. Sokolov, G.A. Matsulevich; Neorg. Perekisnye Soedin., Dokl. Vses. Soveshch., Meeting Date 1973, (Pub. 1975) 95. 
89] G.A. Matsulevich, N.A. Sokolov; Zh. Obshch. Khim. 49 (1) (1979) 3.

90] G.A. Matsulevich, N.A. Sokolov; Zh. Obshch. Khim. 49 (10) (1979) 2182.

91] G.A. Matsulevich, N.A. Sokolov; Zh. Obshch. Khim. 54 (1) (1984) 106.

.92] A. Helms, W. Klemm; Z. Anorg. Allg. Chem. 242 (1939) 33.

[93] C.B. Jackson; U.S. Patent 2405580 (1946).

[94] J.A. Ando; Japan. Kokai 7353, 99 (Cl. 15 F 211), 28 Jul 1973, Appl. 71 88, 722, 09 Nov 1971,4 pp.

[95] E. Yonemitsu, T. Itabashi, H. Masai, M. Abe; Japan. Kokai 7470, 896 (Cl. 15F 211), 09 Jul 1974, Appl. 72 112, 061, 10 Nov. 1972; 3 pp.

[96] F. Chastagner, H. Kessler, A. Hatterer, Bull. Soc. Chim. Fr. 1980 (5-6; Pt. 1) 189.

[97] F.A. Uribe, A.J. Bard; Inorg. Chem. 21 (8) (1982) 3160.

[98] P. Sadhukan, A.T. Bell; J. Inorg. Nucl. Chem. 38 (11) (1976) 1943.

[99] P. Sadhukan, A.T. Bell; U.S. Pat. Appl. 760, 81019 Jan 1977, 16 pp.

[100] J.R. Hollahan, T. Wydeven; J. Inorg. Nucl. Chem. 35 (4) (1973) 1079.

[101] I.I. Vol'nov, V.N. Chamova, E.I. Latycheva, E.Y. Filatov;

Zh. Neorg. Khim. 12 (8) (1967) 2253.

[102] I. Rosenthal; J. Labelled Compd. Radiopharm. 12 (2) (1976) 317.

[103] T. Miyazawa, T. Endo, M. Okawara; J. Org. Chem. 50 (25) (1985) 5389.

[104] M.Bösch, W. Känzig; Helv. Phys. Acta 48 (1975) 743.

[105] M. Ziegler, M. Bösch, H. Arend; First European Conference on Crystal Growth. Zürich, Sept. 12-18, (1976), p. 200.

[106] M. Ziegler, M. Rosenfeld, W. Känzig, P. Fischer, Helv.Phys. Acta 49 (1976) 57.

[107] M. Rosenfeld, M. Ziegler, W. Kănzig; Helv. Phys. Acta 51 (1978) 298.

[108] P. Brüesch, M. Bø̋sch, W. Kănzig, M. Ziegler, W. Bührer; Phys. Stat. Sol. 77b (1976) 153.

[109] A. Zumsteg, M. Ziegler, W. Känzig, M. Bösch; Phys. cond. Matter 17 (1974) 267.

[110] M.A. Bösch, M.E. Lines, M. Labhart; Phys. Rev. Lett. 45 (2) (1980) 140.

[111] M.E. Lines, M.A. Bösch; Phys. Rev. B 23 (1) (1981) 263.

[112] M.E. Lines; Phys. Rev. B 24 (9) (1981) 5248.

[113] W. Känzig, M. Labhart; J. Phys. (Paris) Colloq. 37 (1976) C7.

[114] G. F. Carter, D. H. Templeton; J. Am. Chem. Soc. 75 (1953) 5247.

[115] G. S. Zhdanov, Z. V. Zvonkova; Dokl. Akad. Nauk SSSR 82 (1952) 743.

[116] D. H. Templeton, C. H. Dauben; J. Am. Chem. Soc. 72 (1950) 2251.

[117] A. B. Tsentsiper, T. I. Rogozhnikova;

Izv. Akad. Nauk SSSR, Ser. Khim 1967 (1), 195. 
[118] G. F. Carter, J. L. Margrave, D. H. Templeton; Acta Cryst. 5 (1952) 581.

[119] W. Kassatochkin, W. Kotow; J. Chem. Phys. 4 (1936) 458.

[120] A. Helms, W. Klemm; Z. Anorg. Allg. Chem. 241 (1939) 97.

[121] S. C. Abrahams, J. Kalnajs; Acta Cryst. 8 (1955) 503.

[122] F. Halverson; J. Phys. Chem. Solids 23 (1962) 207.

[123] M. Ziegler, M. Bősch, W. Känzig; Helv. Phys. Acta 47 (1974) 448.

[124] M. Ziegler, H. R. Meister, W. Känzig; Helv. Phys. Acta 48 (1975) 599.

[125] H. G. Smith, R. M. Nicklow, L. J. Raubenheimer, M. K. Wilkinson; J. Appl. Phys. 37 (3) (1966) 1047.

[126] A. Zumsteg, M. Bösch, W. Känzig, H. Rohrer; Helv. Phys. Acta 45 (1972) 28.

[127] A.K. Khan, S.D. Mahanti; J. Chem. Phys. 63 (6) (1975) 2271.

[128] M. Labhart, D. Raoux, W. Känzig; Helv. Phys. Acta 50 (1977) 602.

[129] M. Labhardt, D. Raoux, W. Känzig, M.A. Bösch; Phys. Rev. B 20 (1) (1979) 53.

[130] A. Zumsteg, M. Ziegler, M. Bösch, W. Känzig; Helv. Phys. Acta 46 (1973) 15.

[131] G. Kemeny, T.A. Kaplan, S.D. Mahanti, D. Sahu; Phys. Rev. B 24 (1981) 5222.

[132] V.Ya. Dudarev, A. B. Tsentsiper, M. S. Dobrolyubova; Kristallografiya 18 (1973) 759.

[133] A.B. Tsentsiper, M.S. Dobrolyubova; Izv. Akad. Nauk SSSR 1968 (1), 175.

[134] J.A. Creighton, E.R. Lippincott; J. Chem. Phys. 40 (1964) 1779.

[135] F.J. Blunt, P.J. Hendra, J.R. Mackenzie; Chem. Comm. 1969 (6), 278.

[136] J.B. Bates, M.H. Brooker, G.E. Boyd; Chem. Phys. Lett. 16 (2) (1972) 391.

[137] M. Bösch, W. Känzig, E.F. Steigmeier, Helv. Phys. Acta 46 (1973) 17.

[138] M. Bösch, W. Kănzig, E.F. Steigmeier, Phys. Kond. Mater. 16 (1973) 107.

[139] G. Herzberg; "Molecular Spectra and Molecular Structure", Vol I (Van Norstad Reinhold, New York, 1950).

[140] W. Holzer, W.F. Murphy, H.J. Bernstein, J. Rolfe; J. Mol. Spectrosc. 26 (1968) 543.

[141] N. Wakabayashi, B. Alefeld, W. Buhrer, H.G. Smith; Phys. Rev. B26 (8) (1982) 4160.

[142] S.D. Mahanti, G. Kemeny; Phys. Rev. B20 (1979) 2105.

[143] G. Kemeny, S.D. Mahanti; Phys. Rev. B20 (1979) 2961.

[144] S.D. Mahanti, D. Sahu; Phys. Rev. Lett. 48 (1982) 936.

[145] D. Sahu, S.D. Mahanti; Phys. Rev. B26 (1982) 2981.

[146] P.F. Fracassi, M.L. Klein; Phys. Rev. B28 (1983) 997.

[147] P.F. Fracassi, M.L. Klein, R.G. Della Valle; Can.J.Phys. 62 (1984) 54.

[148] J.R. Tessmann, A.H. Kahn, W. Shockley; Phys. Rev. 72 (1953) 890.

[149] M. Bösch, R. Hofmann; J. Phys. Chem. Solids 36 (1975) 1077. 
[150] A. de Kozak, J.C. Bardin, A.Erb; Rev. Chim. Minér. 13 (1976) 190.

[151] S.P. Berardinelli, D.L. Kraus; Inorg. Chem. 13 (1) (1974) 189.

[152] B. Stojanovic; Naucno-Teh.Pregl. 27 (9) (1977) 9.

[153] B. Stojanovic; Naucno-Teh.Pregl. 28 (9) (1978) 30.

[154] B. Stojanovic; Thermochim. Acta 92 (1985) 231.

[155] A.E. Kharakoz; A.G. Kopylova, S.V. Bleshinskii, O. Satybaldiev; Fiz.-Khim. Issled. Redkoszemel. Elem. 1972122.

[156] V. Bruners, J. Sauka; Zh. Neorg. Khim. 12 (5) (1967) 1316.

[157] V. Bruners, A. Salta, I.I. Vol'nov;

Latv. PSR Zinat. Adad. Vestis, Kim. Ser. 1973 (4) 397.

[158] V. Bruners, A. Salta, G. Ozolins; Latv. PSR Zinat. Akda. Vestis, Kim. Ser. 1976 (2) 203.

[159] A. Salta, V. Bruners; Larv. PSR Zinat. Akad. Vestis, Kim. Ser. 1976 (3) 341.

[1601 A. Salta, V. Bruners; Latv. PSR Zinat. Akad. Vestis, Kim. Ser. 1976 (3) 361.

[161] V. Bruners, J. Kalina; Latv. PSR Zinat. Akad. Vestis, Kim. Ser. 1978 (5) 521.

[162] V. Bruners, G. Ozolins; Latv. PSR Zinat. Akad. Vestis, Kim. Ser. 1986 (4) 411.

[163] R.J. Cava, B. Batlogg, J.J. Krajewski, R. Farrow, L.W. Rupp jr., A.E. White,

K. Short, W.F. Peck \& T. Kometani; Nature 332 (1988) 814.

[164] I.I. Vol'nov, A. N. Shatunina; Dokl. Akad. Nauk SSSR 110 (1956) 87.

[165] I.I. Vol'nov, A. N. Shatunina; Izv. Akad. Nauk SSSR, Ser. Khim. 1966 (11) 2032.

[166] A. B. Tsentsiper, R. P. Vasil'eva; Izv. Akad. Nauk SSSR, Ser. Khim. 1967 (11) 2565.

[167] A. B. Tsentsiper, R. P. Vasil'eva; Izv. Akad. Nauk SSSR, Ser. Khim. 1968 (6) 1380.

[168] A. B. Tsentsiper, R. P. Vasil'eva; Izv. Akad. Nauk SSSR, Ser. Khim. 1968 (7) 1437.

[169] E. V. Ballou, P.C. Wood, L. A. Spitze, T. Wydeven; Am. Soc. Mech. Eng. , [Pap.] 76-ENAs-1 (1976) 9 pp.

[170] E. V. Ballou, P. C. Wood, L. A. Spitze, T. Wydeven; Ind. Eng. Chem., Prod. Res. Dev. 16 (2) (1977) 180.

[171] E. V. Ballou, P. C. Wood, L. A. Spitze, T. Wydeven, R. Stein; J. Eng. Ind. 100 (1) (1978) 26.

[172] E. V. Ballou, P. C. Wood, L. A. Spitze, T. Wydeven; U. S. Pat. Appl. US 814378, 11 Aug. 1977, 29 pp.

[173] I.A. Kazarnovskii, A.B. Neiding; Dokl. Akad. Nauk SSSR 86 (4) (1952) 717.

[174] I.I. Vol'nov, S. A. Tokareva, E. I. Latysheva, V. I. Klimanov; Izv. Akad. Nauk SSSR, Ser. Khim. 1967 (10) 2365. 
[175] I.I. Vol'nov, S. A. Tokareva, V. N. Belevskii, E. I. Latysheva; Izv. Akad. Nauk SSSR, Ser. Khim. 1970513.

[176] E. Seyb jr., J. Kleinberg; J. Am. Chem. Soe. 73 (1951) 2308.

[177] I. I. Vol'nov, S. A. Tokareva, E. N. Cherkasov: Izv. Akad. Nauk SSSR, Ser. Khim. 1969 (9) 2085.

[178] E. I. Latysheva, E. N. Cherkasov, S. A. Tokareva, N. G. Velikova, I. I. Vol'nov; Izv. Akad. Nauk SSSR, Ser. Khim. 1974 (8) 1684-6.

[179] V. M. Bakulina, E. I. Latysheva, S. A. Tokareva, I. I. Vol'nov; Zh. Struktur. Khim. 11 (1970) 158.

[180] V. M. Bakulina, S. A. Tokareva, I. I. Vol'nov; Izv. Akad. Nauk SSSR, Ser. Khim. 1974 (6) 1413.

[181] S.C. Abrahams, J. Kalnajs; Acta Cryst. 7 (1954) 838.

[182] V. N. Belevski, I. I. Vol'nov, S. A. Tokareva; Izv. Akad. Nauk SSSR, Ser. Khim. 1972 (6) 1415.

[183] P. Sadhukhan, A. T. Bell; J. Solid State Chem. 29 (1) (1979) 97.

[184] A. D. Mc Elroy, J. S. Hashman; Inorg. Chem. 3 (12) (1964) 1798.

[185] J. S. Hashman, J. C. Renforth; U. S. 3, 102, 140 (Cl. 260-517.6), Aug. 27, 1963, Appl. Feb. 27, 1961.

[186] J. S. Hashman, J. W. Berkstresser, U. S. 3, 119, 870 (Cl. 260- 567.6), Jan. 28, 1964, Appl. Mar. 21, 1961.

[187] D. T. Sawyer, T. S. Calderwood, K. Yamaguchi, C. T. Angelis; Inorg. Chem. 22 (18) (1983) 2577.

[188] K. Yamaguchi, T. S. Calderwood, D. T. Sawyer; Inorg. Chem. 25 (8) (1986) 1289.

[189] E. N. Cherkasov, S. A. Tokareva, I. I. Vol'nov; Izv. Akad. Nauk SSSR, Ser. Khim 1969 (9) 2074.

[190] E. I. Latycheva, E. N. Cherkasov, S. A. Tokareva, N. G. Velikova, I. I. Vol'nov; Neorg. Perekisnye Soedin., Dokl. Vses. Soveshch., Meeting Date 1973 (1975) 117.

[191] V. M. Bakulina, E. N. Cherkasov, I. I. Vol'nov; Zh. Strukt. Khim. 10 (2) (1969) 344.

[192] V. M. Bakulina, V. A. Sarin, E. I. Latysheva, I. I. Vol'nov; Izv. Akad. Nauk SSSR, Ser. Khim. 1975 (1) 179.

[193] E. N. Cherkasov, S. A. Tokareva, I. I. Vol'nov; Izv. Akad. Nauk SSSR, Ser. Khim. 1969 (1) 152.

[194] A.D. Evdokimova, E.N. Cherkasov; Izv. Akad.Nauk SSSR, Ser. Khim. 1969 (12) 2855.

[195] F. Feher, I. v. Welucki, G. Dost; Chem. Ber. 86 (1953) 1429. 
[196] H. Foppel; Z. Anorg. Allg. Chem. 291 (1957) 12.

[197] N. G. Vannerberg; Lic. thesis, Göteborg, (1957).

[198] V. Kotov; Zhur. Fiz. Khim. 13 (1939) 829.

[199] C. A. Kraus, E. F. Parmenter, J. Am. Chem. Soc. 56 (1934) 2386.

[200] A. Kjekshus, T. Rakke; Acta Chem. Scand. A33 (1979) 617.

[201] C. Brosset, N. G. Vannerberg; Nature 177 (1956) 238.

[202] R. S. Shineman, A. J. King; Acta Cryst. 4 (1951) 67.

[203] J. D. Bernal, F. Diatlova, I. A. Kazarnovskii. S. Reichstein;

Z. Kristallogr. A92 (1935) 344.

[204] N. G. Vannerberg; Ark. Kemi 14 (1959) 17.

[205] T. E. Harr; Thesis, Univ. Syracuse, USA (1947).

[206] H. A. Wriedt; Bull. Alloy Phase Diagrams 6 (6) (1985) 553/573.

[207] T. Tanifuji, S. Nasu; J. Nucl. Mater 87 (1979) 189.

[208] M. Viltange; Anal. Chim. Acta 39 (1967) 491.

[209] T. P. Firsova, N. N. Stasevich; Russ. J. Inorg. Chem. 15 (12) (1970) 1763.

[210] R. J. Seyse, G. Gordon; J. Inorg. Nucl. Chem. 34 (1972) 477.

[211] E. G. Bunzel, F. J. Kohlmeyer, Z. Anorg. Chem. 254 (1947) 1.

[212] R. L. Tallman, J. L. Margrave; J. Inorg. Chem. 21 (1961) 40.

[213] M. Blumenthal; Roczn. Chem. Polska 12 (1932) 125; Bull. Acad. Polon. A1933, 505.

[214] H. J. Byker, I. Eliezer, R. C. Howald, T. C. Ehlert; High Temp. Science 11 (1979) 153.

[215] S. P. Berardinelli, D. L. Kraus; Inorg. Chem. 13 (1) (1974) 189.

[216] R. H. Lamoreaux, D. L. Hildenbrand; J. Phys. Chem. Ref. Data, 13 (1) (1984) 151.

[217] I. I. Vol'nov, E. I. Latysheva; Izv. Akad. Nauk SSSR Ser. Khim. 1970 (1), 13.

[218] Y. Azuma, M. Mizuide, K. Suehiro; Gypsum Lime 162 (1979) 3.

[219] V. Brunere, J. Kalina; Latv. PSR Zinat. Akad. Vestis. Kim. Ser. 1986 (2), 226.

[220] A. B. Tsentsiper, R. P. Vasil'eva; Izv. Akad. Nauk SSSR Ser. Khim. 1967 (11), 2563.

[221] O. V. Kedrovskii, P. V. Kortunewko, E. V. Kiseleva, A. A.Bundel; Zh. Fiz. Khim. 41 (2) (1967) 414.

[222] H. G. Wiedemann, G. Bayer, Proc. Eur. Symp. Therm. Anal., 1 st 1976, 295.

[223] N.G. Vannerberg; Ark. Kemi 14 (1959) 119.

[224] N.G. Vannerberg; Ark.Kemi 10 (1956) 455.

[225] N.G. Vannerberg; Ark. Kemi 13 (1959) 515.

[226] C. Hoffman, R. Ropp, R. Mooney; J. Am. Chem. Soc. 81 (1959) 3830. 
[227] M. Puselj, Z. Ban, J. Morvaj; Croat. Chim. Acta 58 (3) (1985) 283.

[228] M. Puselj, Z. Ban, E. Lukacevic, J. Morvaj; Z. Anorg. Allg. Chem. 528 (1985) 191.

[229] V.A. Lunenok-Burmakina, V.Z. Kuprii; Zh. Neorg. Khim. 16 (9) (1971) 2331.

[230] N.G. Vannerberg; Ark. Kemi 14 (1959) 99.

[231] M. Puselj, Z. Ban, E. Lukacevic; J. Appl. Cryst. 16 (1983) 357.

[232] V. Brunere, J. Kalina, G. Ozolins; Latv. PSR Zinat. Akad. Vest. Kim. Ser. $1986(6) 657$.

[233] R. D. Iyengar, V. V. S. Rao; J. Phys. Chem. 75 (20) (1971) 3089.

[234] K.-J. Range, M. Stadler, F. Rau, U. Klement; Angew. Chem. Int. Ed. Engl. 26 (1987)1174.

[235] V. Brunere, J. Kalina, G. Ozolins; Latv. PSR Zinat. Akad. Vestis 1981 (6), 668.

[236] V. Brunere, J. Kalina, G. Ozolins; Latv. PSR Zinat. Akad. Vestis 1985 (2), 145.

[237] I. A. Marriott, A. Capotosto, A. W. Petrocelli; Anal. Chem. Acta 41(1968) 121.

[238] K. Yvon, A. Bezinge, P. Tissot, P. Fischer, J. Solid State Chem. 65 (1986) 225.

[239] M. Jansen, P. Fischer, J. Less Comm. Met. 137 (1988) 123.

[240] V. Andreeva, N. A. Shishakov; J. Appl. Chem. (London) 11 (1961) 388.

[241] Y. T. Vol, N. A. Shishakov; Izv. Akad. Nauk SSSR Otd. Khim. Nauk 1962, 586.

[242] J. B. Goodenough; Mater. Res. Bull. 23 (1988) 401.

[243] J. C. Evans; Chem. Commun. 1969, 682.

[244] H. H. Eysel, S. Thym; Z. Anorg. Allg. Chem. 411 (2) (1975) 97.

[245] T. Yasuoka, S. Mitsuzawa; Bull. Chem. Soc. Japan 52 (8) (1979) 2287.

[246] S. Mitsuzawa; Nippon Kagaku Kaishi 1978 (12) 1718.

[247] R. Wolf, R. Hoppe; J. Solid State Chem. 70 (1) (1987)12.

[248] G. Wagner, R. Hoppe; Z. Anorg. Allg. Chem. 549 (1987) 26.

[249] G. Wagner, R. Hoppe; Z. Anorg. Allg. Chem. 549 (1987) 15.

[250] H. Stoll, R. Hoppe; Z. Anorg. Allg. Chem. 549 (1987) 87.

[251] H. Stoll, R. Hoppe; Z. Anorg. Allg. Chem. 548 (1987) 167.

[252] R. Wolf, R. Hoppe; Z. Anorg. Allg. Chem. 539 (1987) 127.

[253] G. Wagner, R. Hoppe; Z. Anorg. Allg. Chem. 537 (1986) 115.

[254] G. Wagner, R. Hoppe; J. Less-Common Met. 120 (1986) 225.

[255] R. Wolf, R. Hoppe; Z. Anorg. Allg. Chem. 536 (1986) 77.

[256] R. Wolf, R. Hoppe; Z. Anorg. Allg. Chem. 522 (1985) 39.

[257] W. Losert, R. Hoppe; Z. Anorg. Allg. Chem. 515 (1984) 95.

[258] M. Jansen, R. Hoppe; Z. Anorg. Allg. Chem. 398 (1973) 54.

[259] Y. Takeda, J. Akagi, M. Inagaki, S. Naka; Toyoda Kenkyo Hokoku 33 (1980) 73.

[260] M.G. Barker, A.J. Hooper, J. Chem. Soc. Dalton Trans. 15 (1973) 1513. 